This item was submitted to Loughborough's Research Repository by the author.

Items in Figshare are protected by copyright, with all rights reserved, unless otherwise indicated.

\title{
Linking a storyline with multiple models: a cross-scale study of the UK power system transition
}

\section{PLEASE CITE THE PUBLISHED VERSION}

http://dx.doi.org/10.1016/j.techfore.2014.08.018

\section{PUBLISHER}

(C) Elsevier

\section{VERSION}

AM (Accepted Manuscript)

\section{PUBLISHER STATEMENT}

This work is made available according to the conditions of the Creative Commons Attribution-NonCommercialNoDerivatives 4.0 International (CC BY-NC-ND 4.0) licence. Full details of this licence are available at: https://creativecommons.org/licenses/by-nc-nd/4.0/

\section{LICENCE}

CC BY-NC-ND 4.0

\section{REPOSITORY RECORD}

Trutnevyte, Evelina, John P. Barton, Aine O'Grady, Damiete Emmanuel-Yusuf, Danny Pudjianto, and Elizabeth M. Robertson. 2019. "Linking a Storyline with Multiple Models: A Cross-scale Study of the UK Power System Transition”. figshare. https://hdl.handle.net/2134/25320. 


\section{Elsevier Editorial System(tm) for Technological Forecasting \& Social Change Manuscript Draft}

\section{Manuscript Number: TFSC-13-417R2}

Title: Linking a storyline with multiple models: a cross-scale study of the UK power system transition

\section{Article Type: Research Article}

Keywords: Scenarios; storylines; cross-scale; quantitative models; simulation; energy; environment; climate change; transition pathways

Corresponding Author: Dr. Evelina Trutnevyte, Dr.

Corresponding Author's Institution: University College London, UCL Energy Institute

First Author: Evelina Trutnevyte, Dr.

Order of Authors: Evelina Trutnevyte, Dr.; John Barton, Dr.; Áine O'Grady, MSc; Damiete Ogunkunle, MSc; Danny Pudjianto, Dr.; Elizabeth Robertson, MPhys (Hons)

Abstract: State-of-the-art scenario exercises in the energy and environment fields argue for combining qualitative storylines with quantitative modelling. This paper proposes an approach for linking a highly detailed storyline with multiple, diverse models. This approach is illustrated through a crossscale study of the UK power system transition until 2050. The storyline, called Central Co-ordination, is linked with insights from six power system models and two appraisal techniques. First, the storyline is 'translated' into harmonised assumptions on power system targets for the models. Then, a new concept called the landscape of models is introduced. This landscape helps to map the key fields of expertise of individual models, including their temporal, spatial and disciplinary foci. The storyline is then assessed based on the cross-scale modelling results. While the storyline is important for transmitting information about governance and the choices of key actors, many targets aspired in it are inconsistent with modelling results. The storyline overestimates demand reduction levels, uptake of marine renewables and irreplaceability of carbon capture and storage. It underestimates the supplydemand balancing challenge, the need for back-up capacity and the role of nuclear power and interconnectors with Europe. Thus, iteratively linking storylines and models is key.

\section{Suggested Reviewers:}


Dr Evelina Trutnevyte

UCL Energy Institute

Central House

14 Upper Woburn Place

WC1H 0NN London

United Kingdom

e.trutnevyte@ucl.ac.uk

+44 (0) 2031085924

London, 23 August 2014

Linking a storyline with multiple models: a cross-scale study of the UK power system transition

Dear Prof Phillips,

Thank you for your positive feedback to our manuscript. As recommended by the third reviewer, we now added a sentence explaining our definition of "crossscale" study. Please find the manuscript and a short response to the reviewer's comment attached.

We look forward to hearing from you.

With best wishes on behalf of all co-authors,

Dr Evelina Trutnevyte 


\section{Point-by-point response to the reviewers' comments}

The original comments of the reviewers are typeset in Bold.

Our answers are typeset in Roman.

\section{Reviewer \#3}

This is a significantly revised paper which I was seeing for the first time.

Reading it "raw" I thought that it was original with a very clear exposition and useful implied recommendations for both analysts and policymakers.

I looked back at the original reviewers' constructive comments and would say that the authors have responded fully and without any degree of push-back.

I unreservedly recommend this for publication (almost) "as is".

One tiny point - on p.6 they introduce the term "cross-scale" (apparently to replace "interdisciplinary" in the original submission). The term is not explicitly defined or exemplified, though I can guess the meaning from earlier references to temporal and spatial aspects. Just one additional sentence would clarify the exposition.

We think it is indeed a good idea to clearly define what we mean by the 'cross-scale' term. As suggested by the reviewer, we add an explanation on page 6:

\footnotetext{
114 models to each [41]. Thus, a new approach has to be developed for linking

115 detailed storylines with multiple, cross-scale models, which have different

116 spatial, temporal and disciplinary foci. This paper proposes such an approach.

117 There is a growing number of interdisciplinary projects in energy, climate
}

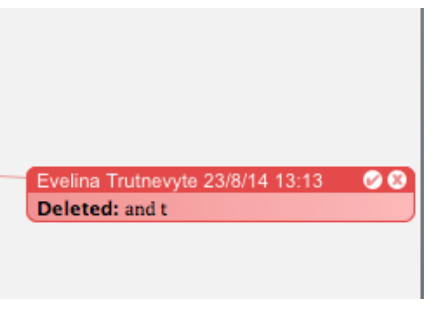




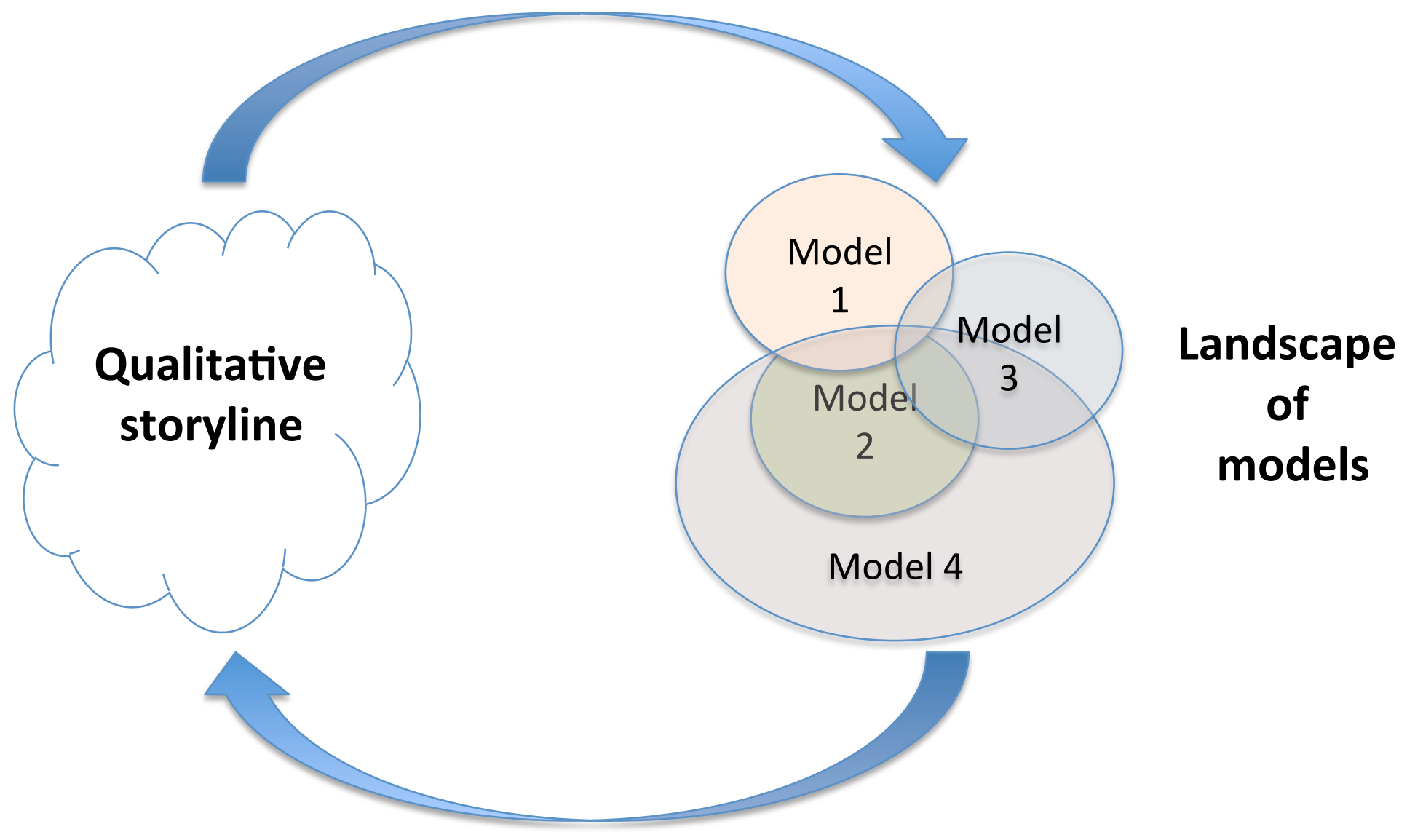




\section{Highlights}

- Linking a qualitative storyline with multiple, diverse quantitative models

- Landscape of models for mapping the fields of expertise of individual models

- Cross-scale analysis of the UK power system transition until 2050 


\section{Step 1:}

'Translating' the storyline into the modelling assumptions

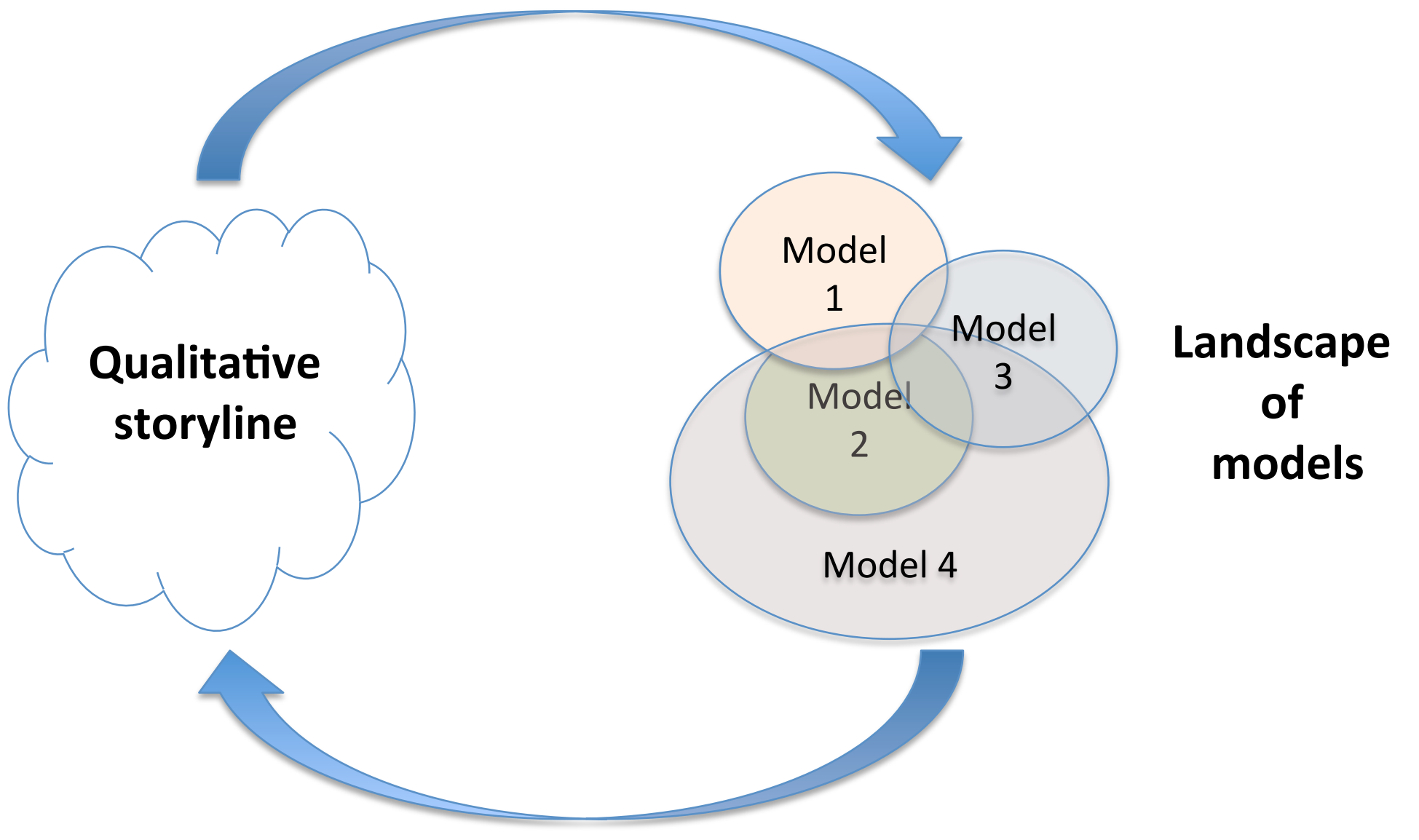

Step 2:

Revisiting the storyline based on the modelling outputs 


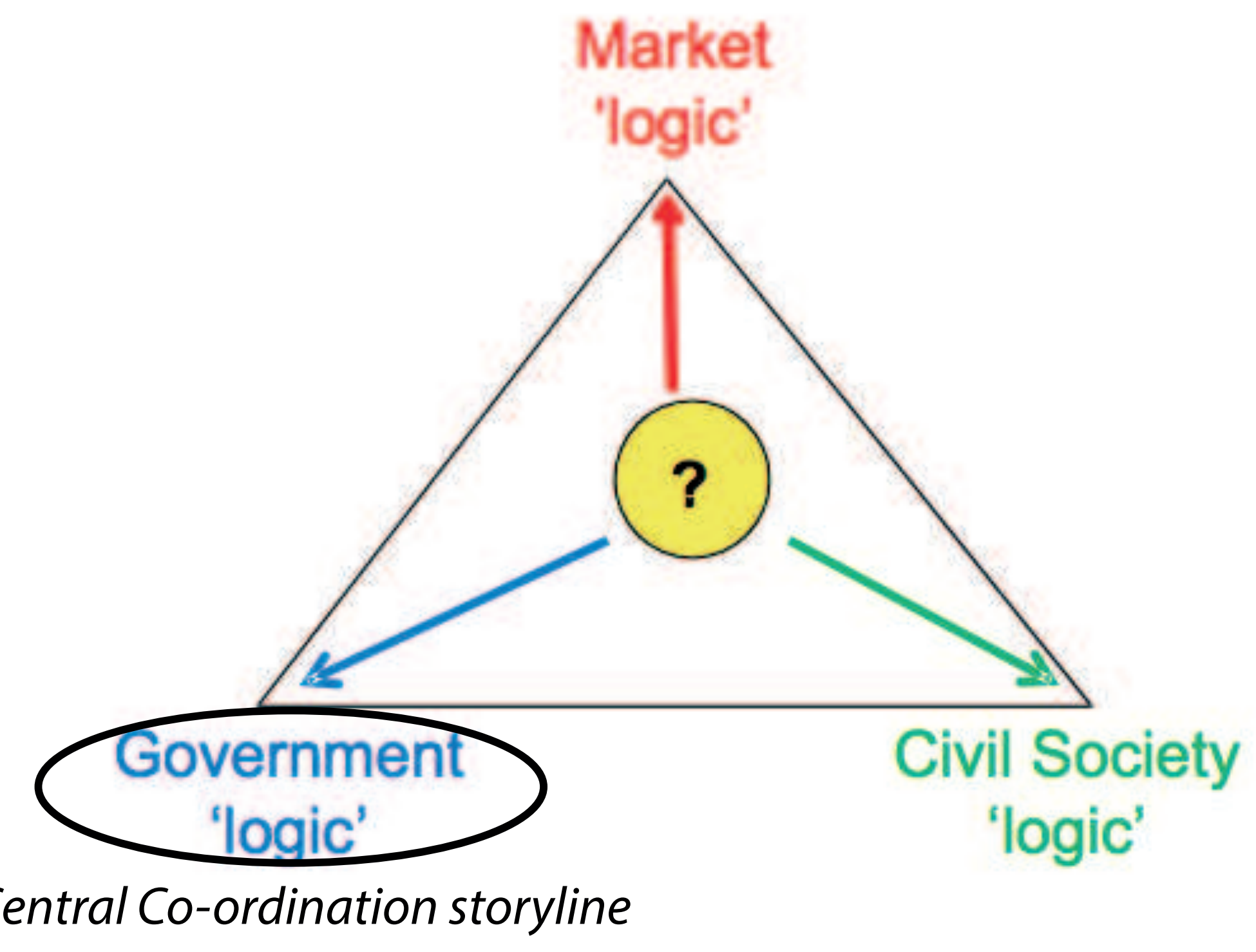

Central Co-ordination storyline

Figure 2

\section{Market} 'logic'

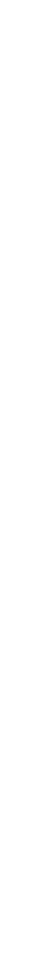

Tovent 'logic'

\section{'logic' \\ Civil Society}




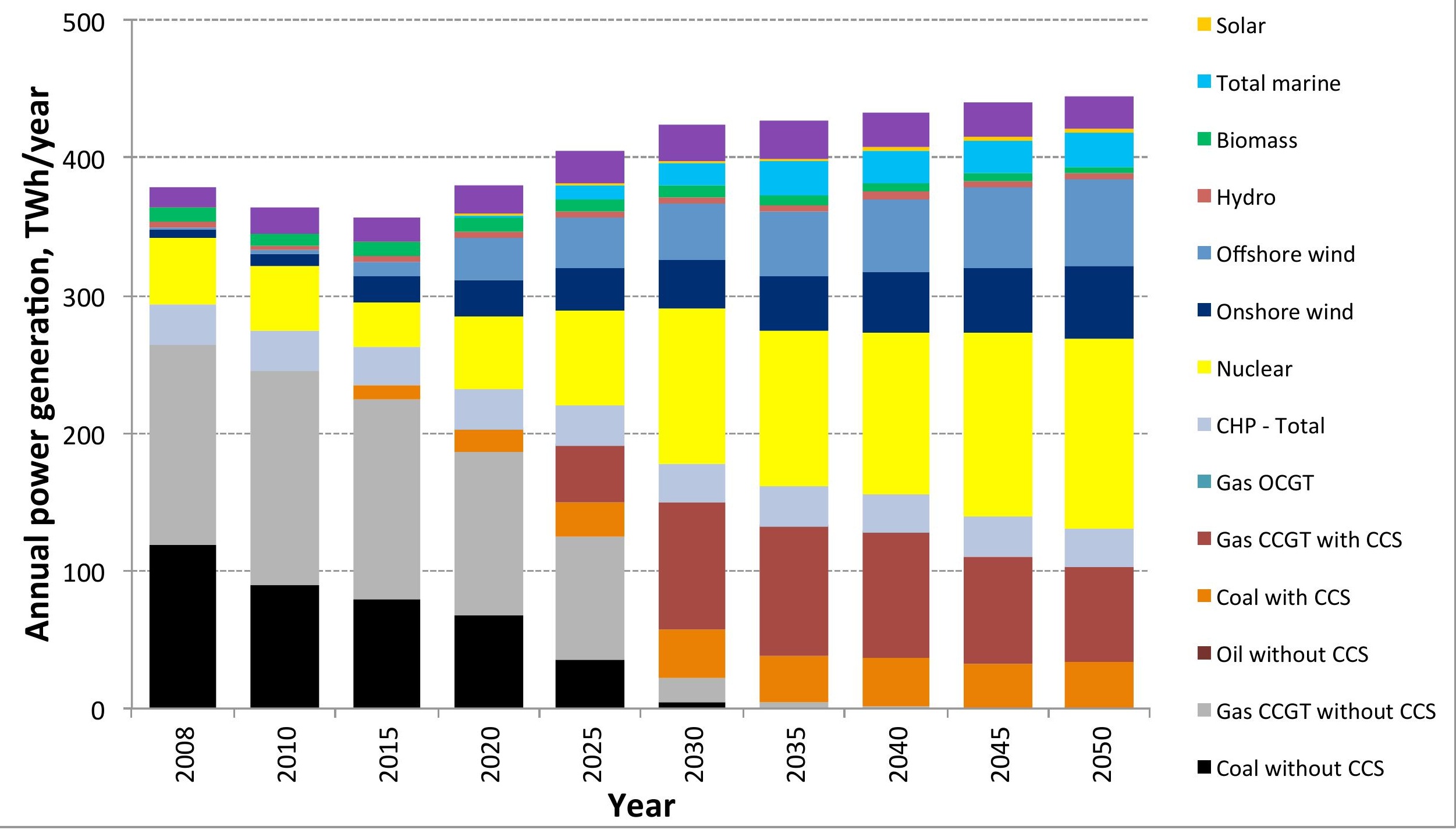



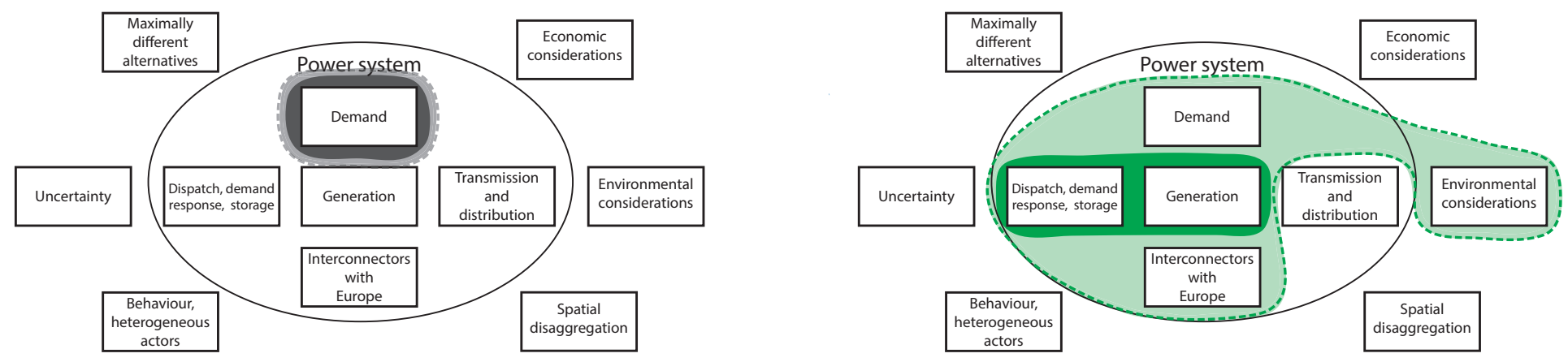

\section{D-EXPANSE}

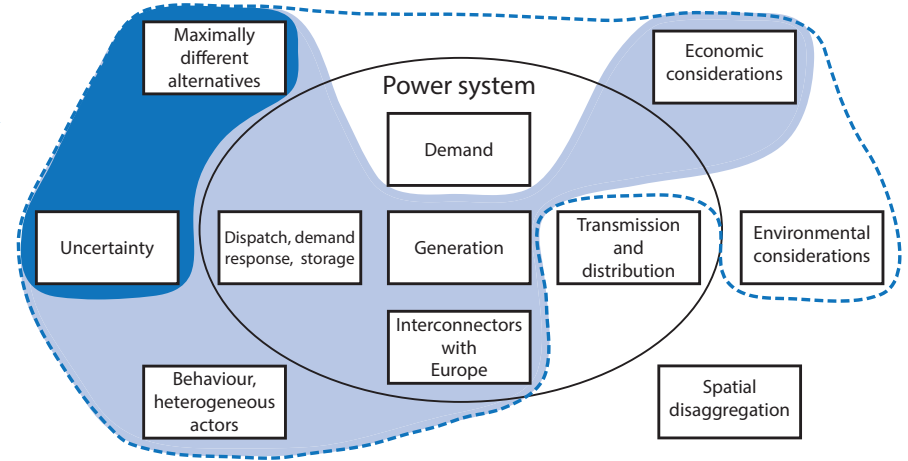

\section{BLUE-MLP}

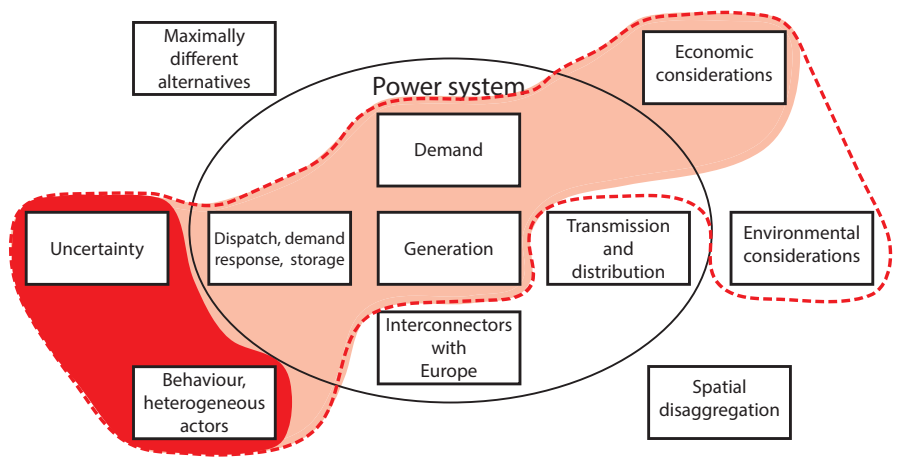

\section{HESA/UK+}
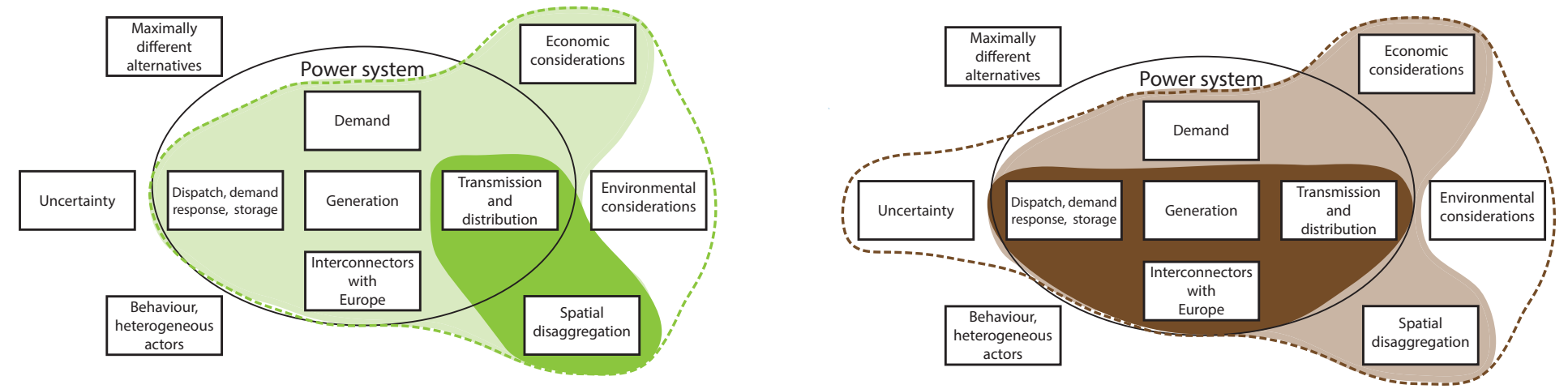
- Dr Evelina Trutnevyte works as a Research Associate at the University College London (UCL) Energy Institute. Her research focuses on the development of context-specific, spatially differentiated energy strategies that combine insights from multiple disciplines and stakeholder engagement. She received her $\mathrm{PhD}$ at the Institute for Environmental Decisions, ETH Zurich, and her Master's degree in Power Engineering from Vilnius Gediminas Technical University. She strengthened her expertise during studies and fellowships at Aalborg University (Denmark), Lithuanian Energy Institute, Power Systems Laboratory at ETH Zurich (Switzerland), University of Oslo (Norway), and during two years of engineering consulting in Lithuania.

- Dr John Barton is a Research Associate at Loughborough University's Centre for Renewable Energy Systems Technology (CREST). He also received his $\mathrm{PhD}$ and Master's degree at Loughborough University. His 7 years of post-doctoral research includes energy storage, whole energy system modelling, distributed generation, demand response, condition monitoring of wind turbines and public engagement with renewable energy. John is also an energy consultant and company director, previously working with Bryte Energy Ltd on hydrogen technologies and now working with Air Fuel Synthesis Ltd making synthetic liquid transport fuels. John co-created and then developed the FESA model.

- Áine O'Grady is a Research Officer at the University of Bath where she is part of the Sustainable Energy Research Team in the Department of Mechanical Engineering. Previously, Áine worked at Aquamarine Power, and carried out a life-cycle assessment of its wave energy device prototype, and contributed to environmental design improvements. Her current research involves the technology assessment of energy systems using a set of appraisal techniques from engineering, environmental sciences and strategic thinking (such as environmental life-cycle assessment, thermodynamic analysis, horizon scanning and other futureoriented technology analysis). 
- Damiete Ogunkunle is a Research Officer at the Centre for Environmental Strategy, University of Surrey, where she obtained her Masters' degree in Environmental Management. She has worked in a range of research projects since 2008 including the sustainability assessment of UK bioenergy supply chains. Currently, she is involved in the development of the energy demand models as part of the Realising Transitions Pathways consortium. She is also working part time towards completing her $\mathrm{PhD}$ degree.

- Dr Danny Pudjianto is a Research Fellow at Imperial College London with the expertise in power system modelling and optimization, power system economics, regulation, system operation, strategic planning, system security, and technology evaluations from power system perspective including smart grids, active network management, demand response, distributed generation, energy storage, and energy networks. He holds degrees in Economics (BA) and Electronics (BSc), and Power System (MSc and $\mathrm{PhD}$ ). He has published more than 40 technical papers.

- Elizabeth Robertson is a Research Assistant at the University of Strathclyde's Institute of Energy and Environment. She received her MPhys (Hons) from the University of York, UK in 2008 and is currently pursuing a PhD at the University of Strathclyde. Her research interests include combined energy system modelling and the interaction of physically connected, but individually operated energy markets. 
Supplementary Files with no Changes Marked
Click here to download Supplementary Files: TFSC supplementary material Rev1-clean.docx

Supplementary Files with no Changes Marked
Click here to download Supplementary Files: TFSC supplementary material Rev1-clean.docx 


\section{Linking a storyline with multiple models: a cross-scale}

2 study of the UK power system transition

3

\section{Authors:}

5 Evelina Trutnevyte*a, John Barton ${ }^{b}$, Áine 0'Gradyc, Damiete Ogunkunled, Danny

6 Pudjianto ${ }^{e}$, Elizabeth Robertson ${ }^{\mathrm{f}}$

* Corresponding author, UCL Energy Institute (permanent and present address), e.trutnevyte@ucl.ac.uk, phone +44 2031085924

a University College London, UCL Energy Institute, 14 Upper Woburn Place, London WC1H 0NN, United Kingdom

b Loughborough University, Leicestershire LE11 3TU, United Kingdom

c University of Bath, Department of Mechanical Engineering, Bath BA2 7AY, United Kingdom

d University of Surrey, Centre For Environmental Strategy, Guildford GU2 7XH, United Kingdom

e Imperial College London, South Kensington, London SW7 2AZ, United Kingdom f University of Strathclyde, Royal College Building, 204 George Street, Glasgow G1 1XW, United Kingdom 
10 State-of-the-art scenario exercises in the energy and environment fields argue

11 for combining qualitative storylines with quantitative modelling. This paper 12 proposes an approach for linking a highly detailed storyline with multiple, 13 diverse models. This approach is illustrated through a cross-scale study of the UK 14 power system transition until 2050. The storyline, called Central Co-ordination, is 15 linked with insights from six power system models and two appraisal 16 techniques. First, the storyline is 'translated' into harmonised assumptions on 17 power system targets for the models. Then, a new concept called the landscape 18 of models is introduced. This landscape helps to map the key fields of expertise 19 of individual models, including their temporal, spatial and disciplinary foci. The 20 storyline is then assessed based on the cross-scale modelling results. While the 21 storyline is important for transmitting information about governance and the 22 choices of key actors, many targets aspired in it are inconsistent with modelling 23 results. The storyline overestimates demand reduction levels, uptake of marine 24 renewables and irreplaceability of carbon capture and storage. It underestimates 25 the supply-demand balancing challenge, the need for back-up capacity and the 26 role of nuclear power and interconnectors with Europe. Thus, iteratively linking 27 storylines and models is key.

28

\section{Keywords}

30 Scenarios, storylines, cross-scale, quantitative models, simulation, energy, 31 environment, climate change, transition pathways 


\section{$34 \quad$ Highlights}

35 - Linking a qualitative storyline with multiple, diverse quantitative models

- Landscape of models for mapping the fields of expertise of individual

37 models

38

- Cross-scale analysis of the UK power system transition until 2050

39

40 Graphical abstract

41 Insert the Graphical abstract about here

42 


\section{Introduction}

Scenario exercises in energy, climate change and other technology- and environment-related studies are based on qualitative storylines, quantitative models or, often, on a combination of both [1-6]. Storyline-based scenarios are expressed as qualitative narratives that in length may range from brief titles to very long and detailed descriptions. Examples of such scenarios are the Tyndall decarbonisation scenarios [7, 8], the CLUES decentralised energy scenarios [9] or the energy visions in Switzerland $[10,11]$. The value of such storylines is threefold $[2,4,12-14]$. First, when these storylines are developed through engagement of experts and stakeholders, they combine multiple perspectives and sources of expertise [2]. They may lead to novel and creative ways of thinking about the future that go beyond modelling insights. Second, storylines are key for communicating the results of scenario exercises. Due to their qualitative nature, they are accessible and memorable to a broad range of audiences. When developed through stakeholder engagement, they are likely to be accepted, supported and used more often [15]. Third, storylines represent a much broader picture than quantitative models and encapsulate a number of softer and subtler aspects, such as governance, institutional changes or energyrelated behaviour, that cannot yet be modelled [16]. Storylines thus can form the input assumptions to the quantitative models and embed these models into a bigger picture $[17,18]$. However, storylines have two key limitations. First, storylines alone at times may be detached from reality as even experts can have a limited understanding of whether a particular storyline is feasible $[10,11,15]$. Second, as storylines are developed by combining multiple views of experts and stakeholders, they can be considered biased, not reproducible and not 
transparent $[2,19]$. Despite the current research on formal techniques for developing better storylines [20-23], these limitations still remain.

Quantitative models-based scenarios are produced by a single or multiple models, such as in the ADAM [24], Energy Modelling Forum [25], Low Carbon Society modelling [26] and NEEDS [27] projects. The key strength of these scenarios is that they satisfy the inherent need for numeric values in the technology- and environment-related fields [2, 10, 13, 15]. Models are based on the empirical data, physical laws, principles of economics and state-of-the-art knowledge about the technology and environmental processes. Thus, peerreviewed, transparently documented models provide rigorous, internally consistent scenarios. However, models can address only a limited number of aspects, such as technology, economic, and environmental aspects. But they still have difficulty in capturing the afore-mentioned softer and subtler aspects. The research priorities are towards developing more detailed models and including softer aspects, such as behaviour and governance, into models [17, 28]. Yet, even better models alone can hardly offer the breadth and engaging nature of the storyline-based scenarios. For example, the models cannot picture organisational and institutional change needed to deliver a wanted transition, even if these elements are important for decision makers to envision and manage this transition. models, state-of-the-art scenario studies argue for combining them [1-5]. In order to complement the models, storylines can reflect such aspects, like (i) exogenous context in which the modelled system is embedded into, (ii) exogenous modelling assumptions, such as drivers for change, or (iii) 
93 aspirational targets for the future system. Many recent scenario exercises

94 already have the elements of both storylines and models: storylines include

95 numbers, while modelling outputs are described in short qualitative narratives.

96 Several scenario exercises explicitly combine the storylines and the quantitative 97 models in an iterative manner [6, 10, 11, 29-31]. Examples of these include key

98 international scenario exercises: the integrated climate change scenarios of the

99 Intergovernmental Panel of the Climate Change [32, 33], the scenarios of 100 ecosystem services in the Millennium Ecosystem Assessment [34] and of the 101 global environment in the Global Environmental Outlook [35].

102 Despite the fact that the combination of storylines and quantitative 103 models has emerged as an established practice in the technology- and 104 environment-related fields [1-6], existing literature runs short in providing 105 methodological insights for how to link detailed storylines, which are developed 106 through stakeholder and expert engagement, with multiple quantitative models. 107 First, if the storylines are very detailed, then numerous additional assumptions 108 are needed to 'translate' them into model parameters. Second, multiple diverse 109 models may be needed to model detailed storylines with various spatial and 110 temporal foci, disciplinary perspective (technical feasibility, economic or 111 environmental appraisal), model objective, and the parts of the system 112 addressed. This diversity is valuable because the storylines can be addressed 113 from multiple angles and across scales, but it is challenging to relate such diverse 114 models to each [36]. Thus, a new approach has to be developed for linking 115 detailed storylines with multiple, cross-scale models, which have different 116 spatial, temporal and disciplinary foci. and twhis paper proposes such an 117 approach. There is a growing number of interdisciplinary projects in energy, 
climate change and other technology- and environment-related studies. It can be

119 expected that many of these projects will attempt to develop cross-scale

120 scenarios by linking storylines with multiple models and will require such an

121 approach.

122 The proposed approach is illustrated with the cross-scale analysis of the

123 UK power system transition until 2050 as a part of the Realising Transition

124 Pathways (RTP) consortium project. A detailed storyline, called the Central Co-

125 ordination, was developed in the preceding Transition Pathways project [37-39]

126 and is used for the cross-scale analysis with six quantitative power system

127 models and two quantitative appraisal techniques. The idea for this analysis

128 arose from discussions at RTP consortium workshops. The authors of this paper

129 took the analysis forward and its results will be an input to further development

130 of the consortium's research.

131 This paper is laid out as follows: Section 2 proposes a general

132 methodological approach; Section 3 gives an example of linking the Central Co-

133 ordination storyline with eight RTP models, present and discusses the findings;

134 Section 4 discusses the general approach; and Section 5 concludes.

2. Proposed approach for linking storylines with multiple models

This section describes the proposed process (Figure 1) of linking a

139 detailed storyline with the insights from multiple diverse models. First of all, one 140 of the biggest challenges in cross-scale scenario studies is ability to 141 systematically combine insights from multiple cross-scale models. 142 Understanding and mapping the breadth and depth of the expertise of every 
143 individual model is challenging, especially given a diverse set of models. This

144 paper proposes mapping this expertise in two complementary ways:

145 (i) List the key characteristics of the models and elicit the key fields of 146 expertise. These key fields of expertise reflect the types of insights that a particular model analyses in most depth, as compared to the other models. This concept of the key field of expertise thus appreciates the distinct value of every model in a multi-model analysis. It shows which conclusions of which model shall be prioritized over the conclusions of other models. The conclusions that are derived from the key fields of expertise of a specific model shall be weighted more than the conclusions on the same topic of the other models.

(ii) Prepare a visual map, called the landscape of models. This map shall summarise the information about the breadth and depth of the analysis, done by every model, and show how these afore-mentioned fields of expertise overlap between the models. This mapping can be done on the basis of the parts of the system addressed and/or other thematic considerations addressed by the models. The mapping characteristics will likely differ from one set of models to another. The depth of analysis can then be defined in three categories: detailed modelling (the key field of expertise), stylised modelling and 
Figure 1. The iterative process of linking storylines with multiple crossscale quantitative models

Both concepts of the model's key field of expertise and the landscape of 171 models help to grasp, where models differ or overlap. If models overlap, then 172 they can validate each other and help cross-check the results. Every model, 173 however, likely has at least one area where it outperforms the other models in 174 depth or breadth as there is no single best model that covers all aspects in depth and across all the relevant scales.

As shown in Figure 1, in order to link a detailed storyline with insights

177 from multiple models, the qualitative storyline is first 'translated' into a set of 178 harmonised assumptions that are necessary for conducting the model runs, specifically tailored for the storyline (Step 1 in Figure 1). Such a 'translation' is a 180 challenging task. On the one hand, these harmonised assumptions will already be 181 a narrower representation of the qualitative storyline that is rich in detail. This is 182 reasonable as quantitative models always represent only a part of the bigger, 183 qualitative picture [10]. On the other hand, these quantitative assumptions 184 should not be too narrow and should allow enough flexibility for the quantitative 185 models to express their perspective and to make their distinct contributions. 186 Every model has a broad range of other, model-specific assumptions. As the 187 models used for cross-scale analyses are often very diverse, it is desirable to 188 harmonise the list of the assumptions so that they could be implemented in all of 189 the models. As a result, there are a lot of possible variations and a certain share 190 of subjectivity involved in the process how a storyline is 'translated' into the 191 model assumptions. 
After the models are run with these harmonised assumptions, the statements of the storyline are checked for their consistency with the modelling results (Step 2 in Figure 1). The storyline can then be revised. The landscape of models plays an important role here as it highlights the key fields of expertise of every model. In this way, it becomes possible to prioritise the models in scrutinising the specific aspects of the storyline

Generally, neither the storyline nor the multiple models are fixed; they are all being updated given the new developments in the real world, new data sources, feedback from peer review and so on. Thus, in line with [2], the process from Figure 1 is repeated iteratively for updating the storyline.

\section{The case of the UK power system transition}

This section provides a cross-scale example of linking a very detailed storyline of the UK power sector transition until 2050 with insights from six power system models and two appraisal techniques. The section starts by describing the UK power sector and the context of the storyline (Section 3.1), then moves to the description of the models (Section 3.2), the process of linking a storyline with multiple models (Section 3.3), and finishes with summarising and discussing the findings.

\subsection{UK power system and the Central Co-ordination storyline}

In the 1990s the UK underwent a major process of liberalisation of its power market and privatisation of its companies [40, 41]. With about three quarters of power produced in fossil fuel-based plants, this market-led approach 
217 came under significant pressure in the last decade due to growing climate change

218 concerns. The UK government undertook several key interventions. In 2008 the

219 UK adopted the Climate Change Act, supported by all major political parties,

220 which sets a legally binding target to cut the country's greenhouse gas emissions

221 by $80 \%$ by 2050 as compared to the emission levels of 1990 . In line with [42],

222 the major decarbonisation of the power sector, together with substantial levels

223 of electric heating and transport, are seen as the key measures to reach this

224 target. However, replacement of the aging coal and nuclear power plants and

225 significant investments in transmission and distribution requires massive

226 investment. An increased deployment of renewable energy sources raises

227 concerns over their intermittency and, thus, supply security. Therefore, this

228 decarbonisation challenge does not stand alone and is a part of the so-called

229 energy policy 'trilemma' of decarbonisation, affordability and supply security

$230[39,43]$. The Energy Bill, released in 2012, and especially its part on Electricity

231 Market Reform, attempts to mediate between these three corners of the

232 'trilemma' [44]. The Energy Bill aims to set a policy framework for the power

233 system transition that meets the 'trilemma.'

234 In light of these developments, the RTP project aims to shed light on the

235 potential transition pathways of the UK power system until 2050. Three

236 transition pathways were developed in the preceding Transition Pathways

237 project: Central Co-ordination, Market Rules and Thousand Flowers [39, 45].

238 Compared to other scenario exercises in the UK $[7-9,46]$ and elsewhere, these

239 pathways are novel because they include storylines that specifically focus on the

240 role of governance 'logics' and multiple actors in actively shaping the power

241 system transition. Traditionally in scenario studies, storylines are used for 
representing key uncertainties or drivers such as population growth,

243 technological development and others, c.f. [32, 34, 35, 47]. The RTP storylines

244 explicitly focus on the uncertainty around governance 'logics' and the choices of

245 actors and how this could affect the power system transitions. In order to

246 achieve this, the RTP storylines combine all three afore-mentioned elements of

247 storylines: exogenous context, transition drivers and - mostly - targets for the

248 future power system.

249 The process of developing these three storylines is described in detail in

250 [39]. In brief, the first version of the storylines was developed in the original

251 Transition Pathways project in a stakeholder workshop in 2008. The technical

252 feasibility, social acceptability and the sustainability of the first version of the

253 storylines were then interrogated in further workshops with experts and key

254 stakeholders, who represented energy companies, policy-makers and non-

255 governmental organisations. This interrogation led to the revised version 2.1 of

256 the pathways, which is currently the latest version. The complete storylines are

257 available online at [45] and shorter summaries are published in [39]. Every

258 storyline consists of four to five pages of qualitative description, a list of key risks

259 for the realisation of the specific storyline and an overview table.

260 Afterwards, a Transition Pathways Technical Elaboration Working Group

261 was set up from the experts in the project in order to assign a quantitative

262 representation for every storyline. This quantitative representation shows the

263 numeric values of the total UK power demand and the power generation mix

264 until 2050 [39]. This process was partly informed by insights from three power

265 system models, but none of these models were informed by economic

266 considerations [39]. In the succeeding RTP project, there are more models 
267 available, of which some include the economic considerations. Therefore, a more

268 structured process was undertaken for linking the storylines with insights from 269 multiple models. In so doing it will show how iteration between storylines and 270 models can fruitfully enhance the process of developing and analysing the 271 broader transition pathways.

272 The Central Co-ordination storyline, analysed in this paper, is one of the 273 three storylines of the RTP project. These storylines picture three ideal types of 274 governance 'logics' in the UK power system (Figure 2): government, market and 275 civil society 'logics'. In these storylines, the views that the government, market or 276 civil society actors respectively need to lead the low-carbon transition emerge as 277 the 'zeitgeist' of the time [39]. In the case of the Central Co-ordination storyline, 278 the central UK government successfully establishes the dominant role by direct 279 co-ordination to deliver the energy policy goals. In the Market Rules storyline, 280 the market actors successfully argue that the energy 'trilemma' is best achieved 281 by the large power companies and other market actors, freely interacting with 282 the policy framework. The investment, made by the large power companies on 283 the basis of investment return (including carbon price effects), available 284 knowledge, regulatory framework and incentives set by the government, will 285 determine the power system transition. The Thousand Flowers storyline argues 286 that society at large shall take an active role in delivering the low-carbon 287 transition as small-scale solutions, especially, but not only through community288 led initiatives and energy service companies (ESCOs). The key recent 289 developments in the UK power sector are described as a hybrid between the 290 Central Co-ordination and the Market Rules storylines [48]. Since the power 291 market liberalisation in 1990s, the market 'logic' has been dominating in the UK, 
but the influence of the government 'logic' has been increasing in recent years, especially after the adoption of the legally binding emissions target. The Central

294 Co-ordination storyline is therefore chosen for in-depth analysis in this paper.

Insert Figure 2 about here

Figure 2. The three ideal types of governance 'logics' in the UK power system transition. Source: J. Burgess and T. Hargreaves. The figure is reproduced from

The Central Co-ordination storyline includes five pages of narrative and here only the key points are summarised. The central UK government is assumed to actively shape the power system transition through the establishment of a new Strategic Energy Agency. This agency will issue tenders for tranches (central contracts) for particular types of low-carbon generation and develop 'technology push' programmes for low-carbon technologies. In order to promote UK industry, the agency will primarily support those technologies where the UK has

309 potential to become a global leader: marine renewables (offshore wind, wave 310 and tidal power), carbon capture and storage (CCS) and electric vehicles. This 311 strong government commitment will underwrite the investment risks for the 312 large power companies. These companies will invest according to the 313 government's plans and deliver the transition, dominated by large-scale power 314 generation. The government will focus on removing any system-wide blockages, 315 such as the lack of transmission capacity, planning issues, supply chains and 316 skills. As a result, the emission mitigation target of $80 \%$ by 2050 , as compared to 
the year 1990, will be achieved for power generation. As noted, society at large

318 will remain a relatively passive player in this storyline. Initially, only non-

319 behavioural measures of demand response will be used, such as increased

320 efficiency standards for appliances and newly built buildings. Later, with the 321 increased industrial and climate benefits, interventions on lifestyles and

322 behaviour will be undertaken by the government, especially through smart 323 metering and demand side response measures. The key risks, identified in the 324 storyline for the realisation of this transition, are (i) the technical and economic 325 feasibility of CCS, (ii) public opposition to costly low-carbon investment due to 326 increased household expenditure, (iii) little effort to incentivise behaviour 327 change of the energy users. The more detailed storyline is also provided in Table 3282

In addition to the qualitative narrative, the Central Co-ordination storyline 330 was already assigned an initial quantitative representation (Figure 3), developed 331 in an iterative process by the Transition Pathways Technical Elaboration 332 Working Group. This quantitative representation served both as an example of 333 how the power sector may look in detail and as a basis for conducting further 334 quantitative research on the storyline (for instance, for environmental or 335 economic appraisals).

Insert Figure 3 about here

339 Figure 3. The initial quantitative representation of the Central Co-ordination 340 storyline. Source: Transition Pathways project. The figure is reproduced from 


\subsection{Landscape of the RTP models}

This section describes the six power system models and two appraisal models that were linked in this paper to the Central Co-ordination storyline.

346 These models are very diverse and this diversity is a strong point as there is not a single best model or methodology that encapsulates all the relevant cross-scale aspects [16]. The RTP leadership envisioned a multi-model analysis, expecting that this analysis, rather than results of a single model, will have potential to provide a broader spectrum of insights.

The eight models used are (in the order of the breadth of the power system boundaries):

- Demand: The energy demand model, developed at the University of Surrey, is a bottom-up model of the UK power demand in the domestic and non-domestic sectors. Due to its highly disaggregated structure, the influence of a range of parameters can be modelled, such as energy service levels, user practices, choices of appliances, building fabric, fuels, deployment of distributed generation and others. The model is based on the synthesis of existing estimates [49-51] and the assumptions from the Central Co-ordination storyline.

- FESA: The Future Energy Scenario Assessment model [52, 53], developed at the Loughborough University, is a single-year UK power generation and demand model, incorporating one-hour time steps for dispatch modelling and using 2001 Met Office weather data on temperature, wind speeds, wave height and solar radiation. The model 
develops scenarios on the basis of the Central Co-ordination storyline and technical feasibility constraints.

- D-EXPANSE: The D-EXPANSE model (Dynamic version of EXploration of PAtterns in Near-optimal energy ScEnarios), developed at the University College London, has the structure of a bottom-up power system model. In addition to the cost optimisation, D-EXPANSE systematically explores the maximally different near-optimal pathways $[15,31,54,55]$. In this way, D-EXPANSE aims to open up the understanding of the fundamentally different ways how the UK power system could evolve. By allowing the deviation from the cost-optimal pathway, D-EXPANSE also explores the structural uncertainty around the concept of rationality and cost-optimisation. The D-EXPANSE model has been validated by comparing its outputs with the results of existing, well-established whole system models and cost estimates for the UK [55].

- EconA: The Economic Appraisal (EconA), conducted by University College London, aims to systematically calculate and compare total investment costs and total system costs for power generation, transmission and distribution for the three transition pathways. The results are disaggregated for the different power generation technologies, which allows for economic feasibility assessment. The EconA is an appraisal technique; it takes the quantitative representation (Figure 3) of the Central Co-ordination storyline and calculates the power system costs for it. In this paper, the EconA is also considered as a model in a broader sense. 
- BLUE-MLP: The BLUE-MLP model (Behaviour Lifestyles and Uncertainty Energy model with Multi-Level Perspective on transitions) is a probabilistic systems dynamic simulation that explores the uncertainties due to sector- and actor- specific behavioural elements $[56,57]$. These behavioural elements include market heterogeneity, intangible costs and benefits, hurdle rates, replacement and refurbishment rates and demand elasticities. In addition, the model links these behavioural uncertainties with the multi-level perspective to transitions [58], where landscape (government decisions and the international context), regime (the current UK power system structure and its regulation) and niche innovations (lifestyle influenced changes in demand) interact with each other.

- EEA: The Energy and Environmental Appraisal (EEA) is a life cycle 405 assessment (LCA) of the UK power system carried out by the University of Bath $[59,60]$. Over 18 environmental impacts were evaluated from cradle to gate, accounting for all upstream and operational activities. Impacts covered in this assessment include climate change, which is quantified through greenhouse gas emissions, and other environmental impacts, such as fossil fuel depletion, human toxicity, particulate matter formation and agricultural land occupation. Similar to the EconA, the EEA framework is a model, which appraises the Central Co-ordination storyline, based on its initial quantitative representation (Figure 3). 
- HESA/UK+: This is a combination of the Hybrid Energy System Analysis tool (HESA) and the Strathclyde UK+ models that were developed at the University of Strathclyde [61-63]. The Strathclyde $\mathrm{UK}+$ model contains all the information for the transition pathways scenarios with spatial disaggregation (17 onshore, five offshore zones and 39 connections) of generation, storage, transmission and distribution. It is linked to the HESA model, which cost-optimises the system, based on the energy hub concept $[64,65]$. The national power demand and generation mix are used as input assumptions. (HAPSO) is developed at the Imperial College London. It is a bottomup, cost-minimisation model that determines the optimal generation, energy storage, transmission, and distribution network infrastructure requirements and their associated cost to achieve three objectives: economic efficiency, security, and sufficient system controllability. The model optimises simultaneously the long-term investment and shortterm operating decisions including hourly generation dispatch, Demand Side Response, storage cycles, and power exchanges taking into account the impact of decisions across all sectors in the power system [66]. The UK power system is embedded in the European power system including UK, Ireland and continental Europe and thus allows for modelling of the power exchange across these regions. 
440 of the power system addressed (demand; generation; dispatch, demand response

441 and storage; transmission and distribution; and interconnectors with Europe)

442 and other thematic considerations addressed by the model (analysis of the

443 maximally different alternatives; uncertainty; behaviour and heterogeneity of

444 actors; economic considerations; environmental considerations; and spatial

445 disaggregation). Both Table 1 and Figure 4 help to show that the eight models,

446 used in this analysis, cover a broad spectrum of cross-scale insights across time,

447 space, system boundaries and disciplines.

448 
449 Table 1. Summary of the eight models (model versions as of April 2013)

\begin{tabular}{|c|c|c|c|c|c|c|c|c|}
\hline Model & Demand & FESA & D-EXPANSE & EconA & BLUE-MLP & EEA & HESA/UK+ & HAPSO \\
\hline Spatial scope & $\begin{array}{l}\text { UK, single } \\
\text { region }\end{array}$ & $\begin{array}{l}\text { UK, single } \\
\text { region }\end{array}$ & UK, single region & $\begin{array}{l}\text { UK, single } \\
\text { region }\end{array}$ & UK, single region & UK, single region & $\begin{array}{l}\text { UK, } 17 \text { onshore } \\
\text { and } 5 \text { offshore } \\
\text { regions }\end{array}$ & $\begin{array}{l}\text { UK, } 5 \text { regions } \\
\text { Europe, incl. UK, } \\
\text { Ireland and } \\
\text { continental Europe }\end{array}$ \\
\hline $\begin{array}{l}\text { Finest temporal } \\
\text { resolution }\end{array}$ & 1 year & 1 hour & 5 years & 1 year & 1 year & 1 year & 1 year & 1 hour \\
\hline \multicolumn{9}{|l|}{$\begin{array}{l}\text { Parts of the } \\
\text { power system } \\
\text { addressed }\end{array}$} \\
\hline $\begin{array}{l}\text {--Power } \\
\text { demand }\end{array}$ & $\begin{array}{l}\text { Total demand; } \\
\text { Demands by } \\
\text { users, energy } \\
\text { services, end- } \\
\text { use equipment }\end{array}$ & $\begin{array}{l}\text { Total demand; } \\
\text { Demands by } \\
\text { users, energy } \\
\text { services, end- } \\
\text { use equipment }\end{array}$ & Total demand & Total demand & $\begin{array}{l}\text { Total demand; } \\
\text { Demands by } \\
\text { users and energy } \\
\text { services }\end{array}$ & Total demand & Total demand & $\begin{array}{l}\text { Total demand; } \\
\text { Demands by users } \\
\text { and energy services }\end{array}$ \\
\hline $\begin{array}{l}\text {-- Power } \\
\text { generation }\end{array}$ & $\begin{array}{l}\text { Decentralised } \\
\text { generation }\end{array}$ & $\begin{array}{l}\text { Large-scale } \\
\text { generation; } \\
\text { Decentralised } \\
\text { generation }\end{array}$ & $\begin{array}{l}\text { Large-scale } \\
\text { generation; } \\
\text { Decentralised } \\
\text { generation }\end{array}$ & $\begin{array}{l}\text { Large-scale } \\
\text { generation; } \\
\text { Decentralised } \\
\text { generation }\end{array}$ & $\begin{array}{l}\text { Large-scale } \\
\text { generation }\end{array}$ & $\begin{array}{l}\text { Large-scale } \\
\text { generation; } \\
\text { Decentralised } \\
\text { generation }\end{array}$ & $\begin{array}{l}\text { Large-scale } \\
\text { generation; } \\
\text { Decentralised } \\
\text { generation }\end{array}$ & $\begin{array}{l}\text { Large-scale } \\
\text { generation; } \\
\text { Decentralised } \\
\text { generation }\end{array}$ \\
\hline $\begin{array}{l}\text {-- Dispatch, } \\
\text { demand } \\
\text { response and } \\
\text { storage }\end{array}$ & & $\begin{array}{l}\text { Dispatch; } \\
\text { Demand } \\
\text { response; } \\
\text { Storage, incl. } \\
\text { hydrogen }\end{array}$ & $\begin{array}{l}\text { Dispatch (stylised); } \\
\text { storage (stylised) }\end{array}$ & $\begin{array}{l}\text { Storage } \\
\text { (stylised) }\end{array}$ & $\begin{array}{l}\text { Dispatch } \\
\text { (stylised); } \\
\text { Demand } \\
\text { response }\end{array}$ & Storage (stylised) & $\begin{array}{l}\text { Dispatch; } \\
\text { Storage }\end{array}$ & $\begin{array}{l}\text { Dispatch; } \\
\text { Demand response; } \\
\text { Storage }\end{array}$ \\
\hline $\begin{array}{l}\text {-- Trans- } \\
\text { mission and }\end{array}$ & & & & & & $\begin{array}{l}\text { Transmission and } \\
\text { distribution }\end{array}$ & $\begin{array}{l}\text { Transmission and } \\
\text { distribution }\end{array}$ & $\begin{array}{l}\text { Transmission and } \\
\text { distribution }\end{array}$ \\
\hline
\end{tabular}




\begin{tabular}{|c|c|c|c|c|c|c|c|c|}
\hline Model & Demand & FESA & D-EXPANSE & EconA & BLUE-MLP & EEA & HESA/UK+ & HAPSO \\
\hline $\begin{array}{l}\text {-- Inter- } \\
\text { connectors to } \\
\text { Europe }\end{array}$ & & $\begin{array}{l}\text { Import; } \\
\text { Export }\end{array}$ & Import & Import & & Import & $\begin{array}{l}\text { Import; } \\
\text { Export }\end{array}$ & $\begin{array}{l}\text { Import; } \\
\text { Export; } \\
\text { UK embedding in } \\
\text { the European } \\
\text { system }\end{array}$ \\
\hline $\begin{array}{l}\text {-- Non-electric } \\
\text { parts of the } \\
\text { energy system }\end{array}$ & $\begin{array}{l}\text { Non-electric } \\
\text { heating }\end{array}$ & $\begin{array}{l}\text { Non-electric } \\
\text { heating; } \\
\text { Non-electric } \\
\text { transport; } \\
\text { Non-electric } \\
\text { industrial and } \\
\text { commercial } \\
\text { uses }\end{array}$ & & & $\begin{array}{l}\text { Non-electric } \\
\text { heating; } \\
\text { Non-electric } \\
\text { transport; } \\
\text { Non-electric } \\
\text { industrial and } \\
\text { commercial uses }\end{array}$ & & $\begin{array}{l}\text { Non-electric } \\
\text { heating }\end{array}$ & \\
\hline $\begin{array}{l}\text { Modelling } \\
\text { method }\end{array}$ & $\begin{array}{l}\text { Deterministic } \\
\text { simulation }\end{array}$ & $\begin{array}{l}\text { Deterministic } \\
\text { simulation }\end{array}$ & $\begin{array}{l}\text { Cost-optimisation } \\
\text { and evaluation of } \\
\text { maximally different } \\
\text { near-optimal } \\
\text { pathways }\end{array}$ & $\begin{array}{l}\text { Appraisal of } \\
\text { exogenous } \\
\text { scenarios }\end{array}$ & $\begin{array}{l}\text { Dynamic } \\
\text { simulation }\end{array}$ & $\begin{array}{l}\text { Appraisal of } \\
\text { exogenous } \\
\text { scenarios }\end{array}$ & Cost-optimisation & Cost-optimisation \\
\hline $\begin{array}{l}\text { Economic } \\
\text { considerations }\end{array}$ & & & $\begin{array}{l}\text { Cost-optimisation; } \\
\text { Exploration of near- } \\
\text { optimal pathways }\end{array}$ & $\begin{array}{l}\text { Post hoc } \\
\text { assessment }\end{array}$ & $\begin{array}{l}\text { Dynamic } \\
\text { simulation, given } \\
\text { the } \\
\text { heterogeneous } \\
\text { sensitivity of the } \\
\text { different actors } \\
\text { to costs }\end{array}$ & & Cost-optimisation & Cost-optimisation \\
\hline
\end{tabular}




\begin{tabular}{|c|c|c|c|c|c|c|c|c|}
\hline Model & Demand & FESA & D-EXPANSE & EconA & BLUE-MLP & EEA & HESA/UK+ & HAPSO \\
\hline $\begin{array}{l}\text { Environmental } \\
\text { considerations }\end{array}$ & & 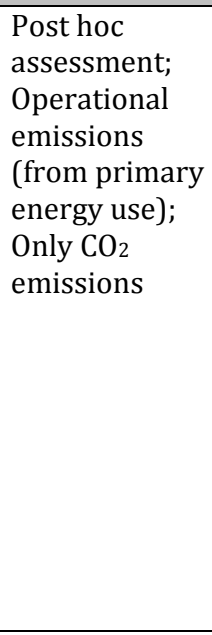 & $\begin{array}{l}\text { Emission constraint; } \\
\text { Operational } \\
\text { emissions; } \\
\text { Only } \mathrm{CO}_{2} \text { emissions }\end{array}$ & $\begin{array}{l}\text { Exogenous } \\
\text { assumptions }\end{array}$ & 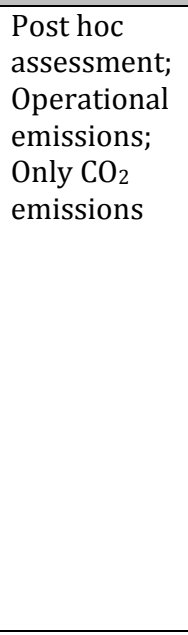 & $\begin{array}{l}\text { Post hoc } \\
\text { assessment; } \\
\text { 'Whole system' } \\
\text { (LCA) } \\
\text { environmental } \\
\text { impacts, including } \\
\text { upstream and } \\
\text { operational } \\
\text { impacts; } \\
\text { Greenhouse gas } \\
\text { emissions }\left(\mathrm{CO}_{2 \mathrm{eq}}\right) \text {; } \\
\text { Fossil fuel } \\
\text { depletion; Human } \\
\text { toxicity; } \\
\text { Particulate matter; } \\
\text { Agricultural land } \\
\text { occupation }\end{array}$ & $\begin{array}{l}\text { Post hoc } \\
\text { assessment; } \\
\text { Operational } \\
\text { emissions; } \\
{\text { Only } \mathrm{CO}_{2}}_{\text {emissions }}\end{array}$ & $\begin{array}{l}\text { Emission constraint; } \\
\text { Operational } \\
\text { emissions; } \\
\text { Only } \mathrm{CO}_{2} \text { emissions }\end{array}$ \\
\hline $\begin{array}{l}\text { Treatment of } \\
\text { uncertainty }\end{array}$ & & & $\begin{array}{l}\text { Structural } \\
\text { uncertainty around } \\
\text { cost-optimisation; } \\
\text { Parametric } \\
\text { uncertainty } \\
\text { accommodated to } \\
\text { some extent through } \\
\text { maximally different, } \\
\text { near-optimal } \\
\text { pathways }\end{array}$ & $\begin{array}{l}\text { Parametric } \\
\text { uncertainty } \\
\text { considered } \\
\text { through } \\
\text { ranges for } \\
\text { uncertain } \\
\text { parameters }\end{array}$ & $\begin{array}{l}\text { Parametric } \\
\text { uncertainty } \\
\text { considered } \\
\text { through } \\
\text { probabilistic } \\
\text { modelling }\end{array}$ & & & $\begin{array}{l}\text { Parametric } \\
\text { uncertainty } \\
\text { considered through } \\
\text { sensitivity analysis }\end{array}$ \\
\hline $\begin{array}{l}\text { Treatment of } \\
\text { behaviour and } \\
\text { heterogeneity } \\
\text { of actors }\end{array}$ & & & $\begin{array}{l}\text { Considered to some } \\
\text { extent through } \\
\text { deviations from cost- } \\
\text { optimal pathway }\end{array}$ & & $\begin{array}{l}\text { Detailed } \\
\text { modelling }\end{array}$ & & & \\
\hline
\end{tabular}




\begin{tabular}{|c|c|c|c|c|c|c|c|c|}
\hline Model & Demand & FESA & D-EXPANSE & EconA & BLUE-MLP & EEA & HESA/UK+ & HAPSO \\
\hline $\begin{array}{l}\text { Key field of } \\
\text { expertise }\end{array}$ & Demand & $\begin{array}{l}\text { Dispatch, } \\
\text { demand } \\
\text { response and } \\
\text { storage; } \\
\text { Generation }\end{array}$ & $\begin{array}{l}\text { Maximally different } \\
\text { alternatives; } \\
\text { Uncertainty }\end{array}$ & $\begin{array}{l}\text { Economic } \\
\text { appraisal }\end{array}$ & $\begin{array}{l}\text { Uncertainty; } \\
\text { Behaviour and } \\
\text { heterogeneity of } \\
\text { the actors }\end{array}$ & $\begin{array}{l}\begin{array}{l}\text { Energy and } \\
\text { environmental } \\
\text { appraisal }\end{array} \\
\text { aprat }\end{array}$ & $\begin{array}{l}\text { Transmission } \\
\text { and distribution; } \\
\text { Generation; } \\
\text { Spatial } \\
\text { disaggregation }\end{array}$ & $\begin{array}{l}\text { Dispatch and } \\
\text { demand response; } \\
\text { Generation; } \\
\text { Transmission and } \\
\text { distribution; } \\
\text { Interconnectors }\end{array}$ \\
\hline
\end{tabular}


Figure 4. The landscape of models (model versions as of April 2013)

\subsection{Process of linking the storyline with multiple models}

For translating the Central Co-ordination storyline into the harmonised modelling assumptions, several key aspects of this storyline are taken. In contrast to the typical story-and-simulation approach, such as [32, 33], where storyline describes the drivers of future transition, the Central Co-ordination storyline includes multiple targets for the future power system that should be met under the increased role of government. The targets that are chosen as harmonised modelling assumptions are: (i) a mild growth of the power demand due to the incentives for end-use energy efficiency, (ii) the increased use of largescale low-carbon technologies, especially of those where UK industry could take a global lead, and a medium uptake of decentralised generation, (iii) the achievement of the emission mitigation goals and (iv) low risk of investment due to the tenders for tranches, issued by the Strategic Energy Agency. More specifically, the models are tuned to match these harmonised assumptions as closely as possible:

i. Total power demand in the UK:

- In 2020, the total power demand, including losses, stabilises at 350 TWh/year;

- In 2030, it increases to 390 TWh/year due to increased electric heating and electric vehicles;

- In 2050, it is equal to $410 \mathrm{TWh} /$ year. 
ii. Power generation mix in the UK:

- In 2020, 40\% of the produced power comes from low-carbon sources, prioritising coal CCS, nuclear and renewable sources. At least $25 \%$ of

iii. Greenhouse gas emissions:

- In $2050,75 \%$ of total produced power comes from large-scale lowcarbon sources, such as nuclear, coal and gas CCS, offshore wind, wave, tidal barrage and tidal stream. At least, 25\% comes from lowcarbon decentralised sources, such as onshore wind and biomass combined heat and power (CHP) plants.

- In 2020, the average carbon intensity in the whole UK power system is $300 \mathrm{gCO}_{2} / \mathrm{kWh}$ of power produced;

- In 2030, this value drops to $30 \mathrm{gCO}_{2} / \mathrm{kWh}$;

- In 2050, it is as low as $20 \mathrm{gCO}_{2} / \mathrm{kWh}$.

iv. Investment:

- Social discount rate of $3.5 \%$ is used for the calculation.

498 assumptions. First, the Demand, FESA models and EEA cannot consider the last 499 assumption about the discount rate as they do not consider costs at all. They, 500 therefore, by-passed this assumption, but implemented the remaining 501 assumptions. Second, the EconA and EEA are appraisal techniques and require 
inputs about the whole power demand structure and generation mix rather than

503 modelling assumptions. Thus, the EconA and EEA are conducted on the basis of

504 the initial quantitative representation of the storyline (Figure 3), which is in line

505 with the harmonised assumptions described above.

506 The qualitative statements from the Central Co-ordination storyline are

507 then scrutinised from the perspective of the outputs of every model. The 508 storyline pictures the contextual information, such as the governance 509 arrangements and the role of the different actors. These aspects can hardly be 510 interrogated by the models. But the description of the targets, that are aspired in

511 the storyline as a result of the governance arrangements and the actors' 512 decisions, can be analysed. For example, the statement "In the financial budget 513 statement in April 2009, the UK Government formally adopts carbon budgets for 514 the periods $2008-12,2013-17$ and $2018-22$ based on a $34 \%$ reduction in 515 greenhouse gas (GHG) emissions by 2020 from 1990 levels" [45, p. 1] is not 516 analysed as it describes the intention of the government. But, the statement "This 517 is realised by the achievement of $25 \%$ of electricity to be generated from 518 renewables by 2020 " [45, p. 3] is interrogated by the eight models.

3.4. Results and discussion on the Central Co-ordination storyline

Table 2 presents the summarized results of revisiting the Central Co523 ordination storyline from the perspective of the eight RTP models; detailed 524 results are available in the Electronic Supplementary Material. Every qualitative 525 statement about the power system targets to be delivered by the governance 
arrangements and actor choices, specified in the storyline, is compared and contrasted with the modelling results.

\section{Robust elements of the storyline}

From the perspective of these eight models, the Central Co-ordination the storyline is almost completely supported by the Demand, FESA and HESA/UK+ models. This is no surprise because these three models specialise in 534 technical feasibility assessment of the power system transitions. These models 535 can be tailored to mimic the storyline and identify only the key mistakes of 536 technical feasibility. Moreover, the researchers, who work with these models, 537 played an active role in the Technical Elaboration Working Group in the original 538 Transition Pathways project. Thus, the storyline is already partly informed by 539 these models and it is not surprising that there is no divergence. The majority of 540 the diverging insights come from the BLUE-MLP, HAPSO and D-EXPANSE models.

541 These models include a broader range of considerations than technical feasibility

542 (Table 1): heterogeneous behaviour of the key actors, uncertainty, detailed 543 dispatch modelling and maximally different alternatives. Thus, naturally these 544 models question the Central Co-ordination storyline more.

\section{Divergence on demand reduction levels}

Although the results from the eight models are in line with most statements of the Central Co-ordination storyline, several clusters of diverging

549 insights are identified. First, the storyline described only a mild increase in the 550 total power demand (20\% higher in 2050 as compared to 2008) due to energy 
551 saving behaviour and efficiency improvements. However, the BLUE-MLP model

552 shows that, when the economic drivers of energy demand and the heterogeneity

553 of the behaviour of the different actors is considered, maintaining slow power

554 demand growth through the entire model horizon appears rather wishful

555 thinking. This finding is in line with the common observation that technically and

556 economically sensible energy demand reduction measures may not be taken up

557 in reality [67]. Storylines developed by the various stakeholders and experts-

558 even more than models-tend to be overly optimistic and fragile from the 559 modelling perspective $[10,11]$. This remark is also consistent with a broader 560 argument that failures of effectively mitigating climate change can be expected 561 [68]. The Central Co-ordination storyline envisions a passive role of the civic 562 society. Without the active energy saving action of the society at large, drastic 563 demand reduction may be challenging to achieve. The UK government could only 564 enforce some types of measures for mitigating the power demand, such as smart 565 meters, efficient domestic appliances or refurbishment of buildings. Thus, the 566 expectation from the storyline about the demand needs to be revisited.

\section{Divergence on back-up capacity}

The Central Co-ordination storyline aspired to the retirement of existing coal and gas power plants by 2037 and their replacement with low-carbon

571 technologies, such as renewable energy sources or gas and coal with CCS.

572 However, both the D-EXPANSE, BLUE-MLP and HAPSO models, which also model 573 the demand response potential, show that this aspiration is challenged by the 574 dispatch (supply-demand balancing) constraint. According to the models, for the 575 aspired high deployment of intermittent renewable energy sources there will be 
576 a need for significant levels of back-up capacity, mostly flexible gas OCGT power

577 plants. The D-EXPANSE model, which explores the many different pathways, 578 shows that at least $15 \mathrm{GW}$ of gas power plants would be required. The power 579 generation mixes of BLUE-MLP also include $15 \mathrm{GW}$ of gas or coal power plants. 580 Most importantly, the HAPSO model, whose key field of expertise is dispatch 581 modelling due to its one-hour temporal resolution and detailed assessment of 582 supply security requirements, proposes 50GW of gas OCGT. The value is higher 583 than the one suggested by the D-EXPANSE and BLUE-MLP models because the 584 HAPSO model assumes higher supply security requirements. Overall, the 585 complete retirement of fossil fuel based power plants is questionable and the 586 results suggest that the storyline needs to include more of that type of plant. As 587 highlighted in Figure 4, the dispatch modelling is the key field of expertise of the 588 HAPSO model. Thus, its conclusion about the 50GW of gas OCGT by 2037 shall be 589 prioritized over the D-EXPANSE and the BLUE-MLP conclusions.

The FESA, BLUE-MLP, EEA, HESA/UK+ and HAPSO models all agree that

593 the target of the greenhouse gas emissions in 2035 would not be met. Instead of 594 the aspired $30 \mathrm{gCO}_{2} / \mathrm{kWh}$ in the storyline, the modelling outcomes range from 33 $595 \mathrm{gCO}_{2} / \mathrm{kWh}$ to $56 \mathrm{gCO}_{2} / \mathrm{kWh}$ for $\mathrm{CO}_{2}$ for operational emissions and equals 120 $596 \mathrm{gCO}_{2 \mathrm{eq}} / \mathrm{kWh}$ for the 'whole system' (cradle to gate) emissions. The D-EXPANSE 597 model shows a number of power generation mixes, which are not necessarily the 598 same as modelled in other seven models, but are still consistent with the 599 harmonised assumptions of the storyline. Some of these mixes could meet the 600 target of $30 \mathrm{gCO}_{2} / \mathrm{kWh}$, but these mixes are different from the mixes evaluated 
601 by the other models. Thus, while reaching the emission target can be technically

602 feasible, it may not be realistic via the means that the storyline describes.

603 According to the EEA, which has the most detailed accounting of the operational

604 and 'whole system' emissions as its key field of expertise, the emissions target 605 would also be missed (although a different target for the 'whole system' 606 emissions could be expected). Thus, either the achieved levels of emissions or 607 the measures (power demand and generation mix) need to be revisited in the 608 storyline.

\section{Divergence on power generation mix}

When the Central Co-ordination storyline was initially developed in the

612 Transition Pathways project, it had little insights from the experts and models,

613 informed by the economic considerations [39]. This is reflected in the points of

614 divergence between the models and the storyline about the power generation 615 mix. The D-EXPANSE, BLUE-MLP and HAPSO models, which include information 616 about costs, the cost-optimal and near-optimal decisions of actors, both include 617 more nuclear power than anticipated by the storyline. The D-EXPANSE model 618 prioritises onshore and offshore wind power as renewable energy sources rather 619 than wave and tidal power, as envisioned in the storyline. The BLUE-MLP model 620 includes a much more significant deployment of nuclear power due to its costs 621 and emissions performance. The HAPSO model raises concerns about significant 622 curtailment of the power produced by the renewable energy sources due to lack 623 of market integration and lack of interconnectors between the UK and 624 continental Europe. This significant curtailment would reduce the economic 625 feasibility of renewable sources. While the storyline also describes a high 
deployment of gas and coal CCS, the D-EXPANSE model shows that many of the

627 cost-optimal and near-optimal pathways could have no CCS in the generation 628 mix. The HAPSO model also questions the large deployment of CCS because, from 629 the dispatch perspective, these plants would run on a low capacity factor (24\% 630 to $36 \%$ ) and thus their economic feasibility is challenged. The EEA model 631 highlighted that the deployment of coal CCS is likely to provide almost a quarter less 632 carbon emission mitigation than is normally assumed on a whole system basis. In 633 brief, these results suggest that a revised version of the Central Co-ordination 634 storyline should consider a higher share of nuclear and wind power, but a more 635 pessimistic deployment of coal and gas CCS and other types of renewable energy 636 sources.

\section{Divergence on the key risk}

The Central Co-ordination storyline identifies the technical and economic

640 feasibility of CCS as one of the key risks for implementing the storyline. While 641 most of the eight models include a share of coal and gas CCS, the D-EXPANSE 642 model shows that this is not a prerequisite. D-EXPANSE generates a large 643 number of maximally different cost-optimal and near-optimal scenarios; near644 optimal scenarios are defined as scenarios that have up to $30 \%$ higher total 645 cumulative system costs by 2050 than the least cost scenario. Many of these 646 scenarios do not have CCS, even if the carbon price rise to $£ 207.5 /$ tonne $\mathrm{CO}_{2 \text { eq }}$ by 6472050 is assumed in line with [69]. This means that the coal and gas CCS are not 648 prerequisites for implementing the Central Co-ordination storyline, as it is 649 described in the harmonised assumptions. As coal and gas CCS is a relatively 650 costly technology, it appears seldom in the cost-optimal and near-optimal 
651 scenarios. In the D-EXPANSE modelling outputs, the environmental gains of the 652 coal and gas CCS are rather replaced by the deployment of other low-carbon 653 technologies (renewable sources and nuclear power), while the role of back-up 654 capacity of coal and gas CCS power plants is compensated by coal and gas plants 655 without CCS. The BLUE-MLP model also provides a range of power generation 656 mixes without CCS, even with the carbon price increase up to $£ 600 /$ tonne $\mathrm{CO}_{2 \mathrm{eq}}$ 657 by 2050 . Thus, instead of suggesting the feasibility of CCS as the key risk, these 658 results seem to imply that Central Co-ordination storyline shall consider other 659 risks that are highlighted by diverging insights from the eight models.

660 One of these key risks is the supply-demand balancing challenge. As the 661 HAPSO, D-EXPANSE and BLUE-MLP models show, supply-demand balancing may 662 be a big challenge in the Central Co-ordination storyline, as it describes high 663 levels of intermittent renewable sources and inflexible power plants with CCS, 664 which are challenging to combine. At the same time, the storyline does not refer 665 to the necessary flexible generation and demand response measures that would 666 guarantee simultaneous integration of CCS and renewable sources into the 667 system. This may cause public concerns over supply security.

668 Another key risk is the failure to meet the greenhouse gas emissions 669 target. The results of these multiple models from Table 2 already show that the 670 target might be missed in 2035. This failure would become even more likely if, in 671 order to meet the balancing challenge, the needed gas power plants would be 672 installed as the back-up capacity. The third key risk is the need for nuclear 673 power, which — as the recent years show—may cause a high public resistance. 
677 seems to miss or under-represent several aspects that are analysed in the eight

678 models (Figure 4). The storyline does not describe any arrangements regarding

679 power import and export as well as the relations with the other European 680 countries, as modelled by the HAPSO and D-EXPANSE models. The storyline does 681 not discuss the governance arrangements and the choices of actors about the 682 power transmission and distribution grid, covered by the HESA/UK+ and HAPSO 683 models. The demand response levels, important for the dispatch modelling by 684 the FESA, HAPSO and other models, have also been only described to a limited 685 extent. The D-EXPANSE and BLUE-MLP models analyse the influence of 686 parametric and structural uncertainty on the power system transition, but these 687 insights are so far not incorporated into the storyline. All these aspects are often 688 forgone not only in the Transition Pathways storylines, but also in wider energy 689 policy discourses. Yet, the future power system transition requires a portfolio of 690 measures on the power demand, generation, transmission and distribution sides. 691 These aspects need to be considered, when developing the next version of the 692 storyline. 
695 Table 2. Revisiting the storyline with the multiple models (detailed documentation and explanation of every cell is available in the 696 Electronic Supplementary Material). Green colour means that the model outputs are in line with the storyline, yellow - that there is a 697 minor divergence, red - that the storyline statement contradicts the model outputs, white - the particular statement is not addressed in 698 the model. 


\begin{tabular}{|c|c|c|c|c|c|c|c|c|}
\hline $\begin{array}{l}\text { Some of the relevant quotes from the storyline, taken from [45]. The complete list } \\
\text { of quotes is available in the Electronic Supplementary Material }\end{array}$ & Demand & FESA & DXPANSE & EconA & $\begin{array}{l}\text { BLUE- } \\
\text { MLP }\end{array}$ & EEA & $\begin{array}{l}\text { HESA/ } \\
\text { UK+ }\end{array}$ & HAPSO \\
\hline $2008-2022$ & & & & & & & & \\
\hline $\begin{array}{l}\text { "By 2020, the energy efficiency measures have led to the stabilisation of electricity } \\
\text { demand." }\end{array}$ & & & & & & & & \\
\hline $\begin{array}{l}\text { "This policy involves a risk being passed to consumers of experiencing higher than } \\
\text { average electricity costs, if the price of natural gas does not rise significantly." }\end{array}$ & & & & & & & & \\
\hline $\begin{array}{l}\text { "By } 2020,<\ldots>\text { the relative decarbonisation of electricity supply has led to the } \\
\text { achievement of the carbon budget of a } 34 \% \text { reduction in } \mathrm{CO}_{2} \text { emissions, compared to } \\
1990 \text { levels." }\end{array}$ & & & & & & & & \\
\hline $\begin{array}{l}\text { "This is realised by the achievement of } 25 \% \text { of electricity to be generated from } \\
\text { renewables by } 2020 . "\end{array}$ & & & & & & & & \\
\hline $\begin{array}{l}\text { "High levels of deployment for onshore (8GW) and offshore wind, (10GW) which } \\
\text { operates at over } 40 \% \text { capacity factor; the first operational CCS coal plant; and four new } \\
(1.6 \mathrm{GW}) \text { nuclear power stations." }\end{array}$ & & & & & & & & \\
\hline $2023-2037$ & & & & & & & & \\
\hline $\begin{array}{l}\text { "Remaining other coal and gas power stations are retired as they reach the end of their } \\
\text { life." }\end{array}$ & & & & & & & & \\
\hline
\end{tabular}




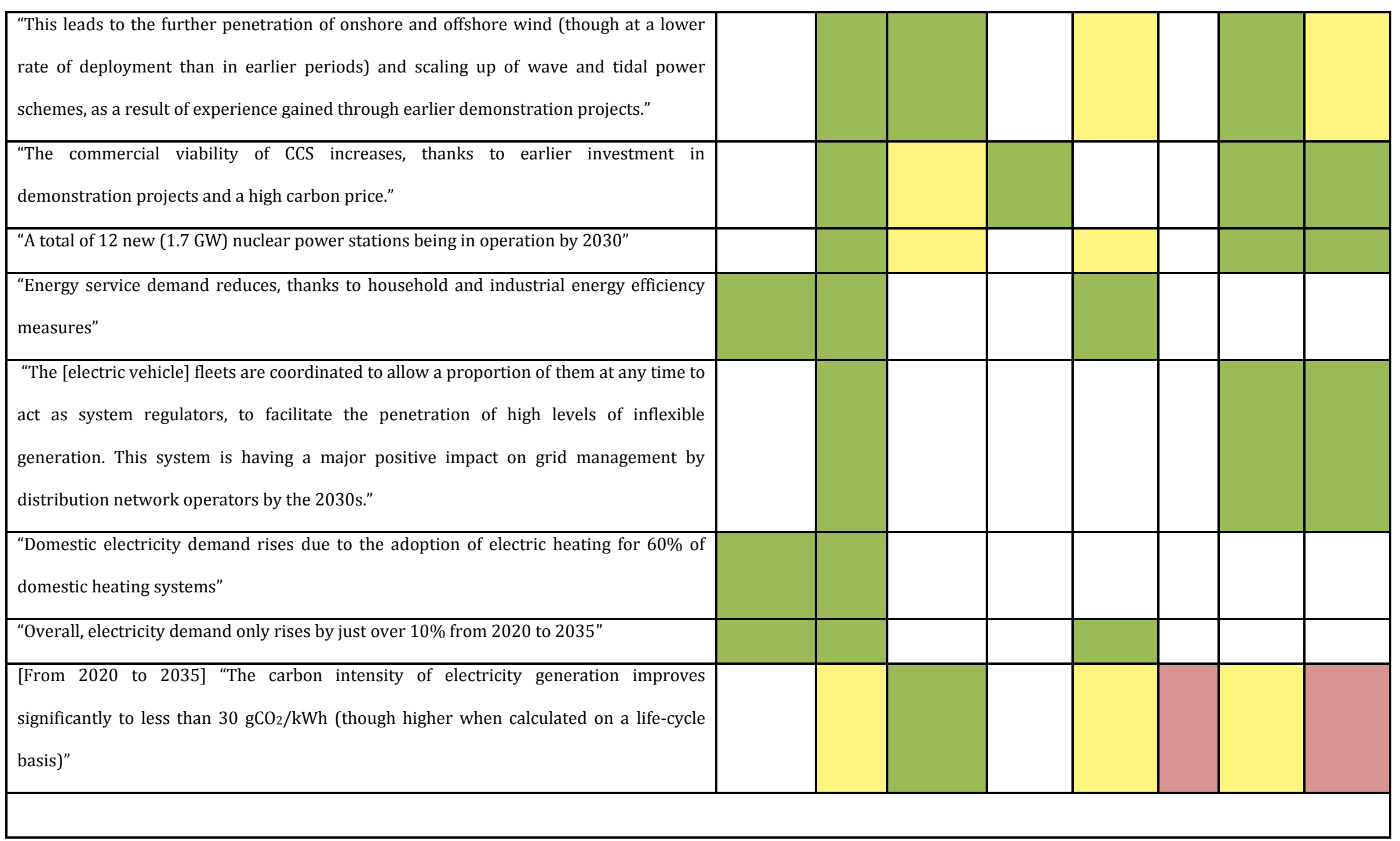




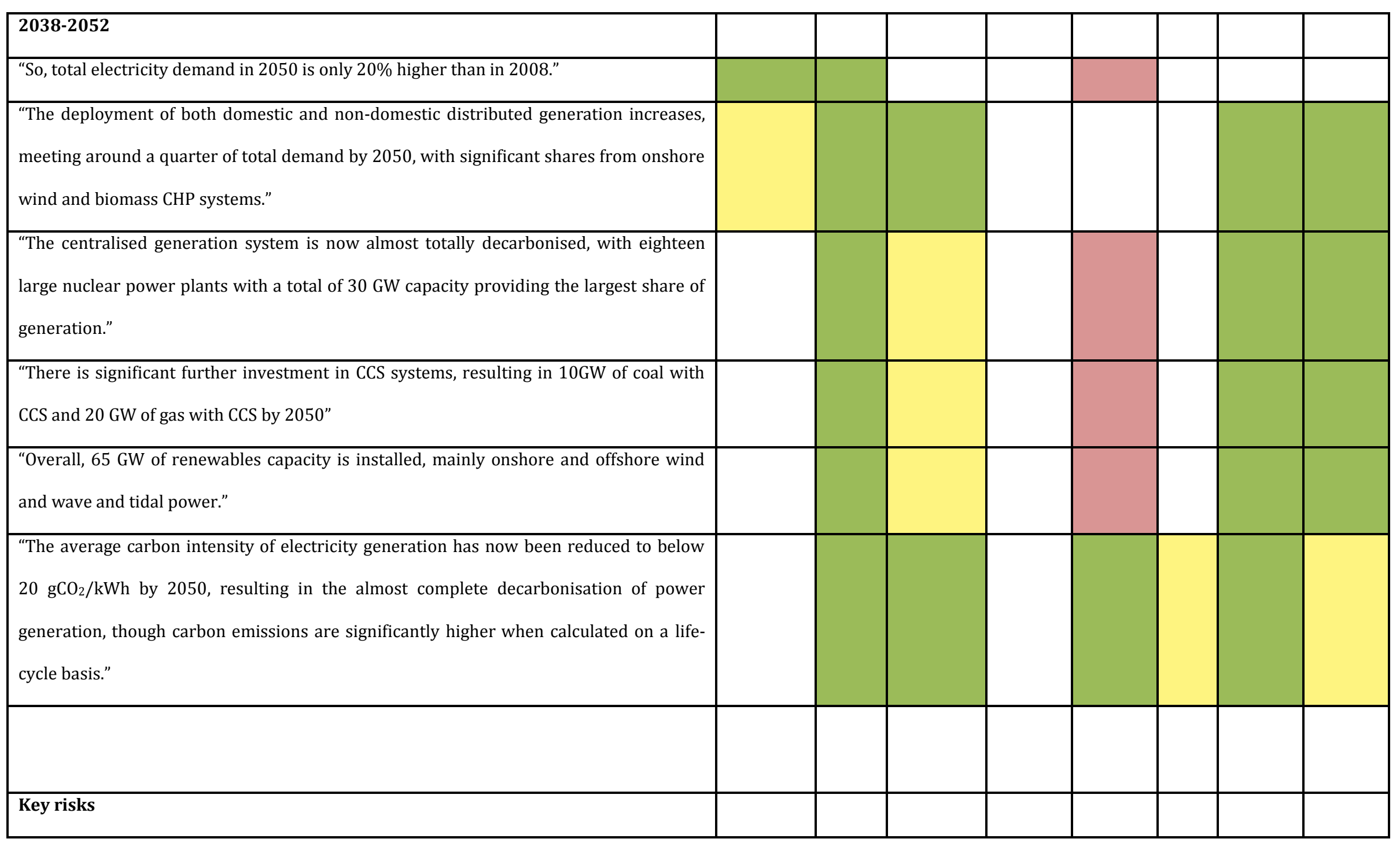




\begin{tabular}{|l|l|l|l|l|l|l|l|l|l|l|}
\hline The key risk is that "Carbon capture and storage turns out to be technologically or & & & (Not key & risk) & & & & & \\
economically unfeasible" \\
investment."
\end{tabular}


This section critically reflects the proposed approach for linking detailed storylines with multiple models, based on the case of the Central Co-ordination storyline.

\section{Development of storylines}

In scenario processes, storylines are often very detailed because they aim to encapsulate numerous details, coming from the different parts of the power system, viewpoints (government, power companies, consumers etc.),

710 stakeholder and expert inputs. Such a process, however, has shortcomings. First, 711 when so many diverse inputs are brought into one storyline under the typical 712 story-and-simulation approach [2] or when using such detailed storylines as in 713 the RTP projects, the internal consistency of this storyline becomes at risk. For 714 example, the comparison of the Central Co-ordination storyline with the outputs 715 of the eight RTP models reveals several inconsistencies. The storyline describes 716 the role of society at large as passive, while the envisioned substantial decrease

717 in the energy service demand may not be feasible without concerted efforts to 718 reduce demand for energy services. In order to avoid such cases, it seems likely

719 that the development of internally consistent, stakeholder-based storylines, 720 facilitated by formal techniques such as formative scenario analysis or cross721 impact balance $[5,20-23,70,71]$, would increase the robustness of the 722 qualitative storyline itself.

723 Second, some internal inconsistencies as well as other mistakes due to the 724 lack of analytical foundation can be eliminated by comparing the storyline with 
725 models (given that these models are available), as done in this paper. This is

726 essential because the power system transition is inherently complex and the 727 qualitative storylines-based approach on its own cannot capture this complexity

728 [11]. The afore-mentioned cross-impact balance or formative scenario analysis 729 can be used for mediating among the diverging perspectives of the experts. The 730 insights from the multiple models could thus perhaps be brought into these 731 analyses too in order to derive storylines that are informed by multiple models 732 and multiple stakeholder views simultaneously.

733 Third, lengthy and detailed storylines may be easier for the audience to 734 imagine, but they also lead to overconfidence about how realistic they are [70]. 735 This is problematic because such exercises distract the attention of the audience 736 from other, as likely or as desirable, scenarios. The scenario approach is 737 expected, however, to expand rather than narrow down the understanding about 738 the plausible futures. Therefore, there is a threshold for how long and detailed 739 the storyline shall be. When storylines are combined with the multiple models as 740 in this paper, a meaningful approach would be to keep in the storyline the details 741 about the governance and the choices of the actors, while leaving the power 742 system description to the multiple models. 'Translation' of storylines into model assumptions The way a qualitative storyline is 'translated' into the assumptions for the 746 quantitative models (Step 1 in 1 ) is decisive for the comparison of the storyline 747 and the modelling results. There is a trade-off between the number of 748 assumptions and how much flexibility the models have to express their 749 perspective. If a large number of assumptions is used, the models would be 
tailored to mimic the storyline almost completely. In this way, the storyline and

751 the multiple targets, aspired by the stakeholders, could be tested in light of

752 modelling results. This can be a useful and creative learning exercise for the 753 stakeholders $[10,11]$. At the same time, the RTP project seeks to better grasp a 754 wide range of plausible future power system developments, if the central UK 755 government plays a more active role in shaping the power sector transition. 756 Thus, models with different rationales could help capturing a wider range of 757 these plausible futures. If too many assumptions would be used, this variety of 758 plausible futures would be lost. For example, in the case of the RTP models, the 759 cost-optimising models, like HAPSO or D-EXPANSE, could be tailored to produce 760 the results, similar to the storyline if there are no major inconsistencies in the 761 storyline. But this would gloss over the fact that the cost-optimal and near762 optimal-thus, perhaps more realistic pathways-may be very different than the 763 one described in the storyline. The modelling assumptions thus shall better allow 764 more flexibility for the models to express their perspective. However, it is challenging to define what the optimal number and type of 766 assumptions are. Moreover, one qualitative statement might have a range of 767 quantitative representations which need to be captured systematically $[10,11]$. 768 The 'translation' procedure, used in this paper, is acknowledged as one of the 769 weaknesses of the study, presented in Section 3. To some extent, this fragility 770 arose because only one storyline was analysed through the perspective of the 771 eight models. If all three storylines of the RTP project were analysed (Central Co772 ordination, Market Rules and Thousand Flowers), this problem could be resolved 773 to some extent, as a unified framework for the 'translation' of these storylines 
into modelling assumptions would need to be defined. By comparing three storylines, a more robust framework could be developed.

\section{Mapping the expertise of models}

The landscape of models (Table 1 and Figure 4) proved to be a useful approach for understanding and mapping the fields of expertise of the eight, very

780 diverse cross-scale models as in the RTP project. This landscape helped to 781 understand where the models overlap and where they have their key, individual 782 fields of expertise as compared to the other models. In line with [16], this 783 landscape approach assumes that the usefulness of the model is the local matter.

784 There is no single best model that covers all the relevant aspects and scales in 785 sufficient depth and breadth. The usefulness of the model depends on the 786 model's suitability to answer the specific question at hand and to fill a gap among 787 the other existing models. In the reported process, due to their different key 788 fields of expertise, all eight RTP models proved to be useful for assessing the 789 storyline from different cross-scale perspectives on space, time, system 790 boundaries, discipline and even technique (Table 1).

However, this landscape of RTP models for revising the Central Co792 ordination storyline is not complete because not all of the qualitative statements 793 in the storyline could be assessed. First, the statements about wider 794 developments of industry and the national economy could not be addressed. For 795 this purpose, a macro-economic model or a whole energy system model would 796 be needed in the RTP landscape. This whole energy system model would need to 797 be broader than the already used HAPSO model, which addresses only the power 798 system. This model would need to have as wide system boundaries as UK 
MARKAL or TIMES [46, 72] and to address the whole supply chain of the whole energy system (not only the power system) and energy-economy interactions.

801 Second, assuming a substantial deployment of distributed generation, there 802 would be a need for improved modelling of local voltage control and two-way 803 power flows. This problem would increase even more if the Thousand Flowers 804 storyline would be analysed, because this storyline pictures a significant uptake 805 of decentralised generation. A model that addresses these issues would need to 806 be added to the landscape of models too.

Third, the storyline raised issues about public acceptability of rising energy prices or, as suggested by the models, possibly decreasing supply security

809 due to the deployment of intermittent renewable energy sources. While the 810 public acceptability issues are challenging to model, they are of high relevance

811 for the future transitions. Therefore, in parallel to the modelling-based 812 assessment of the storyline, a social scientific assessment is required. This social 813 scientific analysis already took place in the Transitions Pathways project [73] 814 and thus, together with the landscape of models, it could improve the analytical 815 assessment of the qualitative storylines.

\section{$\underline{\text { Two-way reflexive collaboration }}$}

The iterative loop in Figure 1 would be completely closed by revising the

819 qualitative storyline on the basis of the results of the eight models. The exercise,

820 reported in Table 2, helped to identify the inconsistencies between the storyline 821 and the models. The diversity of the eight models here proved to be especially 822 useful as the results of the different models were at times diverging. While some 823 models were in line with all or almost all storyline statements, there was almost 
824 always at least one model that diverged from the storyline. Any of these

825 divergences can have credible reasons leading to inconsistencies in the storyline.

826 Unpacking the underlying mechanisms of this divergence (as already reported in

827 Section 3.4) is thus essential for understanding why this divergence appears and,

828 if necessary, revising the storyline and/or the models. The next step of this

829 process would be a collaborative, reflexive effort between the storyline

830 developers and the modellers. In this way, improved versions of the storyline

831 and the models could be developed.

832 The iterative loop in Figure 1 is a two-way reflexive collaboration

833 between the storyline and the models [36]. In this paper, a storyline-led

834 approach is reported. The storyline was developed first and then was assessed

835 from the perspective of the different models, at the same time reflecting on the

836 potentially relevant models that were missing from the analysis. Models alone

837 can hardly capture the broader picture, covered in the storyline, such as the

838 power system governance 'logics' and the choices of the key actors. As these

839 aspects are very challenging to model, it is meaningful to use a storyline-led

840 approach. However, an alternative, modelling-led approach could also be used to

841 derive storylines too. This could be based on the generation of a large number of

842 scenarios with multiple models and extracting a smaller range of scenarios with

843 fundamentally-different structures and describing them in storylines. Some

844 research in this direction is already reported in $[6,11,54,55,74-76]$. Such

845 process could be organised similar to the process of Figure 1, but it would start 846 with the modelling exercise.

\section{5. Conclusions}


850 qualitative storylines with quantitative, cross-scale models. An approach is

851 proposed for linking a very detailed storyline, which describes the governance

852 'logics' and the choices of key system actors, with multiple, very diverse 853 quantitative models. This approach is especially relevant because a growing 854 number of interdisciplinary projects worldwide tend to bring together social 855 scientists with modellers. Most of these models already exist before the projects 856 and differ substantially is their spatial and temporal foci, disciplinary 857 perspective, model objective, system boundaries and the format of inputs and 858 outputs. Cross-comparison of such models is a challenge in itself. In the proposed 859 approach, the comparison of the models is based on a new concept called the 860 landscape of models. Moreover, this paper goes further by linking these multiple, 861 diverse cross-scale models with qualitative storyline. Therefore, the described 862 approach is a novel contribution to the existing literature. In the frame of the Realising Transition Pathways project, the proposed 864 approach is illustrated by revising the Central Co-ordination storyline, developed 865 in the earlier Transition Pathways project, for exploring the UK power system 866 transition until 2050. This storyline describes the governance 'logics' and the 867 choices of the key system actors, when the UK central government should take a 868 more active role in shaping the power system transition. Such contextual 869 considerations as governance and the actors' choices can hardly be modelled in 870 the current RTP models; this highlights the value of the storyline. This qualitative 871 storyline is addressed through the perspective of six, very diverse models and 872 two appraisal techniques: Demand, FESA, D-EXPANSE, EconA, BLUE-MLP, EEA, 873 HESA/UK+ and the HAPSO models. These models and appraisals revealed the 
874 fragile nature of the storyline. From the perspective of the model, the storyline 875 tended to wishfully overestimate the power demand reduction potential and the 876 uptake of marine renewables. The necessity for CCS to meet long-term stringent 877 greenhouse gas emissions targets was also overestimated. But it underestimated 878 the supply-demand balancing challenge, the need for gas power plants as a back879 up capacity, the role of nuclear power and interconnectors with Europe, and the 880 challenge of meeting the stringent emissions targets. Thus, the combination of 881 the qualitative storyline and its revisions from the perspective of multiple, 882 diverse models is key for developing robust future scenarios and transition 883 pathways. An iterative process for this purpose has been proposed in this paper. 884 For the RTP consortium, the interpretation of the results of this analysis 885 and their implications for the future development of both the storylines and the 886 models will be the subject of further debate, research and papers.

\section{Acknowledgements}

This work was conducted as a part of the Realising Transition Pathways consortium project, supported by the UK Engineering and Physical Sciences

891 Research Council (Grant EP/K005316/1). The authors are solely responsible for 892 the analysis and views in this paper.

The authors thank the other members of the Realising Transition

894 Pathways project and the preceding Transition Pathways project, who developed 895 the Central Co-ordination storyline and participated in the workshops that led to 896 the development of this paper (a full list of the consortium members is available 897 at [77]). The substantial contributions of Neil Strachan and other contributions 898 of Graham Ault, Stuart Galloway, Geoff Hammond, Matt Leach, Goran Strbac and 
Murray Thomson in guiding the development and analysis of the models are also

900 acknowledged. The authors especially value the extensive critical review by

901 Geoff Hammond, Peter Pearson and the anonymous reviewers that helped to 902 considerably improve the manuscript.

903

904

Vitae

905

- Dr Evelina Trutnevyte works as a Research Associate at the University College London (UCL) Energy Institute. Her research focuses on the development of context-specific, spatially differentiated energy strategies that combine insights from multiple disciplines and stakeholder engagement. She received her $\mathrm{PhD}$ at the Institute for Environmental Decisions, ETH Zurich, and her Master's degree in Power Engineering from Vilnius Gediminas Technical University. She strengthened her expertise during studies and fellowships at Aalborg University (Denmark), Lithuanian Energy Institute, Power Systems Laboratory at ETH Zurich (Switzerland), University of Oslo (Norway), and during two years of engineering consulting in Lithuania.

- Dr John Barton is a Research Associate at Loughborough University's Centre for Renewable Energy Systems Technology (CREST). He also received his $\mathrm{PhD}$ and Master's degree at Loughborough University. His 7 years of post-doctoral research includes energy storage, whole energy system modelling, distributed generation, demand response, condition monitoring of wind turbines and public engagement with renewable energy. John is also an energy consultant and company director, previously working with Bryte Energy Ltd on hydrogen technologies and 
now working with Air Fuel Synthesis Ltd making synthetic liquid transport fuels. John co-created and then developed the FESA model.

- Áine O'Grady is a Research Officer at the University of Bath where she is part of the Sustainable Energy Research Team in the Department of Mechanical Engineering. Previously, Áine worked at Aquamarine Power, and carried out a life-cycle assessment of its wave energy device prototype, and contributed to environmental design improvements. Her current research involves the technology assessment of energy systems using a set of appraisal techniques from engineering, environmental sciences and strategic thinking (such as environmental life-cycle assessment, thermodynamic analysis, horizon scanning and other futureoriented technology analysis).

- Damiete Ogunkunle is a Research Officer at the Centre for Environmental Strategy, University of Surrey, where she obtained her Masters' degree in Environmental Management. She has worked in a range of research projects since 2008 including the sustainability assessment of UK bioenergy supply chains. Currently, she is involved in the development of the energy demand models as part of the Realising Transitions Pathways consortium. She is also working part time towards completing her $\mathrm{PhD}$ degree.

- Dr Danny Pudjianto is a Research Fellow at Imperial College London with the expertise in power system modelling and optimization, power system economics, regulation, system operation, strategic planning, system security, and technology evaluations from power system perspective including smart grids, active network management, demand response, 
distributed generation, energy storage, and energy networks. He holds degrees in Economics (BA) and Electronics (BSc), and Power System (MSc and $\mathrm{PhD}$ ). He has published more than 40 technical papers.

- Elizabeth Robertson is a Research Assistant at the University of Strathclyde's Institute of Energy and Environment. She received her MPhys (Hons) from the University of York, UK in 2008 and is currently pursuing a PhD at the University of Strathclyde. Her research interests include combined energy system modelling and the interaction of physically connected, but individually operated energy markets.

958

\section{References}

960 [1] B.C. O'Neill, V. Schweizer, Mapping the road ahead, Nat. Clim. Chang. 1 (2011)

$961 \quad 352-353$.

962 [2] J. Alcamo, Chapter Six The SAS Approach: Combining Qualitative and

963 Quantitative Knowledge in Environmental Scenarios, in: A. Joseph (Ed.)

964 Developments in Integrated Environmental Assessment, Elsevier, 2008.

965 [3] G. Wright, G. Cairns, R. Bradfield, Scenario methodology: New developments

966 in theory and practice: Introduction to the Special Issue, Technological 967 Forecasting and Social Change 80 (2013) 561-565.

968 [4] R.J. Swart, P. Raskin, J. Robinson, The problem of the future: Sustainability

969 science and scenario analysis, Global Environmental Change-Human and Policy

970 Dimensions 14 (2004) 137-146.

971 [5] E. Kemp-Benedict, Telling better stories: strengthening the story in story and 972 simulation, Environmental Research Letters 7 (2012). 
974 scenario studies through a dynamic analytical approach using a large number of 975 scenarios, in: International Energy Workshop 2013, 19-21 June 2013, Paris, 976 France, 2013.

977 [7] K.L. Anderson, S.L. Mander, A. Bows, S. Shackley, P. Agnolucci, P. Ekins, The 978 Tyndall decarbonisation scenarios-Part II: Scenarios for a 60\% CO2 reduction in 979 the UK, Energy Policy 36 (2008) 3764-3773.

980 [8] S.L. Mander, A. Bows, K.L. Anderson, S. Shackley, P. Agnolucci, P. Ekins, The 981 Tyndall decarbonisation scenarios-Part I: Development of a backcasting 982 methodology with stakeholder participation, Energy Policy 36 (2008) 37549833763.

984 [9] CLUES, Learning through scenarios: Exploring the future of decentralised 985 energy in the UK, 2012, Sussex Energy Group, Brighton, UK, 986 http://www.ucl.ac.uk/clues/files/scenarios briefing (accessed on 10.09.2013).

987 [10] E. Trutnevyte, M. Stauffacher, R.W. Scholz, Supporting energy initiatives in 988 small communities by linking visions with energy scenarios and multi-criteria 989 assessment, Energy Policy 39 (2011) 7884-7895.

990 [11] E. Trutnevyte, M. Stauffacher, R.W. Scholz, Linking stakeholder visions with 991 resource allocation scenarios and multi-criteria assessment, European Journal of 992 Operational Research 219 (2012) 762-772.

993 [12] G. Bowman, R.B. MacKay, S. Masrani, P. McKiernan, Storytelling and the 994 scenario process: Understanding success and failure, Technological Forecasting 995 and Social Change 80 (2013) 735-748.

996 [13] R. Weijermars, P. Taylor, O. Bahn, S.R. Das, Y.-M. Wei, Review of models and 997 actors in energy mix optimization - can leader visions and decisions align with 
optimum model strategies for our future energy systems?, Energy Strategy 999 Reviews 1 (2012) 5-18.

1000 [14] P.J.H. Schoemaker, Multiple scenario development: Its conceptual and 1001 behavioral foundation, Strategic Management Journal 14 (1993) 193-213.

1002 [15] E. Trutnevyte, The allure of energy visions: Are some visions better than 1003 others?, Energy Strategy Reviews (2014) 211-219.

1004 [16] M.S. Morgan, The World in the Model. How economists work and think, 1005 Cambridge University Press, Cambridge, 2012.

1006 [17] N. Hughes, N. Strachan, Methodological review of UK and international low 1007 carbon scenarios, Energy Policy 38 (2010) 6056-6065.

1008 [18] N. Hughes, Towards improving the relevance of scenarios for public policy 1009 questions: A proposed methodological framework for policy relevant low carbon 1010 scenarios, Technological Forecasting and Social Change 80 (2013) 687-698.

1011 [19] E. Lloyd, V. Schweizer, Objectivity and a comparison of methodological 1012 scenario approaches for climate change research, Synthese 191 (2014) 204910132088.

1014 [20] V.J. Schweizer, E. Kriegler, Improving environmental change research with 1015 systematic techniques for qualitative scenarios, Environmental Research Letters 10167 (2012).

1017 [21] B. Girod, A. Wiek, H. Mieg, M. Hulme, The evolution of the IPCC's emissions 1018 scenarios, Environmental Science \& Policy 12 (2009) 103-118.

1019 [22] R.W. Scholz, O. Tietje, Embedded case study methods: Integrating 1020 quantitative and qualitative knowledge, Sage, Thousand Oaks, 2002. 
1021 [23] W. Weimer-Jehle, Cross-impact balances: A system-theoretical approach to 1022 cross-impact analysis, Technological Forecasting and Social Change 73 (2006) $1023 \quad 334-361$.

1024 [24] O. Edenhofer, B. Knopf, T. Barker, L. Baumstark, E. Bellevrat, B. Chateau, P. 1025 Criqui, M. Isaac, A. Kitous, S. Kypreos, M. Leimbach, K. Lessmann, B. Magne, S. 1026 Scrieciu, H. Turton, D.P. van Vuuren, The Economics of Low Stabilization: Model 1027 Comparison of Mitigation Strategies and Costs, Energy Journal 31 (2010) 11-48. 1028 [25] J.R. Weyant, F.C. de la Chesnaye, G.J. Blanford, Overview of EMF-21: Multigas 1029 mitigation and climate policy, Energy Journal (2006) 1-32.

1030 [26] N. Strachan, T. Foxon, J. Fujino, Policy implications from the Low-Carbon 1031 Society (LCS) modelling project, Climate Policy 8 (2008) S17-S29.

1032 [27] S. Kypreos, D. Van Regemorter, NEEDS New Energy Externalities 1033 Developments for Sustainability. Working paper RS2, WP2.3: key drivers for 1034 energy trends in EU; Specification of the baseline and policy scenarios, 2006, 1035 NEEDS, http://www.needs-project.org/RS2a/Baseline Scenario $1212006 . p d f$ 1036 (accessed on 10.09.2013).

1037 [28] J.C. Hourcade, M. Jaccard, C. Bataille, F. Ghersi, Hybrid modeling: New 1038 answers to old challenges - Introduction to the special issue of The Energy 1039 Journal, Energy Journal (2006) 1-11.

1040 [29] D.P. van Vuuren, K. Riahi, R. Moss, J. Edmonds, A. Thomson, N. Nakicenovic, 1041 T. Kram, F. Berkhout, R. Swart, A. Janetos, S.K. Rose, N. Arnell, A proposal for a 1042 new scenario framework to support research and assessment in different climate 1043 research communities, Global Environmental Change 22 (2012) 21-35.

1044 [30] E. Kriegler, B.C. O’Neill, S. Hallegatte, T. Kram, R.J. Lempert, R.H. Moss, T. 1045 Wilbanks, The need for and use of socio-economic scenarios for climate change 
1046 analysis: A new approach based on shared socio-economic pathways, Global 1047 Environmental Change 22 (2012) 807-822.

1048 [31] E. Trutnevyte, M. Stauffacher, M. Schlegel, R.W. Scholz, Context-specific 1049 energy strategies: Coupling energy system visions with feasible implementation 1050 scenarios, Environ. Sci. Technol. 46 (2012) 9240-9248.

1051 [32] N. Nakicenovic, R. Swart, Special Report on Emissions Scenarios (SRES), in, 1052 Cambridge University Press, Cambridge, 2000.

1053 [33] D. van Vuuren, E. Kriegler, B. O’Neill, K. Ebi, K. Riahi, T. Carter, J. Edmonds, S. 1054 Hallegatte, T. Kram, R. Mathur, H. Winkler, A new scenario framework for 1055 Climate Change Research: scenario matrix architecture, Climatic Change 122 1056 (2014) 373-386.

1057 [34] S. Carpenter, P. Pingali, E. Bennett, M. Zurek, Millennium Ecosystem 1058 Assessment: Volume 2. Scenario Assessment, in, Island Press, Oxford, UK, 2005. 1059 [35] UNEP, GE05 Global Environmental Outlook. Environment for the future we 1060 want, Progress Press Ltd, Valletta, Malta, 2012.

1061 [36] M.B. Zurek, T. Henrichs, Linking scenarios across geographical scales in 1062 international environmental assessments, Technological Forecasting and Social 1063 Change 74 (2007) 1282-1295.

1064 [37] G.P. Hammond, P.J.G. Pearson, Challenges of the transition to a low carbon, 1065 more electric future: From here to 2050, Energy Policy 52 (2013) 1-9.

1066 [38] T.J. Foxon, G.P. Hammond, P.J.G. Pearson, Developing transition pathways 1067 for a low carbon electricity system in the UK, Technological Forecasting and 1068 Social Change 77 (2010) 1203-1213.

1069 [39] T.J. Foxon, Transition pathways for a UK low carbon electricity future, 1070 Energy Policy 52 (2013) 10-24. 
1071 [40] D. Hel, Energy, the State, and the Market: British Energy Policy Since 1979,

1072 Oxford University Press, Oxford, UK, 2003.

1073 [41] P. Pearson, J. Watson, UK Energy Policy, 1980-2010 A history and lessons to 1074 be learned, IET and Parliamentary Group for Energy Studies, London, 2011.

1075 [42] J.H. Williams, A. DeBenedictis, R. Ghanadan, A. Mahone, J. Moore, W.R. 1076 Morrow, S. Price, M.S. Torn, The Technology Path to Deep Greenhouse Gas 1077 Emissions Cuts by 2050: The Pivotal Role of Electricity, Science 335 (2012) 53107859.

1079 [43] A. Boston, Delivering a secure electricity supply on a low carbon pathway, 1080 Energy Policy 52 (2013) 55-59.

1081 [44] DECC, Electricity Market Reform: policy overview, Department of Energy \& 1082 Climate Change, London, 2012.

1083 [45] Transition Pathways, Transition Pathways releases new narratives for

1084 pathways, 2012,

1085 http://www.lowcarbonpathways.org.uk/lowcarbon/news/news 0029.html

1086 (accessed on 18.07.2013).

1087 [46] P. Ekins, G. Anandarajah, N. Strachan, Towards a low-carbon economy: 1088 scenarios and policies for the UK, Climate Policy 11 (2011) 865-882.

1089 [47] B. O’Neill, E. Kriegler, K. Riahi, K. Ebi, S. Hallegatte, T. Carter, R. Mathur, D. 1090 Vuuren, A new scenario framework for climate change research: the concept of 1091 shared socioeconomic pathways, Climatic Change 122 (2014) 387-400.

1092 [48] R. Bolton, T. Foxon, Negotiating the energy policy 'trilemma' - an analysis of 1093 UK energy governance from a socio-technical systems perspective, in: IGov 1094 Workshop: Theorising Governance Change for a Sustainable Economy,, London, 10952013. 
[49] DECC, DECC 2050 Pathway Calculator Excel Model, July 2010 version, DECC, 10972010.

1098 [50] BRE, Carbon dioxide from non-domestic buildings 2000 and beyond, BRE 1099 Energy Technology Centre, 2002.

1100 [51] Carbon Trust, Technology Innovations and Needs Assessment (TINA): Non1101 domestic buildings, Carbon Trust, 2012.

1102 [52] M. Barnacle, E. Robertson, S. Galloway, J. Barton, G. Ault, Modelling 1103 generation and infrastructure requirements for transition pathways, Energy 1104 Policy (2013).

1105 [53] J. Barton, S. Huang, D. Infield, M. Leach, D. Ogunkunle, J. Torriti, M. Thomson, 1106 The evolution of electricity demand and the role for demand side participation, 1107 in buildings and transport, Energy Policy 52 (2013) 85-102.

1108 [54] E. Trutnevyte, EXPANSE methodology for evaluating the economic potential 1109 of renewable energy from an energy mix perspective, Applied Energy 111 (2013) $1110 \quad 593-601$.

1111 [55] E. Trutnevyte, N. Strachan, Nearly perfect and poles apart: investment 1112 strategies into the UK power system until 2050, in: International Energy 1113 Workshop 2013, Paris, France, 2013.

1114 [56] UCL Energy Insitute, Energy models at the UCL Energy Institute, 2013, 1115 http://www.ucl.ac.uk/energy-models (accessed on 10.09.2013).

1116 [57] N. Strachan, P. Warren, Incorporating behavioural complexity in energy1117 economic models, in: Energy and People: Futures, Complexity and Challenges, 1118 Oxford, UK, 2011.

1119 [58] F.W. Geels, J. Schot, Typology of sociotechnical transition pathways, 1120 Research Policy 36 (2007) 399-417. 
1121 [59] G.P. Hammond, A. O'Grady, The Implications of Upstream Emissions from

1122 the Power Sector, Proceedings of the Institution of Civil Engineers - Energy in 1123 press (2013).

1124 [60] G.P. Hammond, H.R. Howard, C.I. Jones, The energy and environmental 1125 implications of UK more electric transition pathways: A whole systems 1126 perspective, Energy Policy 52 (2013) 103-116.

1127 [61] E. Robertson, L. Anderson, S. Galloway, The impact of distributed generation 1128 in Scotland (on the energy system, to consumers and to national emission levels, 1129 in: CIGRÉ, Montreal, Quebec, Canada, 2012.

1130 [62] E. Robertson, S. Galloway, G. Ault, The Impact of Wide Spread Adoption of 1131 High Levels of Distributed Generation in Domestic Properties, in: IEEE Power \& 1132 Energy Society General Meeting, San Diego, US, 2012.

1133 [63] E.M. Robertson, A.D. Alarcon-Rodriguez, S.J. Galloway, G.W. Ault, Outline for 1134 an Integrated Multiple Energy Carrier Model of the UK Energy Infrastructure, 11352009.

1136 [64] M. Geidl, G. Koeppel, P. Favre-Perrod, B. Klockl, G. Andersson, K. Frohlich, 1137 Energy hubs for the future, IEEE Power Energy Mag. 5 (2007) 24-30.

1138 [65] F. Kienzle, E. Trutnevyte, G. Andersson, Comprehensive performance and 1139 incertitude analysis of multi-energy portfolios, in: 2009 IEEE Bucharest 1140 PowerTech, Bucharest, Romania, 2009.

1141 [66] G. Strbac, M. Aunedi, D. Pudjianto, P. Djapic, S. Gammons, R. Druce, 1142 Understanding the balancing challenge, DECC, London, 2012.

1143 [67] S.J. DeCanio, The efficiency paradox: bureaucratic and organizational 1144 barriers to profitable energy-saving investments, Energy Policy 26 (1998) 4411145454. 
1146 [68] N. Strachan, W. Usher, Failure to achieve stringent carbon reduction targets

1147 in a second-best policy world, Climatic Change 113 (2012) 121-139.

1148 [69] DECC, A brief guide to the carbon valuation methodology for UK policy 1149 appraisal, DECC, London, 2011.

1150 [70] M.G. Morgan, D.W. Keith, Improving the way we think about projecting 1151 future energy use and emissions of carbon dioxide, Climatic Change 90 (2008) 1152 189-215.

1153 [71] V. Schweizer, B. O’Neill, Systematic construction of global socioeconomic 1154 pathways using internally consistent element combinations, Climatic Change 122 1155 (2014) 431-445.

1156 [72] N. Strachan, S. Pye, R. Kannan, The iterative contribution and relevance of 1157 modelling to UK energy policy, Energy Policy 37 (2009) 850-860.

1158 [73] T. Hargreaves, Practice-ing behaviour change: Applying social practice 1159 theory to pro-environmental behaviour change, Journal of Consumer Culture $1160 \quad$ (2011) 79-99.

1161 [74] H.C. McJeon, L. Clarke, P. Kyle, M. Wise, A. Hackbarth, B.P. Bryant, R.J. 1162 Lempert, Technology interactions among low-carbon energy technologies: What 1163 can we learn from a large number of scenarios?, Energy Economics 33 (2011) $1164 \quad 619-631$.

1165 [75] J.R. Kasprzyk, S. Nataraj, P.M. Reed, R.J. Lempert, Many objective robust 1166 decision making for complex environmental systems undergoing change, 1167 Environmental Modelling \& Software (2013).

1168 [76] B.P. Bryant, R.J. Lempert, Thinking inside the box: A participatory, 1169 computer-assisted approach to scenario discovery, Technological Forecasting 1170 and Social Change 77 (2010) 34-49. 
1171 [77] Realising Transition Pathways, Realising Transition Pathways: Whole 1172 systems analysis for a UK more electric low carbon energy future, 2013, 1173 http://www.bath.ac.uk/realisingtransitionpathways/ (accessed on 09.09.2013). 1174 1175 


\section{Linking a storyline with multiple models: a cross-scale}

2 study of the UK power system transition

3

\section{Authors:}

5 Evelina Trutnevyte*a, John Barton ${ }^{b}$, Áine O’Gradyc, Damiete Ogunkunled, Danny

6 Pudjianto ${ }^{e}$, Elizabeth Robertson ${ }^{\mathrm{f}}$

* Corresponding author, UCL Energy Institute (permanent and present address), e.trutnevyte@ucl.ac.uk, phone +44 2031085924

a University College London, UCL Energy Institute, 14 Upper Woburn Place, London WC1H 0NN, United Kingdom

b Loughborough University, Leicestershire LE11 3TU, United Kingdom

c University of Bath, Department of Mechanical Engineering, Bath BA2 7AY, United Kingdom

d University of Surrey, Centre For Environmental Strategy, Guildford GU2 7XH, United Kingdom

e Imperial College London, South Kensington, London SW7 2AZ, United Kingdom f University of Strathclyde, Royal College Building, 204 George Street, Glasgow G1 1XW, United Kingdom 
10 State-of-the-art scenario exercises in the energy and environment fields argue

11 for combining qualitative storylines with quantitative modelling. This paper 12 proposes an approach for linking a highly detailed storyline with multiple, 13 diverse models. This approach is illustrated through a cross-scale study of the UK 14 power system transition until 2050. The storyline, called Central Co-ordination, is 15 linked with insights from six power system models and two appraisal 16 techniques. First, the storyline is 'translated' into harmonised assumptions on 17 power system targets for the models. Then, a new concept called the landscape 18 of models is introduced. This landscape helps to map the key fields of expertise 19 of individual models, including their temporal, spatial and disciplinary foci. The 20 storyline is then assessed based on the cross-scale modelling results. While the 21 storyline is important for transmitting information about governance and the 22 choices of key actors, many targets aspired in it are inconsistent with modelling 23 results. The storyline overestimates demand reduction levels, uptake of marine 24 renewables and irreplaceability of carbon capture and storage. It underestimates 25 the supply-demand balancing challenge, the need for back-up capacity and the 26 role of nuclear power and interconnectors with Europe. Thus, iteratively linking 27 storylines and models is key.

28

\section{Keywords}

30 Scenarios, storylines, cross-scale, quantitative models, simulation, energy, 31 environment, climate change, transition pathways 


\section{$34 \quad$ Highlights}

35 - Linking a qualitative storyline with multiple, diverse quantitative models

- Landscape of models for mapping the fields of expertise of individual

37 models

38

- Cross-scale analysis of the UK power system transition until 2050

39

40 Graphical abstract

41 Insert the Graphical abstract about here

42 


\section{Introduction}

Scenario exercises in energy, climate change and other technology- and environment-related studies are based on qualitative storylines, quantitative models or, often, on a combination of both [1-6]. Storyline-based scenarios are expressed as qualitative narratives that in length may range from brief titles to very long and detailed descriptions. Examples of such scenarios are the Tyndall decarbonisation scenarios [7, 8], the CLUES decentralised energy scenarios [9] or the energy visions in Switzerland $[10,11]$. The value of such storylines is threefold $[2,4,12-14]$. First, when these storylines are developed through engagement of experts and stakeholders, they combine multiple perspectives and sources of expertise [2]. They may lead to novel and creative ways of thinking about the future that go beyond modelling insights. Second, storylines are key for communicating the results of scenario exercises. Due to their qualitative nature, they are accessible and memorable to a broad range of audiences. When developed through stakeholder engagement, they are likely to be accepted, supported and used more often [15]. Third, storylines represent a much broader picture than quantitative models and encapsulate a number of softer and subtler aspects, such as governance, institutional changes or energyrelated behaviour, that cannot yet be modelled [16]. Storylines thus can form the input assumptions to the quantitative models and embed these models into a bigger picture $[17,18]$. However, storylines have two key limitations. First, storylines alone at times may be detached from reality as even experts can have a limited understanding of whether a particular storyline is feasible $[10,11,15]$. Second, as storylines are developed by combining multiple views of experts and stakeholders, they can be considered biased, not reproducible and not 
transparent $[2,19]$. Despite the current research on formal techniques for developing better storylines [20-23], these limitations still remain.

Quantitative models-based scenarios are produced by a single or multiple models, such as in the ADAM [24], Energy Modelling Forum [25], Low Carbon Society modelling [26] and NEEDS [27] projects. The key strength of these scenarios is that they satisfy the inherent need for numeric values in the technology- and environment-related fields [2, 10, 13, 15]. Models are based on the empirical data, physical laws, principles of economics and state-of-the-art knowledge about the technology and environmental processes. Thus, peerreviewed, transparently documented models provide rigorous, internally consistent scenarios. However, models can address only a limited number of aspects, such as technology, economic, and environmental aspects. But they still have difficulty in capturing the afore-mentioned softer and subtler aspects. The research priorities are towards developing more detailed models and including softer aspects, such as behaviour and governance, into models [17, 28]. Yet, even better models alone can hardly offer the breadth and engaging nature of the storyline-based scenarios. For example, the models cannot picture organisational and institutional change needed to deliver a wanted transition, even if these elements are important for decision makers to envision and manage this transition. models, state-of-the-art scenario studies argue for combining them [1-5]. In order to complement the models, storylines can reflect such aspects, like (i) exogenous context in which the modelled system is embedded into, (ii) exogenous modelling assumptions, such as drivers for change, or (iii) 
93 aspirational targets for the future system. Many recent scenario exercises

94 already have the elements of both storylines and models: storylines include

95 numbers, while modelling outputs are described in short qualitative narratives.

96 Several scenario exercises explicitly combine the storylines and the quantitative 97 models in an iterative manner [6, 10, 11, 29-31]. Examples of these include key

98 international scenario exercises: the integrated climate change scenarios of the

99 Intergovernmental Panel of the Climate Change [32, 33], the scenarios of 100 ecosystem services in the Millennium Ecosystem Assessment [34] and of the 101 global environment in the Global Environmental Outlook [35].

102 Despite the fact that the combination of storylines and quantitative 103 models has emerged as an established practice in the technology- and 104 environment-related fields [1-6], existing literature runs short in providing 105 methodological insights for how to link detailed storylines, which are developed 106 through stakeholder and expert engagement, with multiple quantitative models. 107 First, if the storylines are very detailed, then numerous additional assumptions 108 are needed to 'translate' them into model parameters. Second, multiple diverse 109 models may be needed to model detailed storylines with various spatial and 110 temporal foci, disciplinary perspective (technical feasibility, economic or 111 environmental appraisal), model objective, and the parts of the system 112 addressed. This diversity is valuable because the storylines can be addressed 113 from multiple angles and across scales, but it is challenging to relate such diverse 114 models to each [36]. Thus, a new approach has to be developed for linking 115 detailed storylines with multiple, cross-scale models, which have different 116 spatial, temporal and disciplinary foci. This paper proposes such an approach. 117 There is a growing number of interdisciplinary projects in energy, climate 
118 change and other technology- and environment-related studies. It can be 119 expected that many of these projects will attempt to develop cross-scale 120 scenarios by linking storylines with multiple models and will require such an 121 approach.

The proposed approach is illustrated with the cross-scale analysis of the

123 UK power system transition until 2050 as a part of the Realising Transition 124 Pathways (RTP) consortium project. A detailed storyline, called the Central Co125 ordination, was developed in the preceding Transition Pathways project [37-39] 126 and is used for the cross-scale analysis with six quantitative power system 127 models and two quantitative appraisal techniques. The idea for this analysis 128 arose from discussions at RTP consortium workshops. The authors of this paper 129 took the analysis forward and its results will be an input to further development 130 of the consortium's research.

131 This paper is laid out as follows: Section 2 proposes a general 132 methodological approach; Section 3 gives an example of linking the Central Co133 ordination storyline with eight RTP models, present and discusses the findings; 134 Section 4 discusses the general approach; and Section 5 concludes.

\section{Proposed approach for linking storylines with multiple models}

This section describes the proposed process (Figure 1) of linking a

139 detailed storyline with the insights from multiple diverse models. First of all, one 140 of the biggest challenges in cross-scale scenario studies is ability to 141 systematically combine insights from multiple cross-scale models. 142 Understanding and mapping the breadth and depth of the expertise of every 
143 individual model is challenging, especially given a diverse set of models. This

144 paper proposes mapping this expertise in two complementary ways:

145 (i) List the key characteristics of the models and elicit the key fields of 146 expertise. These key fields of expertise reflect the types of insights that a particular model analyses in most depth, as compared to the other models. This concept of the key field of expertise thus appreciates the distinct value of every model in a multi-model analysis. It shows which conclusions of which model shall be prioritized over the conclusions of other models. The conclusions that are derived from the key fields of expertise of a specific model shall be weighted more than the conclusions on the same topic of the other models.

(ii) Prepare a visual map, called the landscape of models. This map shall summarise the information about the breadth and depth of the analysis, done by every model, and show how these afore-mentioned fields of expertise overlap between the models. This mapping can be done on the basis of the parts of the system addressed and/or other thematic considerations addressed by the models. The mapping characteristics will likely differ from one set of models to another. The depth of analysis can then be defined in three categories: detailed modelling (the key field of expertise), stylised modelling and 
Figure 1. The iterative process of linking storylines with multiple crossscale quantitative models

Both concepts of the model's key field of expertise and the landscape of 171 models help to grasp, where models differ or overlap. If models overlap, then 172 they can validate each other and help cross-check the results. Every model, 173 however, likely has at least one area where it outperforms the other models in 174 depth or breadth as there is no single best model that covers all aspects in depth 175 and across all the relevant scales.

As shown in Figure 1, in order to link a detailed storyline with insights

177 from multiple models, the qualitative storyline is first 'translated' into a set of 178 harmonised assumptions that are necessary for conducting the model runs, 179 specifically tailored for the storyline (Step 1 in Figure 1). Such a 'translation' is a 180 challenging task. On the one hand, these harmonised assumptions will already be 181 a narrower representation of the qualitative storyline that is rich in detail. This is 182 reasonable as quantitative models always represent only a part of the bigger, 183 qualitative picture [10]. On the other hand, these quantitative assumptions 184 should not be too narrow and should allow enough flexibility for the quantitative 185 models to express their perspective and to make their distinct contributions. 186 Every model has a broad range of other, model-specific assumptions. As the 187 models used for cross-scale analyses are often very diverse, it is desirable to 188 harmonise the list of the assumptions so that they could be implemented in all of 189 the models. As a result, there are a lot of possible variations and a certain share 190 of subjectivity involved in the process how a storyline is 'translated' into the 191 model assumptions. 
After the models are run with these harmonised assumptions, the statements of the storyline are checked for their consistency with the modelling results (Step 2 in Figure 1). The storyline can then be revised. The landscape of models plays an important role here as it highlights the key fields of expertise of every model. In this way, it becomes possible to prioritise the models in scrutinising the specific aspects of the storyline

Generally, neither the storyline nor the multiple models are fixed; they are all being updated given the new developments in the real world, new data sources, feedback from peer review and so on. Thus, in line with [2], the process from Figure 1 is repeated iteratively for updating the storyline.

\section{The case of the UK power system transition}

This section provides a cross-scale example of linking a very detailed storyline of the UK power sector transition until 2050 with insights from six power system models and two appraisal techniques. The section starts by describing the UK power sector and the context of the storyline (Section 3.1), then moves to the description of the models (Section 3.2), the process of linking a storyline with multiple models (Section 3.3), and finishes with summarising and discussing the findings.

\subsection{UK power system and the Central Co-ordination storyline}

In the 1990s the UK underwent a major process of liberalisation of its power market and privatisation of its companies [40, 41]. With about three quarters of power produced in fossil fuel-based plants, this market-led approach 
217 came under significant pressure in the last decade due to growing climate change

218 concerns. The UK government undertook several key interventions. In 2008 the

219 UK adopted the Climate Change Act, supported by all major political parties,

220 which sets a legally binding target to cut the country's greenhouse gas emissions

221 by $80 \%$ by 2050 as compared to the emission levels of 1990 . In line with [42],

222 the major decarbonisation of the power sector, together with substantial levels

223 of electric heating and transport, are seen as the key measures to reach this

224 target. However, replacement of the aging coal and nuclear power plants and

225 significant investments in transmission and distribution requires massive

226 investment. An increased deployment of renewable energy sources raises

227 concerns over their intermittency and, thus, supply security. Therefore, this

228 decarbonisation challenge does not stand alone and is a part of the so-called

229 energy policy 'trilemma' of decarbonisation, affordability and supply security

$230[39,43]$. The Energy Bill, released in 2012, and especially its part on Electricity

231 Market Reform, attempts to mediate between these three corners of the

232 'trilemma' [44]. The Energy Bill aims to set a policy framework for the power

233 system transition that meets the 'trilemma.'

234 In light of these developments, the RTP project aims to shed light on the

235 potential transition pathways of the UK power system until 2050. Three

236 transition pathways were developed in the preceding Transition Pathways

237 project: Central Co-ordination, Market Rules and Thousand Flowers [39, 45].

238 Compared to other scenario exercises in the UK $[7-9,46]$ and elsewhere, these

239 pathways are novel because they include storylines that specifically focus on the

240 role of governance 'logics' and multiple actors in actively shaping the power

241 system transition. Traditionally in scenario studies, storylines are used for 
representing key uncertainties or drivers such as population growth,

243 technological development and others, c.f. [32, 34, 35, 47]. The RTP storylines

244 explicitly focus on the uncertainty around governance 'logics' and the choices of

245 actors and how this could affect the power system transitions. In order to

246 achieve this, the RTP storylines combine all three afore-mentioned elements of

247 storylines: exogenous context, transition drivers and - mostly - targets for the

248 future power system.

249 The process of developing these three storylines is described in detail in

250 [39]. In brief, the first version of the storylines was developed in the original

251 Transition Pathways project in a stakeholder workshop in 2008. The technical

252 feasibility, social acceptability and the sustainability of the first version of the

253 storylines were then interrogated in further workshops with experts and key

254 stakeholders, who represented energy companies, policy-makers and non-

255 governmental organisations. This interrogation led to the revised version 2.1 of

256 the pathways, which is currently the latest version. The complete storylines are

257 available online at [45] and shorter summaries are published in [39]. Every

258 storyline consists of four to five pages of qualitative description, a list of key risks

259 for the realisation of the specific storyline and an overview table.

260 Afterwards, a Transition Pathways Technical Elaboration Working Group

261 was set up from the experts in the project in order to assign a quantitative

262 representation for every storyline. This quantitative representation shows the

263 numeric values of the total UK power demand and the power generation mix

264 until 2050 [39]. This process was partly informed by insights from three power

265 system models, but none of these models were informed by economic

266 considerations [39]. In the succeeding RTP project, there are more models 
available, of which some include the economic considerations. Therefore, a more structured process was undertaken for linking the storylines with insights from multiple models. In so doing it will show how iteration between storylines and 270 models can fruitfully enhance the process of developing and analysing the 271 broader transition pathways.

273 three storylines of the RTP project. These storylines picture three ideal types of 274 governance 'logics' in the UK power system (Figure 2): government, market and 275 civil society 'logics'. In these storylines, the views that the government, market or 276 civil society actors respectively need to lead the low-carbon transition emerge as 277 the 'zeitgeist' of the time [39]. In the case of the Central Co-ordination storyline, 278 the central UK government successfully establishes the dominant role by direct 279 co-ordination to deliver the energy policy goals. In the Market Rules storyline, 280 the market actors successfully argue that the energy 'trilemma' is best achieved 281 by the large power companies and other market actors, freely interacting with 282 the policy framework. The investment, made by the large power companies on 283 the basis of investment return (including carbon price effects), available 284 knowledge, regulatory framework and incentives set by the government, will 285 determine the power system transition. The Thousand Flowers storyline argues 286 that society at large shall take an active role in delivering the low-carbon 287 transition as small-scale solutions, especially, but not only through community288 led initiatives and energy service companies (ESCOs). The key recent 289 developments in the UK power sector are described as a hybrid between the 290 Central Co-ordination and the Market Rules storylines [48]. Since the power 291 market liberalisation in 1990s, the market 'logic' has been dominating in the UK, 
but the influence of the government 'logic' has been increasing in recent years, especially after the adoption of the legally binding emissions target. The Central

294 Co-ordination storyline is therefore chosen for in-depth analysis in this paper.

Insert Figure 2 about here

Figure 2. The three ideal types of governance 'logics' in the UK power system transition. Source: J. Burgess and T. Hargreaves. The figure is reproduced from

The Central Co-ordination storyline includes five pages of narrative and here only the key points are summarised. The central UK government is assumed to actively shape the power system transition through the establishment of a new Strategic Energy Agency. This agency will issue tenders for tranches (central contracts) for particular types of low-carbon generation and develop 'technology push' programmes for low-carbon technologies. In order to promote UK industry, the agency will primarily support those technologies where the UK has

309 potential to become a global leader: marine renewables (offshore wind, wave 310 and tidal power), carbon capture and storage (CCS) and electric vehicles. This 311 strong government commitment will underwrite the investment risks for the 312 large power companies. These companies will invest according to the 313 government's plans and deliver the transition, dominated by large-scale power 314 generation. The government will focus on removing any system-wide blockages, 315 such as the lack of transmission capacity, planning issues, supply chains and 316 skills. As a result, the emission mitigation target of $80 \%$ by 2050 , as compared to 
the year 1990, will be achieved for power generation. As noted, society at large

318 will remain a relatively passive player in this storyline. Initially, only non-

319 behavioural measures of demand response will be used, such as increased

320 efficiency standards for appliances and newly built buildings. Later, with the 321 increased industrial and climate benefits, interventions on lifestyles and

322 behaviour will be undertaken by the government, especially through smart 323 metering and demand side response measures. The key risks, identified in the 324 storyline for the realisation of this transition, are (i) the technical and economic 325 feasibility of CCS, (ii) public opposition to costly low-carbon investment due to 326 increased household expenditure, (iii) little effort to incentivise behaviour 327 change of the energy users. The more detailed storyline is also provided in Table 3282

In addition to the qualitative narrative, the Central Co-ordination storyline 330 was already assigned an initial quantitative representation (Figure 3), developed 331 in an iterative process by the Transition Pathways Technical Elaboration 332 Working Group. This quantitative representation served both as an example of 333 how the power sector may look in detail and as a basis for conducting further 334 quantitative research on the storyline (for instance, for environmental or 335 economic appraisals).

Insert Figure 3 about here

339 Figure 3. The initial quantitative representation of the Central Co-ordination 340 storyline. Source: Transition Pathways project. The figure is reproduced from 


\subsection{Landscape of the RTP models}

This section describes the six power system models and two appraisal models that were linked in this paper to the Central Co-ordination storyline.

346 These models are very diverse and this diversity is a strong point as there is not a single best model or methodology that encapsulates all the relevant cross-scale aspects [16]. The RTP leadership envisioned a multi-model analysis, expecting that this analysis, rather than results of a single model, will have potential to provide a broader spectrum of insights.

The eight models used are (in the order of the breadth of the power system boundaries):

- Demand: The energy demand model, developed at the University of Surrey, is a bottom-up model of the UK power demand in the domestic and non-domestic sectors. Due to its highly disaggregated structure, the influence of a range of parameters can be modelled, such as energy service levels, user practices, choices of appliances, building fabric, fuels, deployment of distributed generation and others. The model is based on the synthesis of existing estimates [49-51] and the assumptions from the Central Co-ordination storyline.

- FESA: The Future Energy Scenario Assessment model [52, 53], developed at the Loughborough University, is a single-year UK power generation and demand model, incorporating one-hour time steps for dispatch modelling and using 2001 Met Office weather data on temperature, wind speeds, wave height and solar radiation. The model 
develops scenarios on the basis of the Central Co-ordination storyline and technical feasibility constraints.

- D-EXPANSE: The D-EXPANSE model (Dynamic version of EXploration of PAtterns in Near-optimal energy ScEnarios), developed at the University College London, has the structure of a bottom-up power system model. In addition to the cost optimisation, D-EXPANSE systematically explores the maximally different near-optimal pathways $[15,31,54,55]$. In this way, D-EXPANSE aims to open up the understanding of the fundamentally different ways how the UK power system could evolve. By allowing the deviation from the cost-optimal pathway, D-EXPANSE also explores the structural uncertainty around the concept of rationality and cost-optimisation. The D-EXPANSE model has been validated by comparing its outputs with the results of existing, well-established whole system models and cost estimates for the UK [55].

- EconA: The Economic Appraisal (EconA), conducted by University College London, aims to systematically calculate and compare total investment costs and total system costs for power generation, transmission and distribution for the three transition pathways. The results are disaggregated for the different power generation technologies, which allows for economic feasibility assessment. The EconA is an appraisal technique; it takes the quantitative representation (Figure 3) of the Central Co-ordination storyline and calculates the power system costs for it. In this paper, the EconA is also considered as a model in a broader sense. 
- BLUE-MLP: The BLUE-MLP model (Behaviour Lifestyles and Uncertainty Energy model with Multi-Level Perspective on transitions) is a probabilistic systems dynamic simulation that explores the uncertainties due to sector- and actor- specific behavioural elements $[56,57]$. These behavioural elements include market heterogeneity, intangible costs and benefits, hurdle rates, replacement and refurbishment rates and demand elasticities. In addition, the model links these behavioural uncertainties with the multi-level perspective to transitions [58], where landscape (government decisions and the international context), regime (the current UK power system structure and its regulation) and niche innovations (lifestyle influenced changes in demand) interact with each other.

- EEA: The Energy and Environmental Appraisal (EEA) is a life cycle 405 assessment (LCA) of the UK power system carried out by the University of Bath $[59,60]$. Over 18 environmental impacts were evaluated from cradle to gate, accounting for all upstream and operational activities. Impacts covered in this assessment include climate change, which is quantified through greenhouse gas emissions, and other environmental impacts, such as fossil fuel depletion, human toxicity, particulate matter formation and agricultural land occupation. Similar to the EconA, the EEA framework is a model, which appraises the Central Co-ordination storyline, based on its initial quantitative representation (Figure 3). 
- HESA/UK+: This is a combination of the Hybrid Energy System Analysis tool (HESA) and the Strathclyde UK+ models that were developed at the University of Strathclyde [61-63]. The Strathclyde $\mathrm{UK}+$ model contains all the information for the transition pathways scenarios with spatial disaggregation (17 onshore, five offshore zones and 39 connections) of generation, storage, transmission and distribution. It is linked to the HESA model, which cost-optimises the system, based on the energy hub concept $[64,65]$. The national power demand and generation mix are used as input assumptions. (HAPSO) is developed at the Imperial College London. It is a bottomup, cost-minimisation model that determines the optimal generation, energy storage, transmission, and distribution network infrastructure requirements and their associated cost to achieve three objectives: economic efficiency, security, and sufficient system controllability. The model optimises simultaneously the long-term investment and shortterm operating decisions including hourly generation dispatch, Demand Side Response, storage cycles, and power exchanges taking into account the impact of decisions across all sectors in the power system [66]. The UK power system is embedded in the European power system including UK, Ireland and continental Europe and thus allows for modelling of the power exchange across these regions.

Figure 4. The landscape of the RTP models is prepared on the basis of the parts 
440 of the power system addressed (demand; generation; dispatch, demand response

441 and storage; transmission and distribution; and interconnectors with Europe)

442 and other thematic considerations addressed by the model (analysis of the

443 maximally different alternatives; uncertainty; behaviour and heterogeneity of

444 actors; economic considerations; environmental considerations; and spatial

445 disaggregation). Both Table 1 and Figure 4 help to show that the eight models,

446 used in this analysis, cover a broad spectrum of cross-scale insights across time,

447 space, system boundaries and disciplines.

448 
449 Table 1. Summary of the eight models (model versions as of April 2013)

\begin{tabular}{|c|c|c|c|c|c|c|c|c|}
\hline Model & Demand & FESA & D-EXPANSE & EconA & BLUE-MLP & EEA & HESA/UK+ & HAPSO \\
\hline Spatial scope & $\begin{array}{l}\text { UK, single } \\
\text { region }\end{array}$ & $\begin{array}{l}\text { UK, single } \\
\text { region }\end{array}$ & UK, single region & $\begin{array}{l}\text { UK, single } \\
\text { region }\end{array}$ & UK, single region & UK, single region & $\begin{array}{l}\text { UK, } 17 \text { onshore } \\
\text { and } 5 \text { offshore } \\
\text { regions }\end{array}$ & $\begin{array}{l}\text { UK, } 5 \text { regions } \\
\text { Europe, incl. UK, } \\
\text { Ireland and } \\
\text { continental Europe }\end{array}$ \\
\hline $\begin{array}{l}\text { Finest temporal } \\
\text { resolution }\end{array}$ & 1 year & 1 hour & 5 years & 1 year & 1 year & 1 year & 1 year & 1 hour \\
\hline \multicolumn{9}{|l|}{$\begin{array}{l}\text { Parts of the } \\
\text { power system } \\
\text { addressed }\end{array}$} \\
\hline $\begin{array}{l}\text {--Power } \\
\text { demand }\end{array}$ & $\begin{array}{l}\text { Total demand; } \\
\text { Demands by } \\
\text { users, energy } \\
\text { services, end- } \\
\text { use equipment }\end{array}$ & $\begin{array}{l}\text { Total demand; } \\
\text { Demands by } \\
\text { users, energy } \\
\text { services, end- } \\
\text { use equipment }\end{array}$ & Total demand & Total demand & $\begin{array}{l}\text { Total demand; } \\
\text { Demands by } \\
\text { users and energy } \\
\text { services }\end{array}$ & Total demand & Total demand & $\begin{array}{l}\text { Total demand; } \\
\text { Demands by users } \\
\text { and energy services }\end{array}$ \\
\hline $\begin{array}{l}\text {-- Power } \\
\text { generation }\end{array}$ & $\begin{array}{l}\text { Decentralised } \\
\text { generation }\end{array}$ & $\begin{array}{l}\text { Large-scale } \\
\text { generation; } \\
\text { Decentralised } \\
\text { generation }\end{array}$ & $\begin{array}{l}\text { Large-scale } \\
\text { generation; } \\
\text { Decentralised } \\
\text { generation }\end{array}$ & $\begin{array}{l}\text { Large-scale } \\
\text { generation; } \\
\text { Decentralised } \\
\text { generation }\end{array}$ & $\begin{array}{l}\text { Large-scale } \\
\text { generation }\end{array}$ & $\begin{array}{l}\text { Large-scale } \\
\text { generation; } \\
\text { Decentralised } \\
\text { generation }\end{array}$ & $\begin{array}{l}\text { Large-scale } \\
\text { generation; } \\
\text { Decentralised } \\
\text { generation }\end{array}$ & $\begin{array}{l}\text { Large-scale } \\
\text { generation; } \\
\text { Decentralised } \\
\text { generation }\end{array}$ \\
\hline $\begin{array}{l}\text {-- Dispatch, } \\
\text { demand } \\
\text { response and } \\
\text { storage }\end{array}$ & & $\begin{array}{l}\text { Dispatch; } \\
\text { Demand } \\
\text { response; } \\
\text { Storage, incl. } \\
\text { hydrogen }\end{array}$ & $\begin{array}{l}\text { Dispatch (stylised); } \\
\text { storage (stylised) }\end{array}$ & $\begin{array}{l}\text { Storage } \\
\text { (stylised) }\end{array}$ & $\begin{array}{l}\text { Dispatch } \\
\text { (stylised); } \\
\text { Demand } \\
\text { response }\end{array}$ & Storage (stylised) & $\begin{array}{l}\text { Dispatch; } \\
\text { Storage }\end{array}$ & $\begin{array}{l}\text { Dispatch; } \\
\text { Demand response; } \\
\text { Storage }\end{array}$ \\
\hline $\begin{array}{l}\text {-- Trans- } \\
\text { mission and }\end{array}$ & & & & & & $\begin{array}{l}\text { Transmission and } \\
\text { distribution }\end{array}$ & $\begin{array}{l}\text { Transmission and } \\
\text { distribution }\end{array}$ & $\begin{array}{l}\text { Transmission and } \\
\text { distribution }\end{array}$ \\
\hline
\end{tabular}




\begin{tabular}{|c|c|c|c|c|c|c|c|c|}
\hline Model & Demand & FESA & D-EXPANSE & EconA & BLUE-MLP & EEA & HESA/UK+ & HAPSO \\
\hline $\begin{array}{l}\text {-- Inter- } \\
\text { connectors to } \\
\text { Europe }\end{array}$ & & $\begin{array}{l}\text { Import; } \\
\text { Export }\end{array}$ & Import & Import & & Import & $\begin{array}{l}\text { Import; } \\
\text { Export }\end{array}$ & $\begin{array}{l}\text { Import; } \\
\text { Export; } \\
\text { UK embedding in } \\
\text { the European } \\
\text { system }\end{array}$ \\
\hline $\begin{array}{l}\text {-- Non-electric } \\
\text { parts of the } \\
\text { energy system }\end{array}$ & $\begin{array}{l}\text { Non-electric } \\
\text { heating }\end{array}$ & $\begin{array}{l}\text { Non-electric } \\
\text { heating; } \\
\text { Non-electric } \\
\text { transport; } \\
\text { Non-electric } \\
\text { industrial and } \\
\text { commercial } \\
\text { uses }\end{array}$ & & & $\begin{array}{l}\text { Non-electric } \\
\text { heating; } \\
\text { Non-electric } \\
\text { transport; } \\
\text { Non-electric } \\
\text { industrial and } \\
\text { commercial uses }\end{array}$ & & $\begin{array}{l}\text { Non-electric } \\
\text { heating }\end{array}$ & \\
\hline $\begin{array}{l}\text { Modelling } \\
\text { method }\end{array}$ & $\begin{array}{l}\text { Deterministic } \\
\text { simulation }\end{array}$ & $\begin{array}{l}\text { Deterministic } \\
\text { simulation }\end{array}$ & $\begin{array}{l}\text { Cost-optimisation } \\
\text { and evaluation of } \\
\text { maximally different } \\
\text { near-optimal } \\
\text { pathways }\end{array}$ & $\begin{array}{l}\text { Appraisal of } \\
\text { exogenous } \\
\text { scenarios }\end{array}$ & $\begin{array}{l}\text { Dynamic } \\
\text { simulation }\end{array}$ & $\begin{array}{l}\text { Appraisal of } \\
\text { exogenous } \\
\text { scenarios }\end{array}$ & Cost-optimisation & Cost-optimisation \\
\hline $\begin{array}{l}\text { Economic } \\
\text { considerations }\end{array}$ & & & $\begin{array}{l}\text { Cost-optimisation; } \\
\text { Exploration of near- } \\
\text { optimal pathways }\end{array}$ & $\begin{array}{l}\text { Post hoc } \\
\text { assessment }\end{array}$ & $\begin{array}{l}\text { Dynamic } \\
\text { simulation, given } \\
\text { the } \\
\text { heterogeneous } \\
\text { sensitivity of the } \\
\text { different actors } \\
\text { to costs }\end{array}$ & & Cost-optimisation & Cost-optimisation \\
\hline
\end{tabular}




\begin{tabular}{|c|c|c|c|c|c|c|c|c|}
\hline Model & Demand & FESA & D-EXPANSE & EconA & BLUE-MLP & EEA & HESA/UK+ & HAPSO \\
\hline $\begin{array}{l}\text { Environmental } \\
\text { considerations }\end{array}$ & & 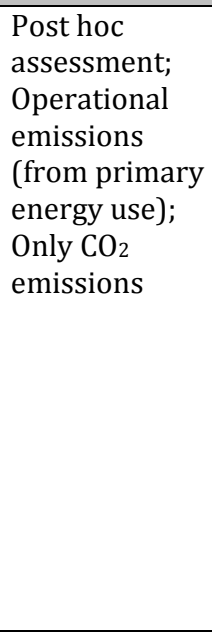 & $\begin{array}{l}\text { Emission constraint; } \\
\text { Operational } \\
\text { emissions; } \\
\text { Only } \mathrm{CO}_{2} \text { emissions }\end{array}$ & $\begin{array}{l}\text { Exogenous } \\
\text { assumptions }\end{array}$ & 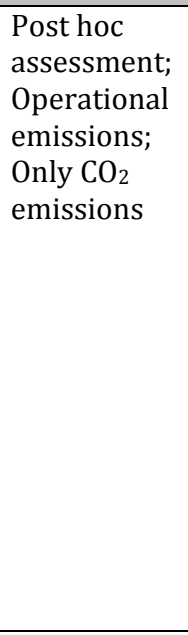 & $\begin{array}{l}\text { Post hoc } \\
\text { assessment; } \\
\text { 'Whole system' } \\
\text { (LCA) } \\
\text { environmental } \\
\text { impacts, including } \\
\text { upstream and } \\
\text { operational } \\
\text { impacts; } \\
\text { Greenhouse gas } \\
\text { emissions }\left(\mathrm{CO}_{2 \mathrm{eq}}\right) \text {; } \\
\text { Fossil fuel } \\
\text { depletion; Human } \\
\text { toxicity; } \\
\text { Particulate matter; } \\
\text { Agricultural land } \\
\text { occupation }\end{array}$ & $\begin{array}{l}\text { Post hoc } \\
\text { assessment; } \\
\text { Operational } \\
\text { emissions; } \\
{\text { Only } \mathrm{CO}_{2}}_{\text {emissions }}\end{array}$ & $\begin{array}{l}\text { Emission constraint; } \\
\text { Operational } \\
\text { emissions; } \\
\text { Only } \mathrm{CO}_{2} \text { emissions }\end{array}$ \\
\hline $\begin{array}{l}\text { Treatment of } \\
\text { uncertainty }\end{array}$ & & & $\begin{array}{l}\text { Structural } \\
\text { uncertainty around } \\
\text { cost-optimisation; } \\
\text { Parametric } \\
\text { uncertainty } \\
\text { accommodated to } \\
\text { some extent through } \\
\text { maximally different, } \\
\text { near-optimal } \\
\text { pathways }\end{array}$ & $\begin{array}{l}\text { Parametric } \\
\text { uncertainty } \\
\text { considered } \\
\text { through } \\
\text { ranges for } \\
\text { uncertain } \\
\text { parameters }\end{array}$ & $\begin{array}{l}\text { Parametric } \\
\text { uncertainty } \\
\text { considered } \\
\text { through } \\
\text { probabilistic } \\
\text { modelling }\end{array}$ & & & $\begin{array}{l}\text { Parametric } \\
\text { uncertainty } \\
\text { considered through } \\
\text { sensitivity analysis }\end{array}$ \\
\hline $\begin{array}{l}\text { Treatment of } \\
\text { behaviour and } \\
\text { heterogeneity } \\
\text { of actors }\end{array}$ & & & $\begin{array}{l}\text { Considered to some } \\
\text { extent through } \\
\text { deviations from cost- } \\
\text { optimal pathway }\end{array}$ & & $\begin{array}{l}\text { Detailed } \\
\text { modelling }\end{array}$ & & & \\
\hline
\end{tabular}




\begin{tabular}{|c|c|c|c|c|c|c|c|c|}
\hline Model & Demand & FESA & D-EXPANSE & EconA & BLUE-MLP & EEA & HESA/UK+ & HAPSO \\
\hline $\begin{array}{l}\text { Key field of } \\
\text { expertise }\end{array}$ & Demand & $\begin{array}{l}\text { Dispatch, } \\
\text { demand } \\
\text { response and } \\
\text { storage; } \\
\text { Generation }\end{array}$ & $\begin{array}{l}\text { Maximally different } \\
\text { alternatives; } \\
\text { Uncertainty }\end{array}$ & $\begin{array}{l}\text { Economic } \\
\text { appraisal }\end{array}$ & $\begin{array}{l}\text { Uncertainty; } \\
\text { Behaviour and } \\
\text { heterogeneity of } \\
\text { the actors }\end{array}$ & $\begin{array}{l}\begin{array}{l}\text { Energy and } \\
\text { environmental } \\
\text { appraisal }\end{array} \\
\text { aprat }\end{array}$ & $\begin{array}{l}\text { Transmission } \\
\text { and distribution; } \\
\text { Generation; } \\
\text { Spatial } \\
\text { disaggregation }\end{array}$ & $\begin{array}{l}\text { Dispatch and } \\
\text { demand response; } \\
\text { Generation; } \\
\text { Transmission and } \\
\text { distribution; } \\
\text { Interconnectors }\end{array}$ \\
\hline
\end{tabular}


Figure 4. The landscape of models (model versions as of April 2013)

\subsection{Process of linking the storyline with multiple models}

For translating the Central Co-ordination storyline into the harmonised modelling assumptions, several key aspects of this storyline are taken. In contrast to the typical story-and-simulation approach, such as [32, 33], where storyline describes the drivers of future transition, the Central Co-ordination storyline includes multiple targets for the future power system that should be met under the increased role of government. The targets that are chosen as harmonised modelling assumptions are: (i) a mild growth of the power demand due to the incentives for end-use energy efficiency, (ii) the increased use of largescale low-carbon technologies, especially of those where UK industry could take a global lead, and a medium uptake of decentralised generation, (iii) the achievement of the emission mitigation goals and (iv) low risk of investment due to the tenders for tranches, issued by the Strategic Energy Agency. More specifically, the models are tuned to match these harmonised assumptions as closely as possible:

i. Total power demand in the UK:

- In 2020, the total power demand, including losses, stabilises at 350 TWh/year;

- In 2030, it increases to 390 TWh/year due to increased electric heating and electric vehicles;

- In 2050, it is equal to $410 \mathrm{TWh} /$ year. 
ii. Power generation mix in the UK:

- In 2020, 40\% of the produced power comes from low-carbon sources, prioritising coal CCS, nuclear and renewable sources. At least $25 \%$ of

iii. Greenhouse gas emissions:

- In $2050,75 \%$ of total produced power comes from large-scale lowcarbon sources, such as nuclear, coal and gas CCS, offshore wind, wave, tidal barrage and tidal stream. At least, 25\% comes from lowcarbon decentralised sources, such as onshore wind and biomass combined heat and power (CHP) plants.

- In 2020, the average carbon intensity in the whole UK power system is $300 \mathrm{gCO}_{2} / \mathrm{kWh}$ of power produced;

- In 2030, this value drops to $30 \mathrm{gCO}_{2} / \mathrm{kWh}$;

- In 2050, it is as low as $20 \mathrm{gCO}_{2} / \mathrm{kWh}$.

iv. Investment:

- Social discount rate of $3.5 \%$ is used for the calculation.

498 assumptions. First, the Demand, FESA models and EEA cannot consider the last 499 assumption about the discount rate as they do not consider costs at all. They, 500 therefore, by-passed this assumption, but implemented the remaining 501 assumptions. Second, the EconA and EEA are appraisal techniques and require 
inputs about the whole power demand structure and generation mix rather than

503 modelling assumptions. Thus, the EconA and EEA are conducted on the basis of

504 the initial quantitative representation of the storyline (Figure 3), which is in line

505 with the harmonised assumptions described above.

506 The qualitative statements from the Central Co-ordination storyline are

507 then scrutinised from the perspective of the outputs of every model. The 508 storyline pictures the contextual information, such as the governance 509 arrangements and the role of the different actors. These aspects can hardly be 510 interrogated by the models. But the description of the targets, that are aspired in

511 the storyline as a result of the governance arrangements and the actors' 512 decisions, can be analysed. For example, the statement "In the financial budget 513 statement in April 2009, the UK Government formally adopts carbon budgets for 514 the periods $2008-12,2013-17$ and $2018-22$ based on a $34 \%$ reduction in 515 greenhouse gas (GHG) emissions by 2020 from 1990 levels" [45, p. 1] is not 516 analysed as it describes the intention of the government. But, the statement "This 517 is realised by the achievement of $25 \%$ of electricity to be generated from 518 renewables by 2020 " [45, p. 3] is interrogated by the eight models.

3.4. Results and discussion on the Central Co-ordination storyline

Table 2 presents the summarized results of revisiting the Central Co523 ordination storyline from the perspective of the eight RTP models; detailed 524 results are available in the Electronic Supplementary Material. Every qualitative 525 statement about the power system targets to be delivered by the governance 
arrangements and actor choices, specified in the storyline, is compared and contrasted with the modelling results.

\section{Robust elements of the storyline}

From the perspective of these eight models, the Central Co-ordination the storyline is almost completely supported by the Demand, FESA and HESA/UK+ models. This is no surprise because these three models specialise in 534 technical feasibility assessment of the power system transitions. These models 535 can be tailored to mimic the storyline and identify only the key mistakes of 536 technical feasibility. Moreover, the researchers, who work with these models, 537 played an active role in the Technical Elaboration Working Group in the original 538 Transition Pathways project. Thus, the storyline is already partly informed by 539 these models and it is not surprising that there is no divergence. The majority of 540 the diverging insights come from the BLUE-MLP, HAPSO and D-EXPANSE models.

541 These models include a broader range of considerations than technical feasibility

542 (Table 1): heterogeneous behaviour of the key actors, uncertainty, detailed 543 dispatch modelling and maximally different alternatives. Thus, naturally these 544 models question the Central Co-ordination storyline more.

\section{Divergence on demand reduction levels}

Although the results from the eight models are in line with most statements of the Central Co-ordination storyline, several clusters of diverging

549 insights are identified. First, the storyline described only a mild increase in the 550 total power demand (20\% higher in 2050 as compared to 2008) due to energy 
551 saving behaviour and efficiency improvements. However, the BLUE-MLP model

552 shows that, when the economic drivers of energy demand and the heterogeneity

553 of the behaviour of the different actors is considered, maintaining slow power

554 demand growth through the entire model horizon appears rather wishful

555 thinking. This finding is in line with the common observation that technically and

556 economically sensible energy demand reduction measures may not be taken up

557 in reality [67]. Storylines developed by the various stakeholders and experts-

558 even more than models-tend to be overly optimistic and fragile from the 559 modelling perspective $[10,11]$. This remark is also consistent with a broader 560 argument that failures of effectively mitigating climate change can be expected 561 [68]. The Central Co-ordination storyline envisions a passive role of the civic 562 society. Without the active energy saving action of the society at large, drastic 563 demand reduction may be challenging to achieve. The UK government could only 564 enforce some types of measures for mitigating the power demand, such as smart 565 meters, efficient domestic appliances or refurbishment of buildings. Thus, the 566 expectation from the storyline about the demand needs to be revisited.

\section{Divergence on back-up capacity}

The Central Co-ordination storyline aspired to the retirement of existing coal and gas power plants by 2037 and their replacement with low-carbon

571 technologies, such as renewable energy sources or gas and coal with CCS.

572 However, both the D-EXPANSE, BLUE-MLP and HAPSO models, which also model 573 the demand response potential, show that this aspiration is challenged by the 574 dispatch (supply-demand balancing) constraint. According to the models, for the 575 aspired high deployment of intermittent renewable energy sources there will be 
576 a need for significant levels of back-up capacity, mostly flexible gas OCGT power

577 plants. The D-EXPANSE model, which explores the many different pathways, 578 shows that at least $15 \mathrm{GW}$ of gas power plants would be required. The power 579 generation mixes of BLUE-MLP also include $15 \mathrm{GW}$ of gas or coal power plants. 580 Most importantly, the HAPSO model, whose key field of expertise is dispatch 581 modelling due to its one-hour temporal resolution and detailed assessment of 582 supply security requirements, proposes 50GW of gas OCGT. The value is higher 583 than the one suggested by the D-EXPANSE and BLUE-MLP models because the 584 HAPSO model assumes higher supply security requirements. Overall, the 585 complete retirement of fossil fuel based power plants is questionable and the 586 results suggest that the storyline needs to include more of that type of plant. As 587 highlighted in Figure 4, the dispatch modelling is the key field of expertise of the 588 HAPSO model. Thus, its conclusion about the 50GW of gas OCGT by 2037 shall be 589 prioritized over the D-EXPANSE and the BLUE-MLP conclusions.

The FESA, BLUE-MLP, EEA, HESA/UK+ and HAPSO models all agree that

593 the target of the greenhouse gas emissions in 2035 would not be met. Instead of 594 the aspired $30 \mathrm{gCO}_{2} / \mathrm{kWh}$ in the storyline, the modelling outcomes range from 33 $595 \mathrm{gCO}_{2} / \mathrm{kWh}$ to $56 \mathrm{gCO}_{2} / \mathrm{kWh}$ for $\mathrm{CO}_{2}$ for operational emissions and equals 120 $596 \mathrm{gCO}_{2 \mathrm{eq}} / \mathrm{kWh}$ for the 'whole system' (cradle to gate) emissions. The D-EXPANSE 597 model shows a number of power generation mixes, which are not necessarily the 598 same as modelled in other seven models, but are still consistent with the 599 harmonised assumptions of the storyline. Some of these mixes could meet the 600 target of $30 \mathrm{gCO}_{2} / \mathrm{kWh}$, but these mixes are different from the mixes evaluated 
601 by the other models. Thus, while reaching the emission target can be technically

602 feasible, it may not be realistic via the means that the storyline describes.

603 According to the EEA, which has the most detailed accounting of the operational

604 and 'whole system' emissions as its key field of expertise, the emissions target 605 would also be missed (although a different target for the 'whole system' 606 emissions could be expected). Thus, either the achieved levels of emissions or 607 the measures (power demand and generation mix) need to be revisited in the 608 storyline.

\section{Divergence on power generation mix}

When the Central Co-ordination storyline was initially developed in the

612 Transition Pathways project, it had little insights from the experts and models,

613 informed by the economic considerations [39]. This is reflected in the points of

614 divergence between the models and the storyline about the power generation 615 mix. The D-EXPANSE, BLUE-MLP and HAPSO models, which include information 616 about costs, the cost-optimal and near-optimal decisions of actors, both include 617 more nuclear power than anticipated by the storyline. The D-EXPANSE model 618 prioritises onshore and offshore wind power as renewable energy sources rather 619 than wave and tidal power, as envisioned in the storyline. The BLUE-MLP model 620 includes a much more significant deployment of nuclear power due to its costs 621 and emissions performance. The HAPSO model raises concerns about significant 622 curtailment of the power produced by the renewable energy sources due to lack 623 of market integration and lack of interconnectors between the UK and 624 continental Europe. This significant curtailment would reduce the economic 625 feasibility of renewable sources. While the storyline also describes a high 
deployment of gas and coal CCS, the D-EXPANSE model shows that many of the

627 cost-optimal and near-optimal pathways could have no CCS in the generation 628 mix. The HAPSO model also questions the large deployment of CCS because, from 629 the dispatch perspective, these plants would run on a low capacity factor (24\% 630 to $36 \%$ ) and thus their economic feasibility is challenged. The EEA model 631 highlighted that the deployment of coal CCS is likely to provide almost a quarter less 632 carbon emission mitigation than is normally assumed on a whole system basis. In 633 brief, these results suggest that a revised version of the Central Co-ordination 634 storyline should consider a higher share of nuclear and wind power, but a more 635 pessimistic deployment of coal and gas CCS and other types of renewable energy 636 sources.

\section{Divergence on the key risk}

The Central Co-ordination storyline identifies the technical and economic

640 feasibility of CCS as one of the key risks for implementing the storyline. While 641 most of the eight models include a share of coal and gas CCS, the D-EXPANSE 642 model shows that this is not a prerequisite. D-EXPANSE generates a large 643 number of maximally different cost-optimal and near-optimal scenarios; near644 optimal scenarios are defined as scenarios that have up to $30 \%$ higher total 645 cumulative system costs by 2050 than the least cost scenario. Many of these 646 scenarios do not have CCS, even if the carbon price rise to $£ 207.5 /$ tonne $\mathrm{CO}_{2 \text { eq }}$ by 6472050 is assumed in line with [69]. This means that the coal and gas CCS are not 648 prerequisites for implementing the Central Co-ordination storyline, as it is 649 described in the harmonised assumptions. As coal and gas CCS is a relatively 650 costly technology, it appears seldom in the cost-optimal and near-optimal 
651 scenarios. In the D-EXPANSE modelling outputs, the environmental gains of the 652 coal and gas CCS are rather replaced by the deployment of other low-carbon 653 technologies (renewable sources and nuclear power), while the role of back-up 654 capacity of coal and gas CCS power plants is compensated by coal and gas plants 655 without CCS. The BLUE-MLP model also provides a range of power generation 656 mixes without CCS, even with the carbon price increase up to $£ 600 /$ tonne $\mathrm{CO}_{2 \mathrm{eq}}$ 657 by 2050 . Thus, instead of suggesting the feasibility of CCS as the key risk, these 658 results seem to imply that Central Co-ordination storyline shall consider other 659 risks that are highlighted by diverging insights from the eight models.

660 One of these key risks is the supply-demand balancing challenge. As the 661 HAPSO, D-EXPANSE and BLUE-MLP models show, supply-demand balancing may 662 be a big challenge in the Central Co-ordination storyline, as it describes high 663 levels of intermittent renewable sources and inflexible power plants with CCS, 664 which are challenging to combine. At the same time, the storyline does not refer 665 to the necessary flexible generation and demand response measures that would 666 guarantee simultaneous integration of CCS and renewable sources into the 667 system. This may cause public concerns over supply security.

668 Another key risk is the failure to meet the greenhouse gas emissions 669 target. The results of these multiple models from Table 2 already show that the 670 target might be missed in 2035. This failure would become even more likely if, in 671 order to meet the balancing challenge, the needed gas power plants would be 672 installed as the back-up capacity. The third key risk is the need for nuclear 673 power, which — as the recent years show—may cause a high public resistance. 
677 seems to miss or under-represent several aspects that are analysed in the eight

678 models (Figure 4). The storyline does not describe any arrangements regarding

679 power import and export as well as the relations with the other European 680 countries, as modelled by the HAPSO and D-EXPANSE models. The storyline does 681 not discuss the governance arrangements and the choices of actors about the 682 power transmission and distribution grid, covered by the HESA/UK+ and HAPSO 683 models. The demand response levels, important for the dispatch modelling by 684 the FESA, HAPSO and other models, have also been only described to a limited 685 extent. The D-EXPANSE and BLUE-MLP models analyse the influence of 686 parametric and structural uncertainty on the power system transition, but these 687 insights are so far not incorporated into the storyline. All these aspects are often 688 forgone not only in the Transition Pathways storylines, but also in wider energy 689 policy discourses. Yet, the future power system transition requires a portfolio of 690 measures on the power demand, generation, transmission and distribution sides. 691 These aspects need to be considered, when developing the next version of the 692 storyline. 
695 Table 2. Revisiting the storyline with the multiple models (detailed documentation and explanation of every cell is available in the 696 Electronic Supplementary Material). Green colour means that the model outputs are in line with the storyline, yellow - that there is a 697 minor divergence, red - that the storyline statement contradicts the model outputs, white - the particular statement is not addressed in 698 the model. 


\begin{tabular}{|c|c|c|c|c|c|c|c|c|}
\hline $\begin{array}{l}\text { Some of the relevant quotes from the storyline, taken from [45]. The complete list } \\
\text { of quotes is available in the Electronic Supplementary Material }\end{array}$ & Demand & FESA & DXPANSE & EconA & $\begin{array}{l}\text { BLUE- } \\
\text { MLP }\end{array}$ & EEA & $\begin{array}{l}\text { HESA/ } \\
\text { UK+ }\end{array}$ & HAPSO \\
\hline $2008-2022$ & & & & & & & & \\
\hline $\begin{array}{l}\text { "By 2020, the energy efficiency measures have led to the stabilisation of electricity } \\
\text { demand." }\end{array}$ & & & & & & & & \\
\hline $\begin{array}{l}\text { "This policy involves a risk being passed to consumers of experiencing higher than } \\
\text { average electricity costs, if the price of natural gas does not rise significantly." }\end{array}$ & & & & & & & & \\
\hline $\begin{array}{l}\text { "By } 2020,<\ldots>\text { the relative decarbonisation of electricity supply has led to the } \\
\text { achievement of the carbon budget of a } 34 \% \text { reduction in } \mathrm{CO}_{2} \text { emissions, compared to } \\
1990 \text { levels." }\end{array}$ & & & & & & & & \\
\hline $\begin{array}{l}\text { "This is realised by the achievement of } 25 \% \text { of electricity to be generated from } \\
\text { renewables by } 2020 . "\end{array}$ & & & & & & & & \\
\hline $\begin{array}{l}\text { "High levels of deployment for onshore (8GW) and offshore wind, (10GW) which } \\
\text { operates at over } 40 \% \text { capacity factor; the first operational CCS coal plant; and four new } \\
(1.6 \mathrm{GW}) \text { nuclear power stations." }\end{array}$ & & & & & & & & \\
\hline $2023-2037$ & & & & & & & & \\
\hline $\begin{array}{l}\text { "Remaining other coal and gas power stations are retired as they reach the end of their } \\
\text { life." }\end{array}$ & & & & & & & & \\
\hline
\end{tabular}




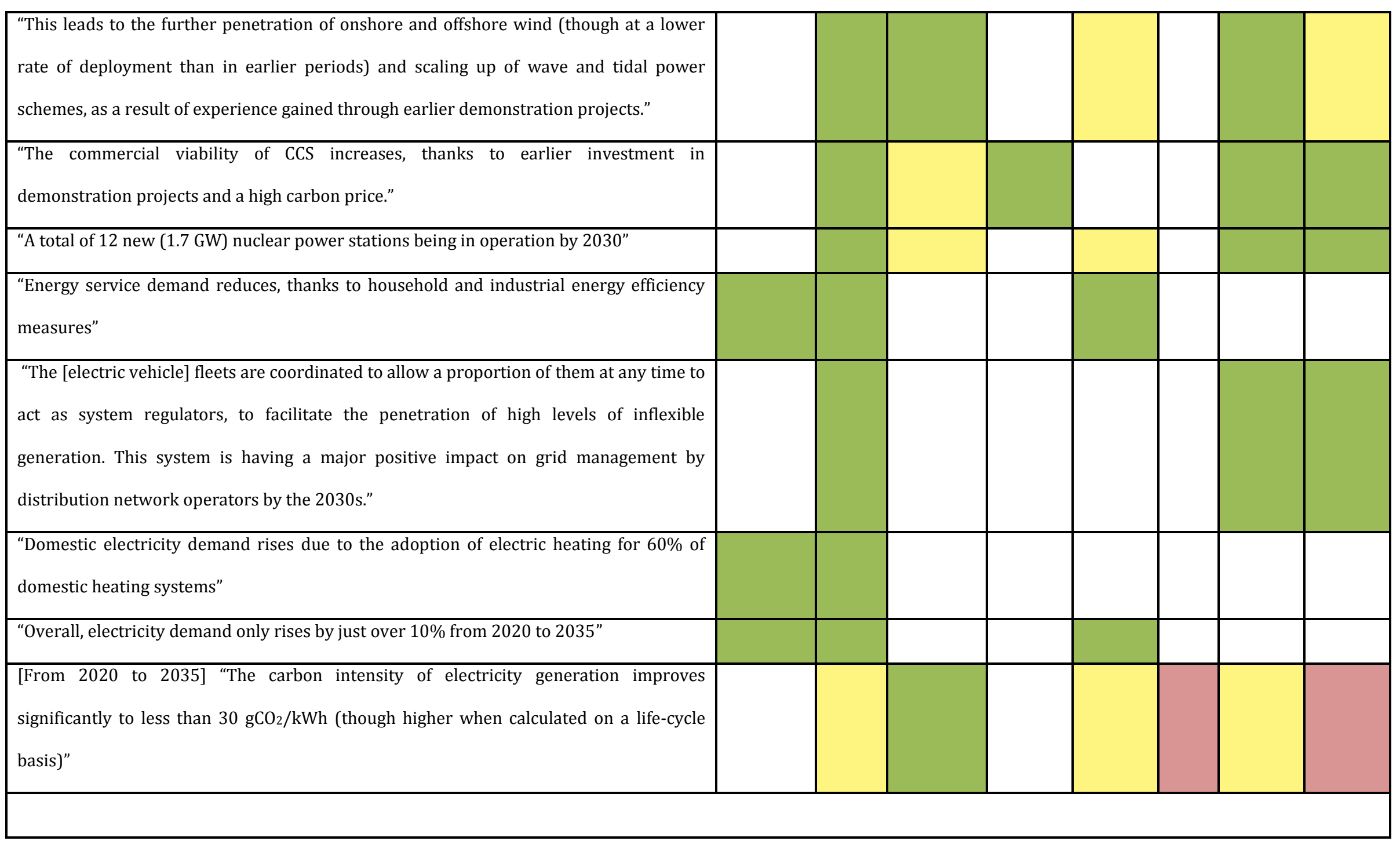




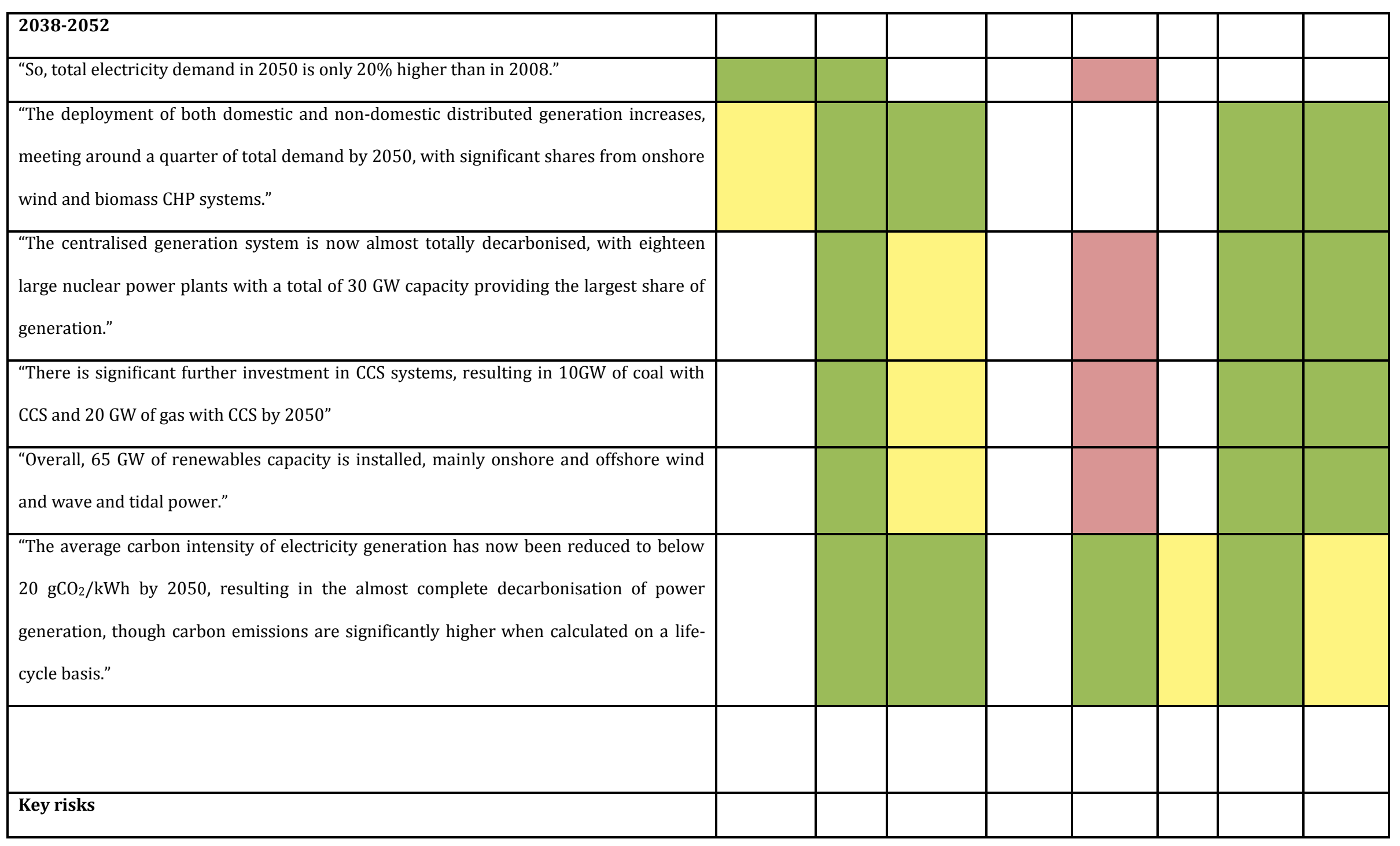




\begin{tabular}{|l|l|l|l|l|l|l|l|l|l|l|}
\hline The key risk is that "Carbon capture and storage turns out to be technologically or & & & (Not key & risk) & & & & & \\
economically unfeasible" \\
investment."
\end{tabular}


This section critically reflects the proposed approach for linking detailed storylines with multiple models, based on the case of the Central Co-ordination storyline.

\section{Development of storylines}

In scenario processes, storylines are often very detailed because they aim to encapsulate numerous details, coming from the different parts of the power system, viewpoints (government, power companies, consumers etc.),

710 stakeholder and expert inputs. Such a process, however, has shortcomings. First, 711 when so many diverse inputs are brought into one storyline under the typical 712 story-and-simulation approach [2] or when using such detailed storylines as in 713 the RTP projects, the internal consistency of this storyline becomes at risk. For 714 example, the comparison of the Central Co-ordination storyline with the outputs 715 of the eight RTP models reveals several inconsistencies. The storyline describes 716 the role of society at large as passive, while the envisioned substantial decrease

717 in the energy service demand may not be feasible without concerted efforts to 718 reduce demand for energy services. In order to avoid such cases, it seems likely

719 that the development of internally consistent, stakeholder-based storylines, 720 facilitated by formal techniques such as formative scenario analysis or cross721 impact balance $[5,20-23,70,71]$, would increase the robustness of the 722 qualitative storyline itself.

723 Second, some internal inconsistencies as well as other mistakes due to the 724 lack of analytical foundation can be eliminated by comparing the storyline with 
725 models (given that these models are available), as done in this paper. This is

726 essential because the power system transition is inherently complex and the 727 qualitative storylines-based approach on its own cannot capture this complexity

728 [11]. The afore-mentioned cross-impact balance or formative scenario analysis 729 can be used for mediating among the diverging perspectives of the experts. The 730 insights from the multiple models could thus perhaps be brought into these 731 analyses too in order to derive storylines that are informed by multiple models 732 and multiple stakeholder views simultaneously.

733 Third, lengthy and detailed storylines may be easier for the audience to 734 imagine, but they also lead to overconfidence about how realistic they are [70]. 735 This is problematic because such exercises distract the attention of the audience 736 from other, as likely or as desirable, scenarios. The scenario approach is 737 expected, however, to expand rather than narrow down the understanding about 738 the plausible futures. Therefore, there is a threshold for how long and detailed 739 the storyline shall be. When storylines are combined with the multiple models as 740 in this paper, a meaningful approach would be to keep in the storyline the details 741 about the governance and the choices of the actors, while leaving the power 742 system description to the multiple models. 'Translation' of storylines into model assumptions The way a qualitative storyline is 'translated' into the assumptions for the 746 quantitative models (Step 1 in 1 ) is decisive for the comparison of the storyline 747 and the modelling results. There is a trade-off between the number of 748 assumptions and how much flexibility the models have to express their 749 perspective. If a large number of assumptions is used, the models would be 
tailored to mimic the storyline almost completely. In this way, the storyline and

751 the multiple targets, aspired by the stakeholders, could be tested in light of

752 modelling results. This can be a useful and creative learning exercise for the 753 stakeholders $[10,11]$. At the same time, the RTP project seeks to better grasp a 754 wide range of plausible future power system developments, if the central UK 755 government plays a more active role in shaping the power sector transition. 756 Thus, models with different rationales could help capturing a wider range of 757 these plausible futures. If too many assumptions would be used, this variety of 758 plausible futures would be lost. For example, in the case of the RTP models, the 759 cost-optimising models, like HAPSO or D-EXPANSE, could be tailored to produce 760 the results, similar to the storyline if there are no major inconsistencies in the 761 storyline. But this would gloss over the fact that the cost-optimal and near762 optimal-thus, perhaps more realistic pathways-may be very different than the 763 one described in the storyline. The modelling assumptions thus shall better allow 764 more flexibility for the models to express their perspective. However, it is challenging to define what the optimal number and type of 766 assumptions are. Moreover, one qualitative statement might have a range of 767 quantitative representations which need to be captured systematically $[10,11]$. 768 The 'translation' procedure, used in this paper, is acknowledged as one of the 769 weaknesses of the study, presented in Section 3. To some extent, this fragility 770 arose because only one storyline was analysed through the perspective of the 771 eight models. If all three storylines of the RTP project were analysed (Central Co772 ordination, Market Rules and Thousand Flowers), this problem could be resolved 773 to some extent, as a unified framework for the 'translation' of these storylines 
into modelling assumptions would need to be defined. By comparing three storylines, a more robust framework could be developed.

\section{Mapping the expertise of models}

The landscape of models (Table 1 and Figure 4) proved to be a useful approach for understanding and mapping the fields of expertise of the eight, very

780 diverse cross-scale models as in the RTP project. This landscape helped to 781 understand where the models overlap and where they have their key, individual 782 fields of expertise as compared to the other models. In line with [16], this 783 landscape approach assumes that the usefulness of the model is the local matter.

784 There is no single best model that covers all the relevant aspects and scales in 785 sufficient depth and breadth. The usefulness of the model depends on the 786 model's suitability to answer the specific question at hand and to fill a gap among 787 the other existing models. In the reported process, due to their different key 788 fields of expertise, all eight RTP models proved to be useful for assessing the 789 storyline from different cross-scale perspectives on space, time, system 790 boundaries, discipline and even technique (Table 1).

However, this landscape of RTP models for revising the Central Co792 ordination storyline is not complete because not all of the qualitative statements 793 in the storyline could be assessed. First, the statements about wider 794 developments of industry and the national economy could not be addressed. For 795 this purpose, a macro-economic model or a whole energy system model would 796 be needed in the RTP landscape. This whole energy system model would need to 797 be broader than the already used HAPSO model, which addresses only the power 798 system. This model would need to have as wide system boundaries as UK 
MARKAL or TIMES [46, 72] and to address the whole supply chain of the whole energy system (not only the power system) and energy-economy interactions.

801 Second, assuming a substantial deployment of distributed generation, there 802 would be a need for improved modelling of local voltage control and two-way 803 power flows. This problem would increase even more if the Thousand Flowers 804 storyline would be analysed, because this storyline pictures a significant uptake 805 of decentralised generation. A model that addresses these issues would need to 806 be added to the landscape of models too.

Third, the storyline raised issues about public acceptability of rising energy prices or, as suggested by the models, possibly decreasing supply security

809 due to the deployment of intermittent renewable energy sources. While the 810 public acceptability issues are challenging to model, they are of high relevance

811 for the future transitions. Therefore, in parallel to the modelling-based 812 assessment of the storyline, a social scientific assessment is required. This social 813 scientific analysis already took place in the Transitions Pathways project [73] 814 and thus, together with the landscape of models, it could improve the analytical 815 assessment of the qualitative storylines.

\section{$\underline{\text { Two-way reflexive collaboration }}$}

The iterative loop in Figure 1 would be completely closed by revising the

819 qualitative storyline on the basis of the results of the eight models. The exercise,

820 reported in Table 2, helped to identify the inconsistencies between the storyline 821 and the models. The diversity of the eight models here proved to be especially 822 useful as the results of the different models were at times diverging. While some 823 models were in line with all or almost all storyline statements, there was almost 
824 always at least one model that diverged from the storyline. Any of these

825 divergences can have credible reasons leading to inconsistencies in the storyline.

826 Unpacking the underlying mechanisms of this divergence (as already reported in

827 Section 3.4) is thus essential for understanding why this divergence appears and,

828 if necessary, revising the storyline and/or the models. The next step of this

829 process would be a collaborative, reflexive effort between the storyline

830 developers and the modellers. In this way, improved versions of the storyline

831 and the models could be developed.

832 The iterative loop in Figure 1 is a two-way reflexive collaboration

833 between the storyline and the models [36]. In this paper, a storyline-led

834 approach is reported. The storyline was developed first and then was assessed

835 from the perspective of the different models, at the same time reflecting on the

836 potentially relevant models that were missing from the analysis. Models alone

837 can hardly capture the broader picture, covered in the storyline, such as the

838 power system governance 'logics' and the choices of the key actors. As these

839 aspects are very challenging to model, it is meaningful to use a storyline-led

840 approach. However, an alternative, modelling-led approach could also be used to

841 derive storylines too. This could be based on the generation of a large number of

842 scenarios with multiple models and extracting a smaller range of scenarios with

843 fundamentally-different structures and describing them in storylines. Some

844 research in this direction is already reported in $[6,11,54,55,74-76]$. Such

845 process could be organised similar to the process of Figure 1, but it would start 846 with the modelling exercise.

\section{5. Conclusions}


850 qualitative storylines with quantitative, cross-scale models. An approach is

851 proposed for linking a very detailed storyline, which describes the governance

852 'logics' and the choices of key system actors, with multiple, very diverse 853 quantitative models. This approach is especially relevant because a growing 854 number of interdisciplinary projects worldwide tend to bring together social 855 scientists with modellers. Most of these models already exist before the projects 856 and differ substantially is their spatial and temporal foci, disciplinary 857 perspective, model objective, system boundaries and the format of inputs and 858 outputs. Cross-comparison of such models is a challenge in itself. In the proposed 859 approach, the comparison of the models is based on a new concept called the 860 landscape of models. Moreover, this paper goes further by linking these multiple, 861 diverse cross-scale models with qualitative storyline. Therefore, the described 862 approach is a novel contribution to the existing literature. In the frame of the Realising Transition Pathways project, the proposed 864 approach is illustrated by revising the Central Co-ordination storyline, developed 865 in the earlier Transition Pathways project, for exploring the UK power system 866 transition until 2050. This storyline describes the governance 'logics' and the 867 choices of the key system actors, when the UK central government should take a 868 more active role in shaping the power system transition. Such contextual 869 considerations as governance and the actors' choices can hardly be modelled in 870 the current RTP models; this highlights the value of the storyline. This qualitative 871 storyline is addressed through the perspective of six, very diverse models and 872 two appraisal techniques: Demand, FESA, D-EXPANSE, EconA, BLUE-MLP, EEA, 873 HESA/UK+ and the HAPSO models. These models and appraisals revealed the 
874 fragile nature of the storyline. From the perspective of the model, the storyline 875 tended to wishfully overestimate the power demand reduction potential and the 876 uptake of marine renewables. The necessity for CCS to meet long-term stringent 877 greenhouse gas emissions targets was also overestimated. But it underestimated 878 the supply-demand balancing challenge, the need for gas power plants as a back879 up capacity, the role of nuclear power and interconnectors with Europe, and the 880 challenge of meeting the stringent emissions targets. Thus, the combination of 881 the qualitative storyline and its revisions from the perspective of multiple, 882 diverse models is key for developing robust future scenarios and transition 883 pathways. An iterative process for this purpose has been proposed in this paper. 884 For the RTP consortium, the interpretation of the results of this analysis 885 and their implications for the future development of both the storylines and the 886 models will be the subject of further debate, research and papers.

\section{Acknowledgements}

This work was conducted as a part of the Realising Transition Pathways consortium project, supported by the UK Engineering and Physical Sciences

891 Research Council (Grant EP/K005316/1). The authors are solely responsible for 892 the analysis and views in this paper.

The authors thank the other members of the Realising Transition

894 Pathways project and the preceding Transition Pathways project, who developed 895 the Central Co-ordination storyline and participated in the workshops that led to 896 the development of this paper (a full list of the consortium members is available 897 at [77]). The substantial contributions of Neil Strachan and other contributions 898 of Graham Ault, Stuart Galloway, Geoff Hammond, Matt Leach, Goran Strbac and 
Murray Thomson in guiding the development and analysis of the models are also

900 acknowledged. The authors especially value the extensive critical review by

901 Geoff Hammond, Peter Pearson and the anonymous reviewers that helped to 902 considerably improve the manuscript.

903

904

Vitae

905

- Dr Evelina Trutnevyte works as a Research Associate at the University College London (UCL) Energy Institute. Her research focuses on the development of context-specific, spatially differentiated energy strategies that combine insights from multiple disciplines and stakeholder engagement. She received her $\mathrm{PhD}$ at the Institute for Environmental Decisions, ETH Zurich, and her Master's degree in Power Engineering from Vilnius Gediminas Technical University. She strengthened her expertise during studies and fellowships at Aalborg University (Denmark), Lithuanian Energy Institute, Power Systems Laboratory at ETH Zurich (Switzerland), University of Oslo (Norway), and during two years of engineering consulting in Lithuania.

- Dr John Barton is a Research Associate at Loughborough University's Centre for Renewable Energy Systems Technology (CREST). He also received his $\mathrm{PhD}$ and Master's degree at Loughborough University. His 7 years of post-doctoral research includes energy storage, whole energy system modelling, distributed generation, demand response, condition monitoring of wind turbines and public engagement with renewable energy. John is also an energy consultant and company director, previously working with Bryte Energy Ltd on hydrogen technologies and 
now working with Air Fuel Synthesis Ltd making synthetic liquid transport fuels. John co-created and then developed the FESA model.

- Áine O'Grady is a Research Officer at the University of Bath where she is part of the Sustainable Energy Research Team in the Department of Mechanical Engineering. Previously, Áine worked at Aquamarine Power, and carried out a life-cycle assessment of its wave energy device prototype, and contributed to environmental design improvements. Her current research involves the technology assessment of energy systems using a set of appraisal techniques from engineering, environmental sciences and strategic thinking (such as environmental life-cycle assessment, thermodynamic analysis, horizon scanning and other futureoriented technology analysis).

- Damiete Ogunkunle is a Research Officer at the Centre for Environmental Strategy, University of Surrey, where she obtained her Masters' degree in Environmental Management. She has worked in a range of research projects since 2008 including the sustainability assessment of UK bioenergy supply chains. Currently, she is involved in the development of the energy demand models as part of the Realising Transitions Pathways consortium. She is also working part time towards completing her $\mathrm{PhD}$ degree.

- Dr Danny Pudjianto is a Research Fellow at Imperial College London with the expertise in power system modelling and optimization, power system economics, regulation, system operation, strategic planning, system security, and technology evaluations from power system perspective including smart grids, active network management, demand response, 
distributed generation, energy storage, and energy networks. He holds degrees in Economics (BA) and Electronics (BSc), and Power System (MSc and $\mathrm{PhD}$ ). He has published more than 40 technical papers.

- Elizabeth Robertson is a Research Assistant at the University of Strathclyde's Institute of Energy and Environment. She received her MPhys (Hons) from the University of York, UK in 2008 and is currently pursuing a PhD at the University of Strathclyde. Her research interests include combined energy system modelling and the interaction of physically connected, but individually operated energy markets.

958

\section{References}

960 [1] B.C. O'Neill, V. Schweizer, Mapping the road ahead, Nat. Clim. Chang. 1 (2011)

$961 \quad 352-353$.

962 [2] J. Alcamo, Chapter Six The SAS Approach: Combining Qualitative and

963 Quantitative Knowledge in Environmental Scenarios, in: A. Joseph (Ed.)

964 Developments in Integrated Environmental Assessment, Elsevier, 2008.

965 [3] G. Wright, G. Cairns, R. Bradfield, Scenario methodology: New developments

966 in theory and practice: Introduction to the Special Issue, Technological 967 Forecasting and Social Change 80 (2013) 561-565.

968 [4] R.J. Swart, P. Raskin, J. Robinson, The problem of the future: Sustainability

969 science and scenario analysis, Global Environmental Change-Human and Policy

970 Dimensions 14 (2004) 137-146.

971 [5] E. Kemp-Benedict, Telling better stories: strengthening the story in story and 972 simulation, Environmental Research Letters 7 (2012). 
974 scenario studies through a dynamic analytical approach using a large number of 975 scenarios, in: International Energy Workshop 2013, 19-21 June 2013, Paris, 976 France, 2013.

977 [7] K.L. Anderson, S.L. Mander, A. Bows, S. Shackley, P. Agnolucci, P. Ekins, The 978 Tyndall decarbonisation scenarios-Part II: Scenarios for a 60\% CO2 reduction in 979 the UK, Energy Policy 36 (2008) 3764-3773.

980 [8] S.L. Mander, A. Bows, K.L. Anderson, S. Shackley, P. Agnolucci, P. Ekins, The 981 Tyndall decarbonisation scenarios-Part I: Development of a backcasting 982 methodology with stakeholder participation, Energy Policy 36 (2008) 37549833763.

984 [9] CLUES, Learning through scenarios: Exploring the future of decentralised 985 energy in the UK, 2012, Sussex Energy Group, Brighton, UK, 986 http://www.ucl.ac.uk/clues/files/scenarios briefing (accessed on 10.09.2013).

987 [10] E. Trutnevyte, M. Stauffacher, R.W. Scholz, Supporting energy initiatives in 988 small communities by linking visions with energy scenarios and multi-criteria 989 assessment, Energy Policy 39 (2011) 7884-7895.

990 [11] E. Trutnevyte, M. Stauffacher, R.W. Scholz, Linking stakeholder visions with 991 resource allocation scenarios and multi-criteria assessment, European Journal of 992 Operational Research 219 (2012) 762-772.

993 [12] G. Bowman, R.B. MacKay, S. Masrani, P. McKiernan, Storytelling and the 994 scenario process: Understanding success and failure, Technological Forecasting 995 and Social Change 80 (2013) 735-748.

996 [13] R. Weijermars, P. Taylor, O. Bahn, S.R. Das, Y.-M. Wei, Review of models and 997 actors in energy mix optimization - can leader visions and decisions align with 
optimum model strategies for our future energy systems?, Energy Strategy 999 Reviews 1 (2012) 5-18.

1000 [14] P.J.H. Schoemaker, Multiple scenario development: Its conceptual and 1001 behavioral foundation, Strategic Management Journal 14 (1993) 193-213.

1002 [15] E. Trutnevyte, The allure of energy visions: Are some visions better than 1003 others?, Energy Strategy Reviews (2014) 211-219.

1004 [16] M.S. Morgan, The World in the Model. How economists work and think, 1005 Cambridge University Press, Cambridge, 2012.

1006 [17] N. Hughes, N. Strachan, Methodological review of UK and international low 1007 carbon scenarios, Energy Policy 38 (2010) 6056-6065.

1008 [18] N. Hughes, Towards improving the relevance of scenarios for public policy 1009 questions: A proposed methodological framework for policy relevant low carbon 1010 scenarios, Technological Forecasting and Social Change 80 (2013) 687-698.

1011 [19] E. Lloyd, V. Schweizer, Objectivity and a comparison of methodological 1012 scenario approaches for climate change research, Synthese 191 (2014) 204910132088.

1014 [20] V.J. Schweizer, E. Kriegler, Improving environmental change research with 1015 systematic techniques for qualitative scenarios, Environmental Research Letters 10167 (2012).

1017 [21] B. Girod, A. Wiek, H. Mieg, M. Hulme, The evolution of the IPCC's emissions 1018 scenarios, Environmental Science \& Policy 12 (2009) 103-118.

1019 [22] R.W. Scholz, O. Tietje, Embedded case study methods: Integrating 1020 quantitative and qualitative knowledge, Sage, Thousand Oaks, 2002. 
1021 [23] W. Weimer-Jehle, Cross-impact balances: A system-theoretical approach to 1022 cross-impact analysis, Technological Forecasting and Social Change 73 (2006) $1023 \quad 334-361$.

1024 [24] O. Edenhofer, B. Knopf, T. Barker, L. Baumstark, E. Bellevrat, B. Chateau, P. 1025 Criqui, M. Isaac, A. Kitous, S. Kypreos, M. Leimbach, K. Lessmann, B. Magne, S. 1026 Scrieciu, H. Turton, D.P. van Vuuren, The Economics of Low Stabilization: Model 1027 Comparison of Mitigation Strategies and Costs, Energy Journal 31 (2010) 11-48. 1028 [25] J.R. Weyant, F.C. de la Chesnaye, G.J. Blanford, Overview of EMF-21: Multigas 1029 mitigation and climate policy, Energy Journal (2006) 1-32.

1030 [26] N. Strachan, T. Foxon, J. Fujino, Policy implications from the Low-Carbon 1031 Society (LCS) modelling project, Climate Policy 8 (2008) S17-S29.

1032 [27] S. Kypreos, D. Van Regemorter, NEEDS New Energy Externalities 1033 Developments for Sustainability. Working paper RS2, WP2.3: key drivers for 1034 energy trends in EU; Specification of the baseline and policy scenarios, 2006, 1035 NEEDS, http://www.needs-project.org/RS2a/Baseline Scenario $1212006 . p d f$ 1036 (accessed on 10.09.2013).

1037 [28] J.C. Hourcade, M. Jaccard, C. Bataille, F. Ghersi, Hybrid modeling: New 1038 answers to old challenges - Introduction to the special issue of The Energy 1039 Journal, Energy Journal (2006) 1-11.

1040 [29] D.P. van Vuuren, K. Riahi, R. Moss, J. Edmonds, A. Thomson, N. Nakicenovic, 1041 T. Kram, F. Berkhout, R. Swart, A. Janetos, S.K. Rose, N. Arnell, A proposal for a 1042 new scenario framework to support research and assessment in different climate 1043 research communities, Global Environmental Change 22 (2012) 21-35.

1044 [30] E. Kriegler, B.C. O’Neill, S. Hallegatte, T. Kram, R.J. Lempert, R.H. Moss, T. 1045 Wilbanks, The need for and use of socio-economic scenarios for climate change 
1046 analysis: A new approach based on shared socio-economic pathways, Global 1047 Environmental Change 22 (2012) 807-822.

1048 [31] E. Trutnevyte, M. Stauffacher, M. Schlegel, R.W. Scholz, Context-specific 1049 energy strategies: Coupling energy system visions with feasible implementation 1050 scenarios, Environ. Sci. Technol. 46 (2012) 9240-9248.

1051 [32] N. Nakicenovic, R. Swart, Special Report on Emissions Scenarios (SRES), in, 1052 Cambridge University Press, Cambridge, 2000.

1053 [33] D. van Vuuren, E. Kriegler, B. O’Neill, K. Ebi, K. Riahi, T. Carter, J. Edmonds, S. 1054 Hallegatte, T. Kram, R. Mathur, H. Winkler, A new scenario framework for 1055 Climate Change Research: scenario matrix architecture, Climatic Change 122 1056 (2014) 373-386.

1057 [34] S. Carpenter, P. Pingali, E. Bennett, M. Zurek, Millennium Ecosystem 1058 Assessment: Volume 2. Scenario Assessment, in, Island Press, Oxford, UK, 2005. 1059 [35] UNEP, GE05 Global Environmental Outlook. Environment for the future we 1060 want, Progress Press Ltd, Valletta, Malta, 2012.

1061 [36] M.B. Zurek, T. Henrichs, Linking scenarios across geographical scales in 1062 international environmental assessments, Technological Forecasting and Social 1063 Change 74 (2007) 1282-1295.

1064 [37] G.P. Hammond, P.J.G. Pearson, Challenges of the transition to a low carbon, 1065 more electric future: From here to 2050, Energy Policy 52 (2013) 1-9.

1066 [38] T.J. Foxon, G.P. Hammond, P.J.G. Pearson, Developing transition pathways 1067 for a low carbon electricity system in the UK, Technological Forecasting and 1068 Social Change 77 (2010) 1203-1213.

1069 [39] T.J. Foxon, Transition pathways for a UK low carbon electricity future, 1070 Energy Policy 52 (2013) 10-24. 
1071 [40] D. Hel, Energy, the State, and the Market: British Energy Policy Since 1979,

1072 Oxford University Press, Oxford, UK, 2003.

1073 [41] P. Pearson, J. Watson, UK Energy Policy, 1980-2010 A history and lessons to 1074 be learned, IET and Parliamentary Group for Energy Studies, London, 2011.

1075 [42] J.H. Williams, A. DeBenedictis, R. Ghanadan, A. Mahone, J. Moore, W.R. 1076 Morrow, S. Price, M.S. Torn, The Technology Path to Deep Greenhouse Gas 1077 Emissions Cuts by 2050: The Pivotal Role of Electricity, Science 335 (2012) 53107859.

1079 [43] A. Boston, Delivering a secure electricity supply on a low carbon pathway, 1080 Energy Policy 52 (2013) 55-59.

1081 [44] DECC, Electricity Market Reform: policy overview, Department of Energy \& 1082 Climate Change, London, 2012.

1083 [45] Transition Pathways, Transition Pathways releases new narratives for

1084 pathways, 2012,

1085 http://www.lowcarbonpathways.org.uk/lowcarbon/news/news 0029.html

1086 (accessed on 18.07.2013).

1087 [46] P. Ekins, G. Anandarajah, N. Strachan, Towards a low-carbon economy: 1088 scenarios and policies for the UK, Climate Policy 11 (2011) 865-882.

1089 [47] B. O’Neill, E. Kriegler, K. Riahi, K. Ebi, S. Hallegatte, T. Carter, R. Mathur, D. 1090 Vuuren, A new scenario framework for climate change research: the concept of 1091 shared socioeconomic pathways, Climatic Change 122 (2014) 387-400.

1092 [48] R. Bolton, T. Foxon, Negotiating the energy policy 'trilemma' - an analysis of 1093 UK energy governance from a socio-technical systems perspective, in: IGov 1094 Workshop: Theorising Governance Change for a Sustainable Economy,, London, 10952013. 
[49] DECC, DECC 2050 Pathway Calculator Excel Model, July 2010 version, DECC, 10972010.

1098 [50] BRE, Carbon dioxide from non-domestic buildings 2000 and beyond, BRE 1099 Energy Technology Centre, 2002.

1100 [51] Carbon Trust, Technology Innovations and Needs Assessment (TINA): Non1101 domestic buildings, Carbon Trust, 2012.

1102 [52] M. Barnacle, E. Robertson, S. Galloway, J. Barton, G. Ault, Modelling 1103 generation and infrastructure requirements for transition pathways, Energy 1104 Policy (2013).

1105 [53] J. Barton, S. Huang, D. Infield, M. Leach, D. Ogunkunle, J. Torriti, M. Thomson, 1106 The evolution of electricity demand and the role for demand side participation, 1107 in buildings and transport, Energy Policy 52 (2013) 85-102.

1108 [54] E. Trutnevyte, EXPANSE methodology for evaluating the economic potential 1109 of renewable energy from an energy mix perspective, Applied Energy 111 (2013) $1110 \quad 593-601$.

1111 [55] E. Trutnevyte, N. Strachan, Nearly perfect and poles apart: investment 1112 strategies into the UK power system until 2050, in: International Energy 1113 Workshop 2013, Paris, France, 2013.

1114 [56] UCL Energy Insitute, Energy models at the UCL Energy Institute, 2013, 1115 http://www.ucl.ac.uk/energy-models (accessed on 10.09.2013).

1116 [57] N. Strachan, P. Warren, Incorporating behavioural complexity in energy1117 economic models, in: Energy and People: Futures, Complexity and Challenges, 1118 Oxford, UK, 2011.

1119 [58] F.W. Geels, J. Schot, Typology of sociotechnical transition pathways, 1120 Research Policy 36 (2007) 399-417. 
1121 [59] G.P. Hammond, A. O'Grady, The Implications of Upstream Emissions from

1122 the Power Sector, Proceedings of the Institution of Civil Engineers - Energy in 1123 press (2013).

1124 [60] G.P. Hammond, H.R. Howard, C.I. Jones, The energy and environmental 1125 implications of UK more electric transition pathways: A whole systems 1126 perspective, Energy Policy 52 (2013) 103-116.

1127 [61] E. Robertson, L. Anderson, S. Galloway, The impact of distributed generation 1128 in Scotland (on the energy system, to consumers and to national emission levels, 1129 in: CIGRÉ, Montreal, Quebec, Canada, 2012.

1130 [62] E. Robertson, S. Galloway, G. Ault, The Impact of Wide Spread Adoption of 1131 High Levels of Distributed Generation in Domestic Properties, in: IEEE Power \& 1132 Energy Society General Meeting, San Diego, US, 2012.

1133 [63] E.M. Robertson, A.D. Alarcon-Rodriguez, S.J. Galloway, G.W. Ault, Outline for 1134 an Integrated Multiple Energy Carrier Model of the UK Energy Infrastructure, 11352009.

1136 [64] M. Geidl, G. Koeppel, P. Favre-Perrod, B. Klockl, G. Andersson, K. Frohlich, 1137 Energy hubs for the future, IEEE Power Energy Mag. 5 (2007) 24-30.

1138 [65] F. Kienzle, E. Trutnevyte, G. Andersson, Comprehensive performance and 1139 incertitude analysis of multi-energy portfolios, in: 2009 IEEE Bucharest 1140 PowerTech, Bucharest, Romania, 2009.

1141 [66] G. Strbac, M. Aunedi, D. Pudjianto, P. Djapic, S. Gammons, R. Druce, 1142 Understanding the balancing challenge, DECC, London, 2012.

1143 [67] S.J. DeCanio, The efficiency paradox: bureaucratic and organizational 1144 barriers to profitable energy-saving investments, Energy Policy 26 (1998) 4411145454. 
1146 [68] N. Strachan, W. Usher, Failure to achieve stringent carbon reduction targets

1147 in a second-best policy world, Climatic Change 113 (2012) 121-139.

1148 [69] DECC, A brief guide to the carbon valuation methodology for UK policy 1149 appraisal, DECC, London, 2011.

1150 [70] M.G. Morgan, D.W. Keith, Improving the way we think about projecting 1151 future energy use and emissions of carbon dioxide, Climatic Change 90 (2008) 1152 189-215.

1153 [71] V. Schweizer, B. O’Neill, Systematic construction of global socioeconomic 1154 pathways using internally consistent element combinations, Climatic Change 122 1155 (2014) 431-445.

1156 [72] N. Strachan, S. Pye, R. Kannan, The iterative contribution and relevance of 1157 modelling to UK energy policy, Energy Policy 37 (2009) 850-860.

1158 [73] T. Hargreaves, Practice-ing behaviour change: Applying social practice 1159 theory to pro-environmental behaviour change, Journal of Consumer Culture $1160 \quad$ (2011) 79-99.

1161 [74] H.C. McJeon, L. Clarke, P. Kyle, M. Wise, A. Hackbarth, B.P. Bryant, R.J. 1162 Lempert, Technology interactions among low-carbon energy technologies: What 1163 can we learn from a large number of scenarios?, Energy Economics 33 (2011) $1164 \quad 619-631$.

1165 [75] J.R. Kasprzyk, S. Nataraj, P.M. Reed, R.J. Lempert, Many objective robust 1166 decision making for complex environmental systems undergoing change, 1167 Environmental Modelling \& Software (2013).

1168 [76] B.P. Bryant, R.J. Lempert, Thinking inside the box: A participatory, 1169 computer-assisted approach to scenario discovery, Technological Forecasting 1170 and Social Change 77 (2010) 34-49. 
1171 [77] Realising Transition Pathways, Realising Transition Pathways: Whole 1172 systems analysis for a UK more electric low carbon energy future, 2013, 1173 http://www.bath.ac.uk/realisingtransitionpathways/ (accessed on 09.09.2013). 1174 1175 